\title{
Lead-free hybrid perovskites for photovoltaics
}

\author{
Oleksandr Stroyuk§
}

\begin{tabular}{|c|c|}
\hline Review & Open Access \\
\hline Address: & Beilstein J. Nanotechnol. 2018, 9, 2209-2235. \\
\hline Physikalische Chemie, Technische Universität Dresden, 01062 & doi:10.3762/bjnano.9.207 \\
\hline \multicolumn{2}{|l|}{ Dresden, Germany and L.V. Pysarzhevsky Institute of Physical } \\
\hline \multirow[t]{2}{*}{ Chemistry, National Academy of Sciences of Ukraine } & Received: 25 March 2018 \\
\hline & Accepted: 25 July 2018 \\
\hline Email: & Published: 21 August 2018 \\
\hline \multicolumn{2}{|l|}{ Oleksandr Stroyuk - alstroyuk@ukr.net } \\
\hline & $\begin{array}{l}\text { This article is part of the thematic issue "Nano- and microstructures for } \\
\text { energy conversion: materials and devices". }\end{array}$ \\
\hline \multicolumn{2}{|l|}{ § Tel. +49(0)35146334351 } \\
\hline \multicolumn{2}{|l|}{ Keywords: } \\
\hline $\begin{array}{l}\text { light harvesting; low-toxic materials; organo-inorganic perovskites; } \\
\text { solar cells }\end{array}$ & $\begin{array}{l}\text { (c) } 2018 \text { Stroyuk; licensee Beilstein-Institut. } \\
\text { License and terms: see end of document. }\end{array}$ \\
\hline
\end{tabular}

\begin{abstract}
This review covers the state-of-the-art in organo-inorganic lead-free hybrid perovskites (HPs) and applications of these exciting materials as light harvesters in photovoltaic systems. Special emphasis is placed on the influence of the spatial organization of HP materials both on the micro- and nanometer scale on the performance and stability of perovskite-based solar light converters. This review also discusses HP materials produced by isovalent lead(II) substitution with $\mathrm{Sn}^{2+}$ and other metal(II) ions, perovskite materials formed on the basis of $\mathrm{M}^{3+}$ cations $\left(\mathrm{Sb}^{3+}, \mathrm{Bi}^{3+}\right)$ as well as on combinations of $\mathrm{M}^{+} / \mathrm{M}^{3+}$ ions aliovalent to $2 \mathrm{~Pb}^{2+}\left(\mathrm{Ag}^{+} / \mathrm{Bi}^{3+}\right.$, $\mathrm{Ag}^{+} / \mathrm{Sb}^{3+}$, etc.). The survey is concluded with an outlook highlighting the most promising strategies for future progress of photovoltaic systems based on lead-free perovskite compounds.
\end{abstract}

\section{Review \\ Introduction}

The field of photovoltaics and photochemical light harvesting using nanocrystalline semiconductor materials is a thriving field of research that intersects physics, physical and material chemistry, photonics and photochemistry. The investment in photovoltaic solar cells has increased among other sustainable sources of electricity, whereby the market is dominated by silicon solar cells with top light-to-current conversion efficiencies reaching $\approx 27 \%$ [1]. As an alternative to the Si-based cells requiring a relatively thick absorber layer due to the indirect character of electron transitions in $\mathrm{Si}$, direct-bandgap metal chalcogenide semiconductors have been employed as nanome- ter-thin-film light harvesters, such as $\mathrm{Cu}(\mathrm{Ga}) \operatorname{InS}(\mathrm{Se})_{2}$ or $\mathrm{CdTe}$, showing a light conversion efficiency of up to $21 \%[1,2]$. Progress in dye-sensitized solar cells (reaching $\approx 12 \%$ efficiency $[1,2])$ has stimulated attempts in using metal chalcogenide nanocrystals (NCs) as sensitizers in liquid-junction solar cells $[3,4]$. These systems have shown remarkable progress, improving from $0.1 \%$ a decade ago to over $12 \%$ in 2018 [5].

Simultaneously, a new rising star in semiconductor photovoltaics - hybrid organo-inorganic lead-based perovskites $\left(\mathrm{MPbX}_{3}\right.$, where $\mathrm{M}=$ methylammonium (MA), formamidinium 
(FA), Cs; $\mathrm{X}=\mathrm{Cl}, \mathrm{Br}, \mathrm{I}$ ) - first employed only several years ago are making a fast progress increasing from $\approx 2 \%$ in 2006 to more than $20 \%$ starting from 2015 (Figure 1a) [6-31].

The avalanche progress of the hybrid perovskite (HP) photovoltaic system was documented in detail by numerous review papers covering all aspects of the preparative chemistry and photophysics of lead-based HPs, solar cell design, challenges and pitfalls on the way to the HP cells competitive with the silicon counterparts, as well as issues of stability, environmental impact and possible recycling of the Pb-HP-based devices [11-13,16,23,26,27,29-50]. A tremendous amount of work has been performed in searching for the most efficient and stable compounds with mixed cations (e.g., $\mathrm{MA}^{+} / \mathrm{Cs}^{+}$, $\left.\mathrm{MA}^{+} / \mathrm{FA}^{+}\right)$and mixed halide components $[20,21,29,30,49,51]$.

It was recognized that $\mathrm{Pb}-\mathrm{HPs}$, especially with inorganic $\mathrm{Cs}^{+}$ ions that have no asymmetry typical for organic MA or FA cations, also have an extremely high potential for application in other areas, in particular as light emitters for LEDs, laser applications and in photodetectors [28-31,35,43,47,50,52-54]. The versatility of the possible optoelectronic applications of $\mathrm{Pb}-\mathrm{HPs}$ has stimulated an explosive progress in preparative chemistry and photophysics of HP nanocrystals (NCs) [16,24,28$30,43,50,53-56]$. Recently, broad recognition was gained by 1D and 2D layered hybrid perovskite materials with strong anisotropy of electron properties. Such materials are currently treated as very promising light harvesters with highly tunable optical and charge transport characteristics [14,16,24,28$31,44,47,57,58]$.

In recent years, some saturation of the initial drastic growth of the power conversion efficiency (PCE) of lead-HP-based solar cells has been observed (Figure 1a). Simultaneously a number of critical challenges related to these materials were recognized as limiting their future broad implementation [29$31,36,39,40,42,48-50,57,59]$. The unrivaled light-to-current conversion efficiency of lead-based HP absorbers is largely compromised by the hydrolytic and photochemical instability of $\mathrm{Pb}$-HPs as well as the highly toxic character of the released $\mathrm{Pb}^{2+}$, which requires the development of special recycling protocols $[40,42]$. While the first problem seems to be solvable, in particular by the encapsulation and a design of the cationic sublattice, the presence of $\mathrm{Pb}^{2+}$ cannot be avoided.

Lead is allowed for usage in the outdoor photovoltaic modules, but the utilization of alternative, less toxic metals is highly welcomed [40,42,54,57,59-61]. One of the promising routes to decrease the environmental burden of $\mathrm{Pb}-\mathrm{HP}$ cells and to maintain reasonably high PCEs was to partially substitute $\mathrm{Pb}^{2+}$ with other double-charged cations, such as $\mathrm{Sn}^{2+}, \mathrm{Mn}^{2+}$, or $\mathrm{Ge}^{2+}$, where the tin-based materials have gained the most attention and progress [10,16,18,29,30,38,44,54,59-65]. The Sn-based HPs $\left(\mathrm{CsSnX}_{3}, \mathrm{MASnX}_{3}\right)$ show a high charge carrier mobility and diffusion length, comparable to the $\mathrm{Pb}$-based analogs $[16,18,57,59,60,62,63,65,66]$. Despite large recombination losses reported for $\mathrm{CsSnX}_{3}$ materials, solar cells based on these compounds showed a promising light conversion efficiency of $\approx 13 \%$ indicating a great potential for the lead-free HP $[59,62,63]$. Numerous attempts and probes have shown that photoactive perovskite compounds can be developed also for other metals, in particular for $\mathrm{Bi}^{3+}, \mathrm{Sb}^{3+}, \mathrm{Cu}^{2+}$, and combinations of $\mathrm{Ag}^{+} / \mathrm{Bi}^{3+}, \mathrm{Ag}^{+} / \mathrm{Sb}^{3+}$, and $\mathrm{In}^{+} / \mathrm{Bi}^{3+}$.

A drastic growth of interest in lead-free HPs has been witnessed in the past three years, where the number of relevant publications has skyrocketed by more than an order of magnitude from 2014 to 2017 with the number of papers published in the first half of 2018 already exceeding the number in 2016 (Figure 1b). The fast progress in the area of lead-free HPs is also supported
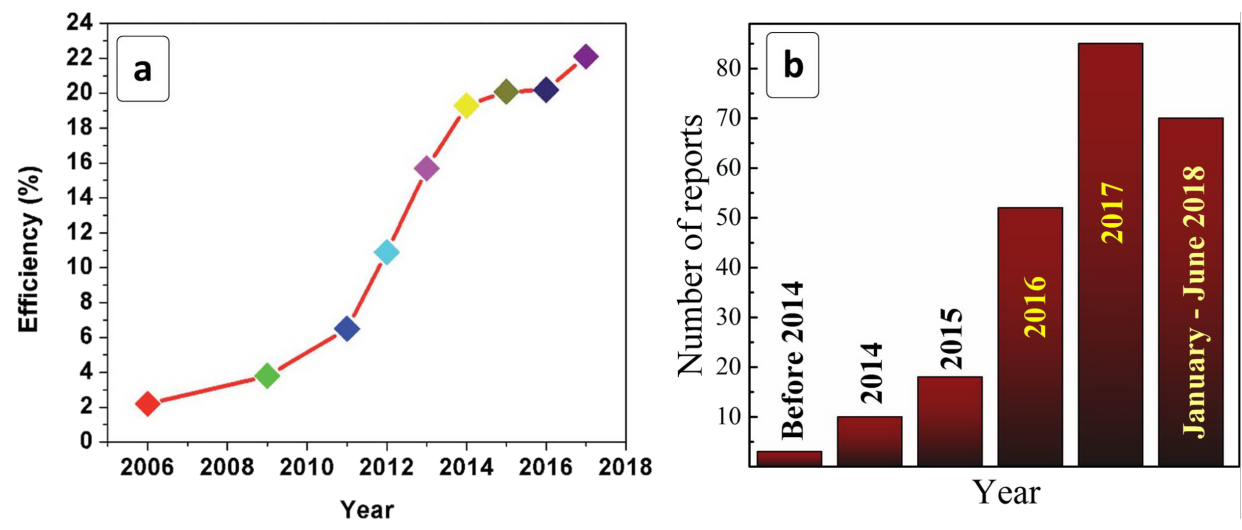

Figure 1: Temporal evolution of (a) the power conversion efficiency of lead-HP-based solar cells and (b) the number of publications on lead-free HPs (a) Reprinted with permission from [27], copyright 2018 The Royal Society of Chemistry. 
by an ever-growing number of review papers trying to distinguish the most promising venues and materials and to suggest outlines of further exploration [28-30,42,50,53,54,57,59$61,64,65]$.

Historically, the first HP cell was built basing on a "classic" design of the dye-sensitized solar cells with the HP layer acting as a sensitizer of a mesoporous metal oxide $\left(\mathrm{TiO}_{2}\right)$ scaffold [67]. Later, it was recognized that Pb-based HPs are incomparably more efficient when applied as light harvesters in photovoltaic planar or bulk heterojunction solar cells. Such cells have two designs - a "conventional" $\mathrm{n}-\mathrm{i}-\mathrm{p}$ design with a HP layer deposited onto the metal oxide electron transport layer (ETL) and then covered with an organic hole transport layer (HTL) and an "inverted" $p-i-n$ design, where an HP layer is formed on an HTL support and covered with an organic ETL, such as fullerene derivatives (see below in Figure 2). The conventional $\mathrm{n}-\mathrm{i}-\mathrm{p}$ scheme dominates in the studies of HPs with the typical ETLs being titania and various $\mathrm{TiO}_{2}$-based composites [27]. The most efficient and frequently used HTLs are among the derivatives of spirobifluorene (Spiro-OMeTAD, see Table 1) and polythiophenes (PEDOT:PSS).

Table 1: Photovoltaic characteristics of selected mixed and lead-free HP-based solar cells. ${ }^{\text {a }}$

Perovskite $\quad$ Cell configuration $\quad J_{\mathrm{sc}}, \mathrm{A} / \mathrm{cm}^{2} \quad V_{\mathrm{oc}}, \mathrm{V} \quad \mathrm{FF} \quad \mathrm{PCE}, \% \quad \mathrm{Ref}$.

\begin{tabular}{|c|c|c|c|c|c|c|}
\hline \multicolumn{7}{|c|}{$\mathrm{Sn}, \mathrm{Pb}-\mathrm{HPs}$} \\
\hline MASn $_{0.5} \mathrm{~Pb}_{0.5} \mathrm{l}_{3}$ & $\mathrm{FTP} / \mathrm{TiO}_{2} / \mathrm{HP} / \mathrm{P} 3 \mathrm{HT} / \mathrm{Au}-\mathrm{Ag}$ & 20.04 & 0.42 & 0.50 & 4.18 & {$[68]$} \\
\hline $\mathrm{MASn}_{0.1} \mathrm{~Pb}_{0.9} \mathrm{IBr}_{2}$ & $\mathrm{FTO} / \mathrm{TiO}_{2} / \mathrm{HP} / \mathrm{C}$ & 14.3 & 1.26 & 0.63 & 11.33 & {$[69]$} \\
\hline $\mathrm{MAPb}_{0.5} \mathrm{Sn}_{0.5}\left(\mathrm{I}_{0.8} \mathrm{Br}_{0.2}\right)_{3}$ & ITO/PEDOT:PSS/HP/ICBA/Ag & 25.9 & 0.90 & 0.75 & 17.63 & {$[70]$} \\
\hline \multicolumn{7}{|c|}{ Sn-HPs } \\
\hline $\mathrm{MASnl}_{3}$ & $\mathrm{FTO} / \mathrm{TiO}_{2} / \mathrm{HP} / \mathrm{PTAA} / \mathrm{Au}$ & 24.28 & 0.429 & 0.64 & 6.63 & {$[71]$} \\
\hline $\mathrm{CsSnl}_{3}$ & 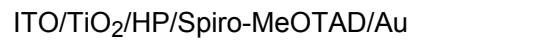 & 23.2 & 0.86 & 0.65 & 12.96 & {$[72]$} \\
\hline $\mathrm{MASnIBr}_{1.8} \mathrm{Cl}_{0.2}$ & $\mathrm{FTO} / \mathrm{TiO}_{2} / \mathrm{HP} / \mathrm{C}$ & 14.0 & 0.38 & 0.57 & 3.1 & {$[73]$} \\
\hline $\mathrm{MASnIBr}_{2}$ & $\mathrm{FTO} / \mathrm{TiO}_{2} / \mathrm{HP} / \mathrm{Sp}$ iro-MeOTAD/Au & 12.30 & 0.82 & 0.57 & 5.73 & {$[74]$} \\
\hline $\mathrm{BA}_{2} \mathrm{MA}_{3} \mathrm{Sn}_{4} \mathrm{I}_{13}$ & $\mathrm{FTO} / \mathrm{TiO}_{2} / \mathrm{HP} / \mathrm{PTAA} / \mathrm{Au}$ & 24.1 & 0.229 & 0.46 & 2.53 & {$[75]$} \\
\hline $\mathrm{FASnl}_{3}$ & ITO/PEDOT/HP/C $60 / B C P / A I$ & 24.1 & 0.525 & 0.71 & 9.0 & {$[76]$} \\
\hline $\mathrm{FASnl}_{3}$ & $\mathrm{ITO} / \mathrm{SnO}_{2} / \mathrm{C}_{60} / \mathrm{HP} / \mathrm{Sp}$ iro-MeOTAD/Ag & 22.45 & 0.47 & 0.68 & 7.09 & {$[77]$} \\
\hline \multicolumn{7}{|c|}{ Ge-HPs } \\
\hline $\mathrm{MAGel}_{3}$ & $\mathrm{FTO} / \mathrm{TiO}_{2} / \mathrm{HP} / \mathrm{Sp}$ iro-MeOTAD/Au & 4.0 & 0.150 & 0.30 & 0.20 & {$[119]$} \\
\hline $\mathrm{MAGel}_{2.7} \mathrm{Br}_{0.3}$ & ITO/PEDOT:PSS/HP/PC 70 BM/Ag & 2.43 & 0.460 & 0.51 & 0.57 & {$[123]$} \\
\hline \multicolumn{7}{|c|}{$\mathrm{Bi}-\mathrm{HPs}$} \\
\hline $\mathrm{MA}_{3} \mathrm{Bi}_{2} \mathrm{l}_{9}$ & $\mathrm{FTO} / \mathrm{TiO}_{2} / \mathrm{HP} / \mathrm{Sp}$ iro-MeOTAD/Au & 0.798 & 0.486 & 0.42 & 0.164 & {$[132]$} \\
\hline $\mathrm{MA}_{3} \mathrm{Bi}_{2} \mathrm{l}_{9}$ & $\mathrm{FTO} / \mathrm{TiO}_{2} / \mathrm{HP} / \mathrm{Sp}$ iro-MeOTAD/Au & 3.00 & 0.83 & 0.79 & 1.64 & {$[64]$} \\
\hline $\mathrm{MA}_{3} \mathrm{Bi}_{2} \mathrm{l}_{9}$ & $\mathrm{FTO} / \mathrm{TiO}_{2} / \mathrm{HP} / \mathrm{P} 3 \mathrm{HT} / \mathrm{Au}$ & 1.157 & 0.354 & 0.464 & 0.19 & {$[65]$} \\
\hline $\mathrm{Cs}_{2} \mathrm{AgBiBr}_{6}$ & $\mathrm{FTO} / \mathrm{TiO}_{2} / \mathrm{HP} / \mathrm{Sp}$ iro-MeOTAD/Au & 3.93 & 0.98 & 0.63 & 2.43 & {$[170]$} \\
\hline \multicolumn{7}{|c|}{ Sb-HPs } \\
\hline $\mathrm{MA}_{3} \mathrm{Sb}_{2} \mathrm{l}_{9}$ & ITO/PEDOT:PSS/HP/PC 61 BM/ZnO/AI & 1.0 & 0.896 & 0.55 & 0.49 & {$[130]$} \\
\hline $\mathrm{MA}_{3} \mathrm{Sb}_{2} \mathrm{I}_{9}$ & ITO/PEDOT:PSS/HP/PC $71 \mathrm{BM} / \mathrm{C}_{60}-\mathrm{BCP} / \mathrm{Al}$ & 5.41 & 0.62 & 0.61 & 2.04 & {$[70]$} \\
\hline $\mathrm{MASbSI}_{2}$ & $\mathrm{FTO} / \mathrm{TiO}_{2} / \mathrm{HP} / \mathrm{PCPSTBT}$ & 8.12 & 0.65 & 0.59 & 3.08 & {$[67]$} \\
\hline $\mathrm{MA}_{3} \mathrm{Sb}_{2} \mathrm{Cl}_{x} \mathrm{l}_{9-x}$ & $\mathrm{FTO} / \mathrm{TiO}_{2} / \mathrm{HP} / \mathrm{Sp}$ iro-MeOTAD/Au & 5.04 & 0.69 & 0.63 & 2.19 & {$[131]$} \\
\hline $\mathrm{Rb}_{3} \mathrm{Sb}_{2} \mathrm{l}_{9}$ & $\mathrm{FTO} / \mathrm{TiO}_{2} / \mathrm{HP} / \mathrm{Poly}-\mathrm{TPD} / \mathrm{Au}$ & 2.11 & 0.55 & 0.57 & 0.66 & {$[71]$} \\
\hline $\mathrm{Cs}_{3} \mathrm{Sb}_{2} \mathrm{l}_{9}$ & ITO/PEDOT:PSS/HP/PC 70 BM/AI & 5.31 & 0.72 & 0.39 & 1.49 & [69] \\
\hline
\end{tabular}

aThe accuracy of values presented as reported, $J_{\mathrm{sc}}$ - short-circuit photocurrent density, $V_{\mathrm{oc}}-$ open-circuit photovoltage, FF - fill factor. Abbreviations: $\mathrm{BA}=\mathrm{CH}_{3}\left(\mathrm{CH}_{2}\right)_{3} \mathrm{NH}_{3}$; P3HT - poly(3-hexylthiophen-2,5-diyl); Spiro-MeOTAD - 2,2',7,7'-tetrakis-( $N, N$-di- $p$-methoxyphenylamine)-9,9'-spirobifluorene; PCPSTBT -poly(2,6-(4,4-bis(2-ethylhexyl)-4H-cyclopenta[2,1-b;3,4- $\left.b^{\prime}\right]$ dithiophene)-alt-4,7(2,1,3-benzothiadiazole)); poly-TPD - poly( $N, N$ '-bis-4butylphenyl- $N, N^{\prime}$-bisphenyl)benzidine; PEDOT:PSS - poly(ethylenedioxythiophene):polystyrenesulfonate; $\mathrm{PC}_{\mathrm{x}} \mathrm{BM}-[6,6]-$ phenyl $\mathrm{C}_{\mathrm{x}}$ butyric acid methyl ester; BCP - 2,9-dimethyl-4,7-diphenyl-1,10-phenanthroline; ICBA - indene- $C_{60}$ adduct; PTAA - poly[bis(4-phenyl)(2,4,6-trimethylphenyl)amine]. 
Recently, very good prospects were recognized for the cell design without organic HTL and back contacts, both roles played by a carbon layer. Panels (c) and (d) in Figure 2 show $\mathrm{CB} / \mathrm{VB}$ levels of selected lead-free perovskites based on $\mathrm{Sn}^{2+} / \mathrm{Sn}^{4+}$ (Figure 2c) and $\mathrm{Sb}^{3+} / \mathrm{Bi}^{3+}$ (Figure 2d) with respect to the acceptor/donor levels of a series of typical ETL/HTL materials.

The present review aims to survey lead-free perovskites and closely related compounds reported in light of their possible applications as light harvesters in photovoltaic systems. Special focus is placed on the influence of the spatial organization of HP materials both on the micro- and nanoscale levels with respect to the performance and stability of perovskite-based solar light converters. The survey starts from HPs with lead ions partially substituted by isovalent cations of other less toxic metals, then focuses on lead-free HPs where the central metal ion is in the oxidation state of +2 , predominantly, $\mathrm{Sn}^{2+}$ and $\mathrm{Ge}^{2+}$. Then, hybrid perovskite materials formed on the basis of $\mathrm{M}^{3+}$ cations $\left(\mathrm{Sb}^{3+}, \mathrm{Bi}^{3+}\right)$ as well as on combinations of $\mathrm{M}^{+} / \mathrm{M}^{3+}$ ions aliovalent to $2 \mathrm{~Pb}^{2+}$ (like $\mathrm{Ag}^{+} / \mathrm{Bi}^{3+}, \mathrm{Ag}^{+} / \mathrm{Sb}^{3+}$ ) are dis- cussed as one of the most promising avenues to further progress in the research of lead-free perovskite light harvesters. The final Conclusion and Outlook section is focused on future strategies of the design of photovoltaic systems on lead-free perovskite compounds and the materials that have a high potential to be discovered.

\section{Hybrid perovskites with partially/completely substituted $\mathrm{Pb}^{2+}$ cations \\ Hybrid perovskites with partially substituted lead ions}

Using a small "tool kit" of two metals, $\mathrm{Sn}$ and $\mathrm{Pb}$, and two organic cations, $\mathrm{A}=\mathrm{MA}$ and $\mathrm{FA}$, a broad variety of isostructural $\mathrm{Pb}$-, $\mathrm{Sn}$ - and $\mathrm{Pb}-\mathrm{Sn}$-based $\mathrm{ASn}_{x} \mathrm{~Pb}_{1-x} \mathrm{I}_{3}$ HPs can be synthesized with a bandgap varying from 1.25 to $1.75 \mathrm{eV}$ depending on the HP composition [92]. By simultaneously tuning the composition of $\mathrm{Pb}-\mathrm{Sn}$ and halide components, a solar light absorber was designed with a bandgap of $1.35 \mathrm{eV}$ ideal for the solar light harvesting. The inverted cells based on $\mathrm{MAPb}_{0.5} \mathrm{Sn}_{0.5}\left(\mathrm{I}_{0.8} \mathrm{Br}_{0.2}\right)_{3}$ demonstrated PCEs of up to $17.63 \%$ [70]. A suppressed lattice disorder of this HP results in a low
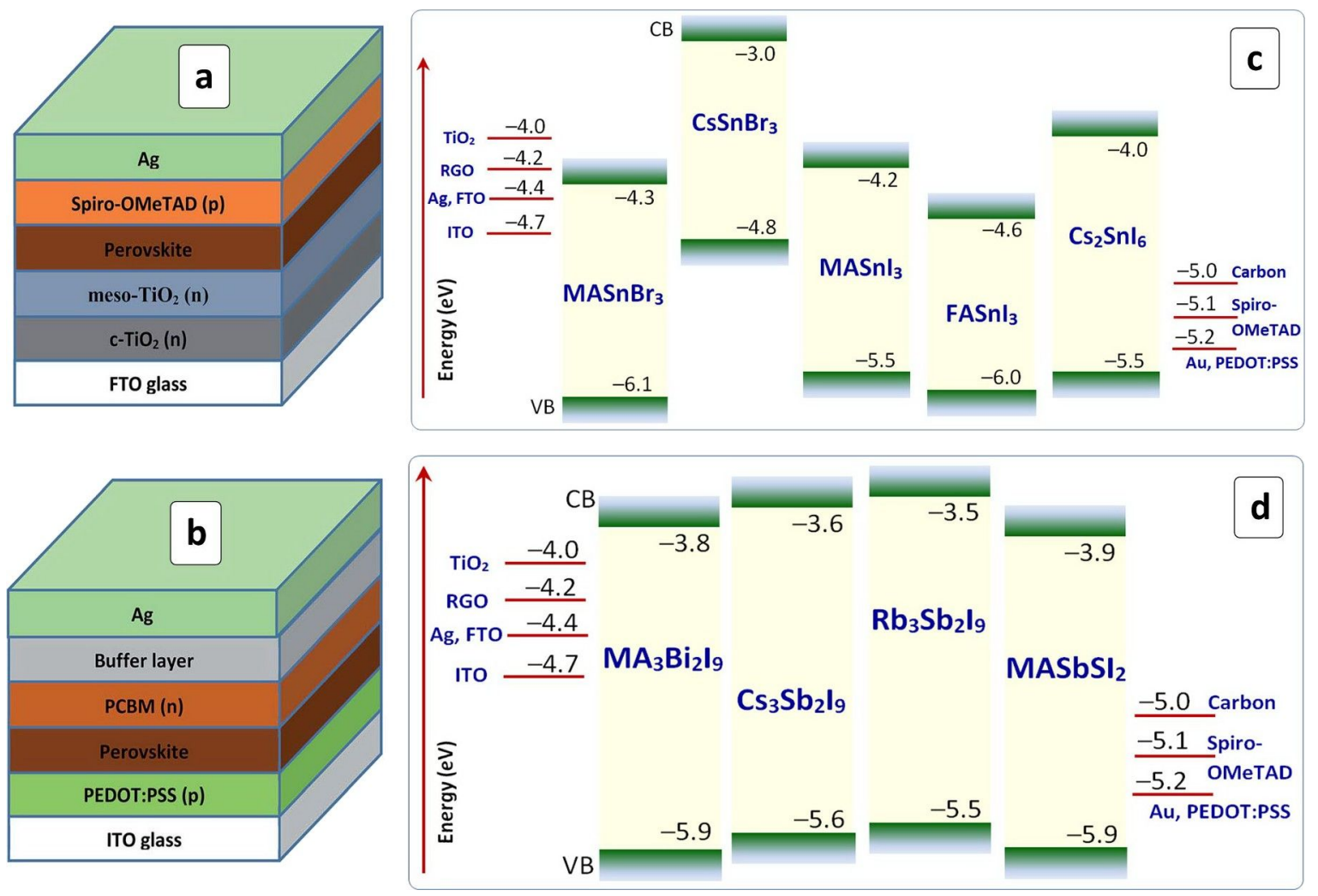

Figure 2: Schemes of conventional (a) and inverted (b) HP-based solar cell; energy diagrams of selected $\mathrm{Sn}$-based $\mathrm{HPs}$ (c) and $\mathrm{Bi}$ - and $\mathrm{Sb}$-based $\mathrm{HPs}(\mathrm{d})$ relative to the levels of some ETL and HTL materials. The CB/VB levels are taken from [78] $\left(\mathrm{MASnBr}_{3}\right),[79]\left(\mathrm{CsSnBr}_{3}\right),[80,81]\left(\mathrm{MASnl}_{3}\right)$, $[80,82]\left(\mathrm{FASnl}_{3}\right)$, and $[80,83]\left(\mathrm{Cs}_{2} \mathrm{Snl}_{6}\right)$, [67-86] $\left(\mathrm{MA}_{3} \mathrm{Bi}_{2} \mathrm{l}_{\mathrm{g}}\right)$, [87] $\left(\mathrm{MASbSl}_{2}\right)$, [88-90] $\left(\mathrm{Cs}_{3} \mathrm{Sb}_{2} \mathrm{l}_{9}\right)$, and [91] $\left(\mathrm{Rb}_{3} \mathrm{Sb}_{2} \mathrm{l}_{\mathrm{g}}\right)$. (a,b) Reprinted with permission from [27], copyright 2018 The Royal Society of Chemistry. 
density of traps and sub-bandgap states reflecting in a relatively small $E_{\mathrm{g}}-V_{\text {oc }}$ loss of $0.45 \mathrm{eV}[70]$.

The bandgap of alloyed $\mathrm{FASn}_{x} \mathrm{~Pb}_{1-x} \mathrm{I}_{3}$ HPs was found to vary in an unexpected way, that is, decreasing upon the introduction of $\mathrm{Sn}$ from $\approx 1.5 \mathrm{eV}$ for MAPI to $1.24 \mathrm{eV}$ for $x=0.4$ and then increasing to $\approx 1.3 \mathrm{eV}$ for the $\mathrm{FASnI}_{3}$ perovskite [93]. The "bowing" of the $E_{\mathrm{g}}(x)$ dependence may originate from a transition from cubic to orthorhombic lattice symmetry upon increasing tin content [93]. A similar anomalous variation of the bandgap, as well as the $\mathrm{CB} / \mathrm{VB}$ level positions with the Sn content, was reported for $\mathrm{CH}_{3} \mathrm{NH}_{3} \mathrm{Sn}_{x} \mathrm{~Pb}_{1-x} \mathrm{I}_{3-y} \mathrm{Cl}_{y}$ HPs [94].

A study of alloyed $\mathrm{ASn}_{1-x} \mathrm{~Pb}_{x} \mathrm{I}_{3}\left(\mathrm{~A}=\mathrm{Cs}^{+}, \mathrm{FA}^{+}, \mathrm{MA}^{+}\right.$or their combinations) produced in the form of $\mathrm{NCs}$ showed the mixed compounds to be much more stable to ambient air as compared to both $\mathrm{ASnI}_{3}$ and $\mathrm{APbI}_{3}$ individually [95-97]. The cationexchange approach applied to produce $\mathrm{FASn}_{1-x} \mathrm{~Pb}_{x} \mathrm{I}_{3}$ and
$\mathrm{FAPbI}_{3}$ from $\mathrm{FASnI}_{3}$ is expected to be a general one and appropriate for the introduction of other isovalent and aliovalent cations such as $\mathrm{Mn}^{2+}, \mathrm{Co}^{2+}, \mathrm{Bi}^{3+}$, and $\mathrm{Al}^{3+}$ into the sites of $\mathrm{Sn}^{2+}$ or $\mathrm{Pb}^{2+}$ [97]. The chemical stability of mixed $\mathrm{Sn}-\mathrm{Pb}$ perovskites can be further enhanced by the passivation with a $\mathrm{C}_{60}$ layer [98]. The fullerene was found to eliminate the surface trap states of $\mathrm{MAPb}_{0.75} \mathrm{Sn}_{0.25} \mathrm{I}_{3}$ crystals suppressing the electron-hole recombination as well as shielding the HP layer from the ambient moisture and oxygen.

Solar cells with mixed MASn $\mathrm{Pb}_{1-x} \mathrm{I}_{3}$ HPs and a P3HT HTL showed a dome-shaped PCE dependence on the lead content (Figure 3a), where a maximum $\eta$ of $4.18 \%$ was achieved at an $\mathrm{Sn} / \mathrm{Pb}$ atomic ratio of 1:1 [68]. The conventional MAPI HP displayed a much lower efficiency, while a pure Sn-based HP turned out to be inactive with this HTL material. A higher efficiency of mixed $\mathrm{Sn}, \mathrm{Pb}-\mathrm{HPs}$ stems largely from a broader absorption range extending to $\lambda_{\mathrm{e}}=1060 \mathrm{~nm}$ as compared to
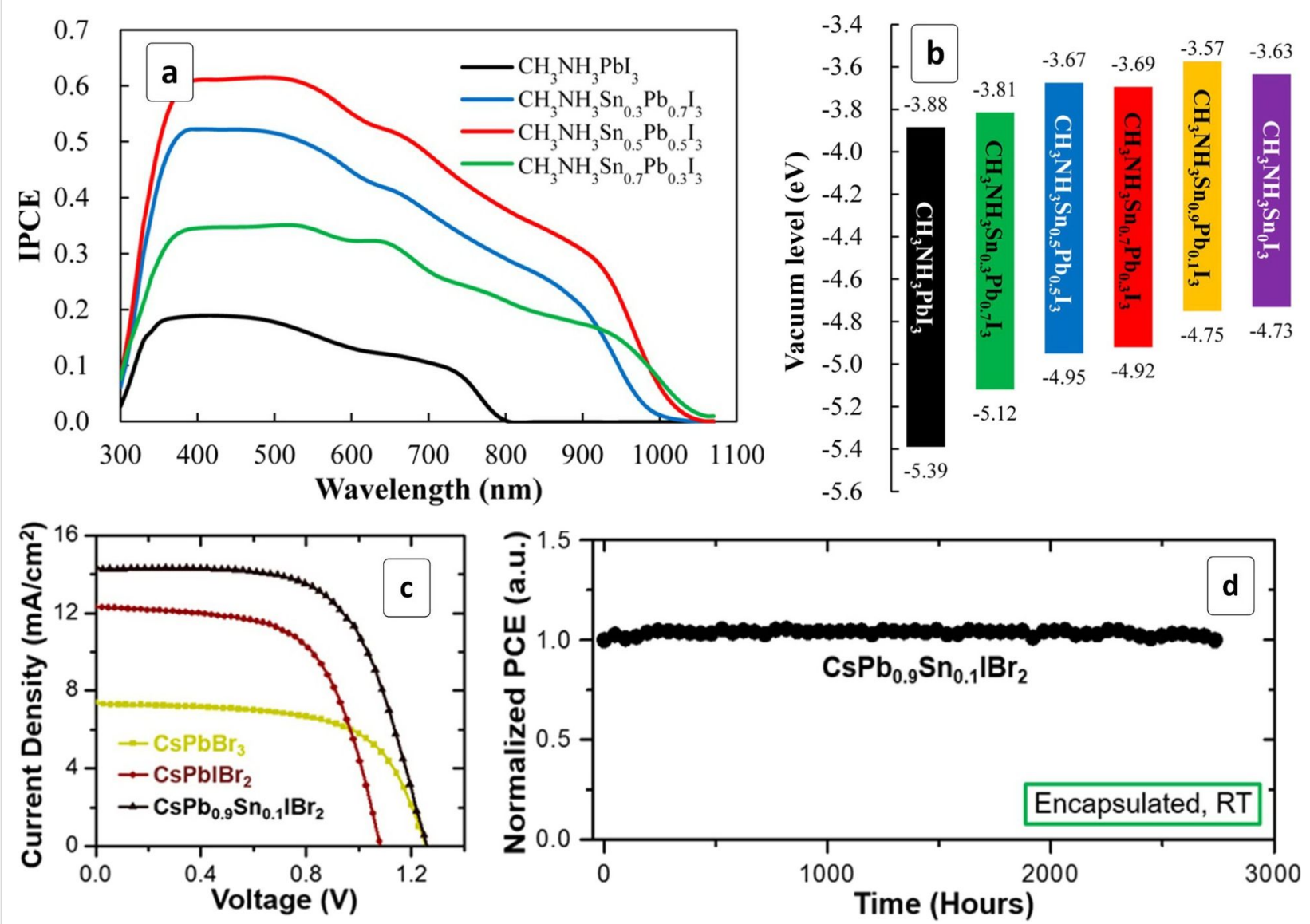

Figure 3: (a,b) Internal photon-to-current conversion efficiency (IPCE) spectra of solar cells comprising a series of Sn,Pb-based HPs with different $\mathrm{Sn} / \mathrm{Pb}$ ratios (a) and energy diagram of the corresponding perovskites (b); (c) current-voltage curves for solar cells based on $\mathrm{CsPbBr}_{3}$, $\mathrm{CsPbIBr}{ }_{2}$ and $\mathrm{CsPb}_{0.9} \mathrm{Sn}_{0.1} \mathrm{IBr}_{2} \mathrm{HPs}$; (d) test of prolonged performance stability of a solar cell based on $\mathrm{CsPb}_{0.9} \mathrm{Sn}_{0.1} \mathrm{IBr}_{2} \mathrm{HP}, \mathrm{RT}-\mathrm{room}$ temperature.

(a,b) Reprinted with permission from [68], copyright 2014 American Chemical Society and (c,d) Reprinted with permission from [69], copyright 2017 American Chemical Society. 
only $800 \mathrm{~nm}$ for MAPI (Figure 3a). A partial substitution of the lead with tin was found to affect the VB position of the HP much stronger than the corresponding CB level (Figure $3 b$ ). This fact hints at the importance of the selection of an appropriate hole transport material for each particular HP composition to realize the potential of such materials to a full extent.

The introduction of $10 \% \mathrm{Sn}$ into $\mathrm{CsPbIBr}_{2} \mathrm{HP}$ results in a bandgap narrowing from 1.90 to $1.79 \mathrm{eV}$ and an increase of the solar cell performance (Figure $3 \mathrm{c}$ ) from $8.25 \%$ for the undoped $\mathrm{Pb}$-HP to $11.33 \%$ for the $\mathrm{CsSn}_{0.1} \mathrm{~Pb}_{0.9} \mathrm{IBr}_{2}$-based device [69]. The latter cell also exhibited a record $V_{\mathrm{oc}}$ of $1.26 \mathrm{~V}$ amounting to $\approx 70 \%$ of the optical bandgap and vividly showing a high potential of such photovoltaic materials. Additionally, the cell fitted with an encapsulating protective layer showed a remarkable stability with the PCE unchanged in a more than $2500 \mathrm{~h}$ test trial (Figure 3d) [69].

Manganese(II) ions were found to substitute $\mathrm{Pb}(\mathrm{II})$ in MA-PbCl-Br HPs, the perovskite preserving the crystal structure up to $90 \% \mathrm{Mn}$ [99]. Up to $46 \% \mathrm{~Pb}^{2+}$ ions can be exchanged with $\mathrm{Mn}^{2+}$ in $\mathrm{CsPbCl}_{3} \mathrm{NCs}$ produced by hot-injection, resulting in a highly increased photoluminescence (PL) efficiency [100]. Mixed $\mathrm{MAPb}_{x} \mathrm{Mn}_{1-x} \mathrm{I}_{1+2 x} \mathrm{Cl}_{2-2 x}(x=0.1-1.0)$ synthesized by a solid-state reaction displayed an unprecedentedly high open-circuit voltage of up to $1.19 \mathrm{~V}$ and fill factor (FF) of almost $90 \%$ when introduced into inverted solar cells with PEDOT:PSS and PCBM charge transport layers [101]. Despite the high $V_{\mathrm{oc}}$ and FF values, the cells showed quite a low efficiency of $\approx 0.3 \%$ indicating huge recombinational losses and leaving large room for further improvement of the structural quality of the perovskite absorber layer.

The substitution of a mere $2 \%$ lead with $\mathrm{Sr}(\mathrm{II})$ in $\mathrm{CsPbI}_{2} \mathrm{Br} \mathrm{HP}$ was found to result in a spectacular PCE increase from $6.6 \%$ to $10.1 \%$ and an enhancement of the thermal HP stability [102]. Strontium ions accumulate in a surface layer of the HP film exerting a passivating effect and resulting in a longer charge carrier lifetime [102]. The introduction of $\mathrm{Ca}^{2+}$ on the $\mathrm{Pb}^{2+}$ sites of $\mathrm{CsPbI}_{3} \mathrm{HP}$ results in a more homogeneous a better contact between the HP and HTL, as well as the surface passivation by a Ca-enriched surface layer [103]. The best Ca-substituted $\mathrm{CsPbI}_{3}$ HPs show a PCE of higher than $13 \%$ and maintain more than $85 \%$ of the initial efficiency for more than two months of testing with encapsulation [103].

A partial substitution of $\mathrm{Pb}$ (II) with $\mathrm{In}(\mathrm{III})$ yields HPs with a reduced lead content and a promising PCE exceeding 17.5\% [104]. The introduction of $\mathrm{Sb}(\mathrm{III})$ during the growth of MAPI HP results in the substitution of lead with antimony and formation of a $\mathrm{MA}_{3} \mathrm{Sb}_{2} \mathrm{I}_{9}$ layer on the surface of growing MAPI crys- tals thus limiting their size to $\approx 50 \mathrm{~nm}$ [105]. An enhanced PL of the Sb-doped MAPI crystals indicates that the electron-hole recombination is efficiently suppressed by the surface antimony-rich layer [105].

\section{Sn-based hybrid perovskites}

The $\mathrm{MASnI}_{3}$ perovskite displays a bandgap of $\approx 1.3 \mathrm{eV}[74,81]$ corresponding to the absorption onset at $\lambda_{\mathrm{e}} \approx 950 \mathrm{~nm}$, which is significantly shifted as compared to the MAPI counterpart $\left(E_{\mathrm{g}}=1.55 \mathrm{eV}, \approx 800 \mathrm{~nm}\right.$ ) [74] and comparably high absorption coefficients of $\approx 10^{5} \mathrm{~cm}^{-1}$ [106]. Thick $\mathrm{MASnI}_{3}$ perovskite wafers synthesized by a temperature-reduction-induced crystallization showed an even narrower bandgap of $\approx 1.2 \mathrm{eV}$ [107]. The $\mathrm{FASnI}_{3}$ compound with a bulkier formamidinium cation displayed a larger bandgap of $1.41 \mathrm{eV}$ [82]. A partial substitution of I with $\mathrm{Br}$ results in a controlled expansion of the bandgap up to $1.68 \mathrm{eV}$ for $\mathrm{FASnI}_{2} \mathrm{Br}$ [108]. The reported bandgaps of selected Sn-based HPs are collected in Table 2.

\begin{tabular}{|c|c|c|c|}
\hline Perovskite & $E_{\mathrm{g}}, \mathrm{eV}$ & $\lambda_{\mathrm{e}}, \mathrm{nm}$ & Ref. \\
\hline $\mathrm{MASnCl}_{3}$ & 2.1 & 590 & [109] \\
\hline $\mathrm{MASnBr}_{3}$ & 2.2 & 570 & [78] \\
\hline $\mathrm{CsSnBr}_{3}$ & 1.80 & 690 & {$[110]$} \\
\hline $\mathrm{MASnl}_{3}$ & $\begin{array}{l}1.21-1.23 \\
1.3\end{array}$ & $\begin{array}{l}1010-1030 \\
960\end{array}$ & $\begin{array}{l}{[111]} \\
{[74,79,81]}\end{array}$ \\
\hline $\mathrm{FASnl}_{3}$ & 1.41 & 880 & [82] \\
\hline $\mathrm{FASnl}_{2} \mathrm{Br}$ & 1.68 & 740 & [108] \\
\hline $\mathrm{Cs}_{2} \mathrm{Snl}_{6}$ & 1.48 & 840 & {$[83,112]$} \\
\hline $\mathrm{MA}_{2} \mathrm{Snl}_{6}$ & 1.81 & 690 & {$[54]$} \\
\hline
\end{tabular}

Similar to MAPI, the morphology of $\mathrm{MASnI}_{3}$ plays an important role in the efficiency of the solar cells based on this light harvester. This fact stimulated a screening of suitable solvents and deposition conditions, revealing dimethylsulfoxide (DMSO) as one of the most promising candidates for spincoating deposition technology [113,114], which produced uniform pin-hole-free $\mathrm{MASnI}_{3}$ films due to the formation of an intermediate $\mathrm{SnI}_{2} \times \mathrm{DMSO}$ phase [114]. Trimethylamine acts in a similar way forming intermediate complexes with $\mathrm{SnI}_{2}$ (and $\mathrm{SnF}_{2}$ as a stability-enhancing additive) and facilitating the formation of dense and uniform $\mathrm{MASnI}_{3}$ and $\mathrm{FASnI}_{3}$ films [77]. The simultaneous presence of the trimethylamine and $\mathrm{SnF}_{2}$ was found to be crucial both for conventional and inverted solar cell configurations. For example, the modification of an inverted $\mathrm{FASnI}_{3}$-based cell with $\mathrm{SnF}_{2}$ resulted in a spectacular PCE increase from 0.52 to $4.20 \%$ with a further increase to $7.09 \%$ (Table 1) induced by the introduction of trimethylamine as a morphology-directing agent [77]. 
The quality of $\mathrm{MASnI}_{3}$ films as components of solar cells can be ameliorated by introducing ethylenediamine (en) acting simultaneously as an additional organic cation in the HP lattice and as a morphology-directing agent [71]. The cells with such modified $\mathrm{MASnI}_{3}$ absorbers showed a PCE of $6.63 \%$ (Table 1) with a relatively high FF of $\approx 64 \%$ (Figure $4 a$ ). High-quality $\mathrm{MASnI}_{3}$ films yielding a PCE of $1.86 \%$ were prepared using a low-temperature vapor-assisted deposition [115].

The stability of $\mathrm{MASnI}_{3}$ - and $\mathrm{CsSnI}_{3}$-based solar cells is largely compromised by a low HP stability to oxidation $[80,116]$. It was found that the $\mathrm{Sn}^{2+}$ state of the central ion can be stabilized by introducing an excess of $\mathrm{SnI}_{2}$, with the best cells showing a
PCE of $4.81 \%$ (Figure $4 \mathrm{~b}$ ) and a prolonged stability of the photovoltaic parameters [80]. Calculations by the density functional theory (DFT) indicated that a partial substitution of $\mathrm{Cs}^{+}$ with $\mathrm{Rb}^{+}$should considerably increase the stability of $\mathrm{CsSnI}_{3}$ [117].

To avoid a partial conversion of $\mathrm{Sn}^{2+}$ into $\mathrm{Sn}^{4+}$, the latter acting as charge carrier traps in $\mathrm{ASnX}_{3} \mathrm{HPs}$, it was suggested to deposit the perovskite layer under a reductive atmosphere, for example, in the presence of hydrazine vapors [119]. The conversion of $\mathrm{Sn}^{4+}$ into $\mathrm{Sn}^{2+}$, which can be described as $2 \mathrm{SnI}_{6}{ }^{2-}+\mathrm{N}_{2} \mathrm{H}_{4}=2 \mathrm{SnI}_{4}{ }^{2-}+\mathrm{N}_{2}+2 \mathrm{HI}$, results in a reduction of the density of $\mathrm{Sn}^{2+}$ vacancies (Figure 5a) suppressing the unde-
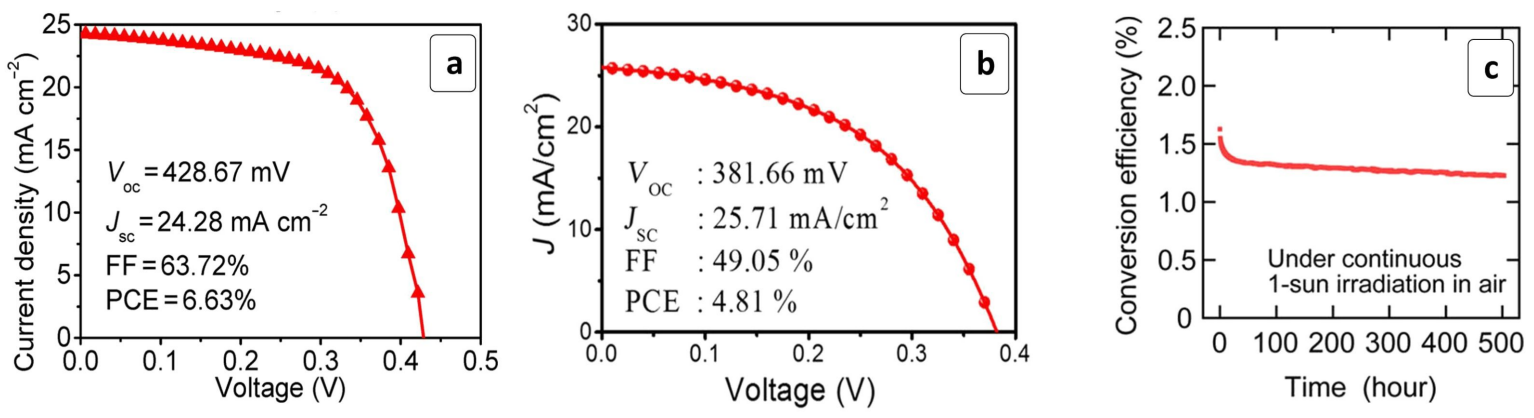

Figure 4: (a,b) Photocurrent density-voltage curves recorded for the solar cells based on MASnl 3 HPs (a) and CsSnl 3 HPs (b); (c) test of prolonged performance stability of a solar cell based on MASnl 3 HPs. (a) Reprinted with permission from [71], copyright 2017 American Chemical Society; (b) Reprinted with permission from [80], copyright 2017 American Chemical Society; (c) Reprinted with permission from [118], copyright 2017 American Chemical Society.
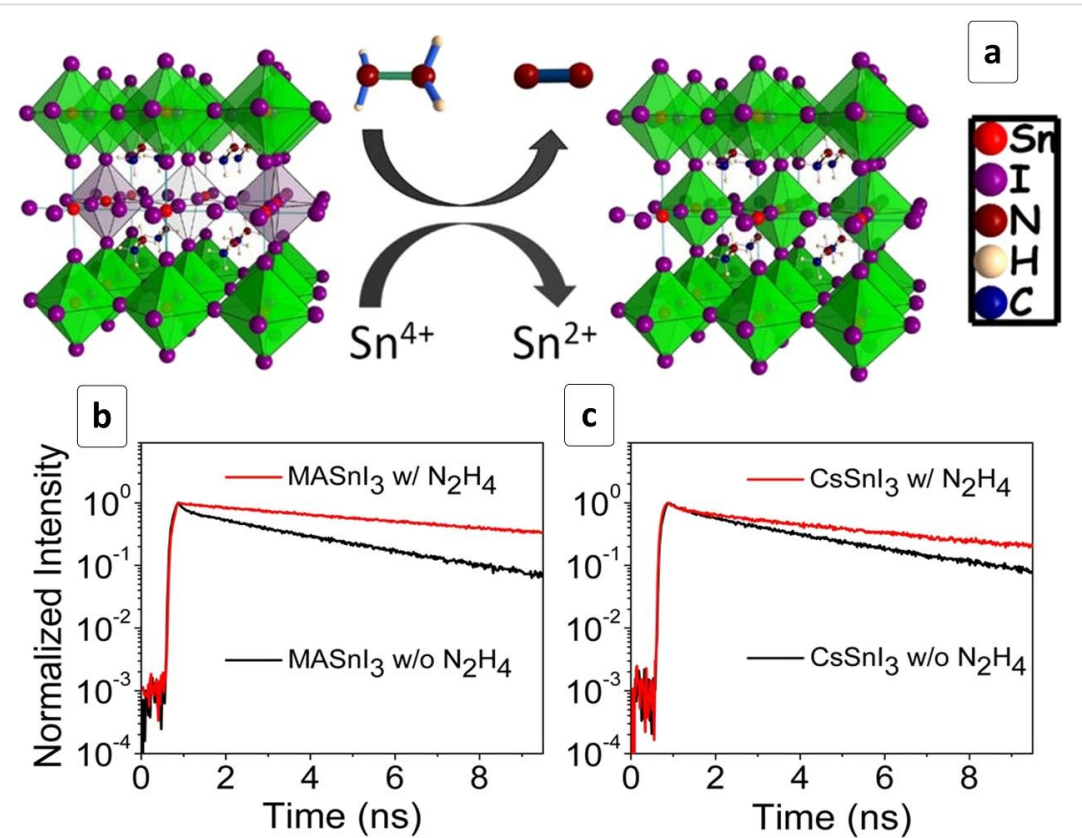

Figure 5: (a) Scheme of a possible mechanism of Sn-based HP transformation upon reaction with hydrazine; (b,c) kinetic photoluminescence decay curves for $\mathrm{MASnl}_{3}$ (b) and $\mathrm{CsSnl}_{3}$ (c) produced without treatment (black lines) and with an $\mathrm{N}_{2} \mathrm{H}_{4}$ vapor treatment (red lines). Reprinted and adapted with permission from [119], copyright, 2016 American Chemical Society. 
sirable p-type conductivity and reverting the perovskites back to n-type semiconducting behavior [119]. The hydrazine treatment results in an appreciable increase of the radiative lifetime of $\mathrm{ASnX}_{3}$ HPs irrespective of the type of cation A (Figure 5b,c) and halide component composition, clearly indicating a reduction of the trap-mediated non-radiative recombination losses.

The effect of elimination of $\mathrm{Sn}^{2+}$ vacancies in $\mathrm{FASnI}_{3} \mathrm{HP}$ resulting from tin(II) oxidation can also be achieved by a partial substitution of iodide with bromide [120]. The devices with a mixed $\mathrm{Br} / \mathrm{I}$ halide component displayed a reduced dark current and lower recombination rate, resulting in an increased $V_{\mathrm{oc}}$ and FF and showed a PCE above 5\%, whereby the cells retained stability over a $1000 \mathrm{~h}$ time trial span [120]. In a similar manner, the mixed $\mathrm{CsSnIBr}_{2} \mathrm{HP}$ revealed a higher stability and a lower density of $\mathrm{Sn}^{2+}$ vacancies which can be further decreased by growing the HP crystals in the presence of hypophosphoric acid as a tin(II) complexant [121]. The corresponding cells revealed the stable PCE for a 77 day trial at room temperature and during a $9 \mathrm{~h}$ test at $473 \mathrm{~K}$ [121].

An elegant way of simultaneously ordering $\mathrm{MASnI}_{3}$ deposits and protecting them from exposure to air/moisture was suggested via the growth of HP nanowires in the pores of anodized alumina membranes [122]. The effective blockage of the diffusion of water and oxygen molecules to the alumina-incorporated $\mathrm{MASnI}_{3}$ nanowires resulted in a three order of magnitude slower degradation of this material as compared to planar films of the same composition [122].

It was found that of the three "homologs" of $\mathrm{CsSnX}_{3}$ HPs $(\mathrm{X}=\mathrm{Cl}, \mathrm{Br}, \mathrm{I})$ the bromide-based compound shows an exceptionally high photochemical and chemical stability, which can further be enhanced by doping with $\mathrm{SnF}_{2}$ [110].

The stability of $\mathrm{MASnI}_{3}$-based cells can also be strongly enhanced by doping with $\mathrm{SnF}_{2}[118,123,124]$. The doped materials showed a remarkable stability when illuminated under ambient air conditions without additional encapsulation (Figure 4c). Additionally, the $\mathrm{SnF}_{2}$ doping results in a decrease of the HP bandgap down to $1.25 \mathrm{eV}$, which is highly beneficial for the cell performance. This redshift effect was attributed to the Burstein-Moss effect arising from a significant doping of the absorber material with holes [118]. The $\mathrm{SnF}_{2}$ doping was found to almost double the radiative lifetime of charge carriers and considerably increase the carrier diffusion length [125]. A similar approach can be applied to increase the stability of $\mathrm{FASnI}_{3}$ absorbers [82].

The quality and stability of $\mathrm{FASnI}_{3}$ can be strongly enhanced by introducing trace amounts of 2D tin HPs comprising both FA and 2-phenylethylammonium cations [126]. The presence of 2D HP favors a more homogeneous growth of $\mathrm{FASnI}_{3}$ crystals, resulting in a reduced number of grain boundaries and the suppression of the formation of $\mathrm{Sn}^{4+}$. The high quality of such $\mathrm{FASnI}_{3}$ films was evidenced by a strongly reduced background carrier density and a longer charge carrier lifetime [126]. The solar cells produced from these highly uniform HP layers revealed a negligible hysteresis and no light soaking effect, indicating a largely suppressed recombination. The best PCE was $9 \%$, which is by $50 \%$ higher than for similar cells with the HP layer modified by $\mathrm{SnF}_{2}$ [76].

A compositional variation of the halide component of $\mathrm{CsSnX}_{3}$ HPs is a potent instrument allowing the bandgap and CB/VB energies to be changed, and therefore, to affect the spectral sensitivity range and $V_{\text {oc }}$ of the $\mathrm{CsSnX}_{3}$-based solar cells. The individual and mixed-halide Sn-HPs demonstrated a broad spectrum of bandgaps varying from $2.97 \mathrm{eV}$ for $\mathrm{CsSnCl}_{3}$ to $1.31 \mathrm{eV}$ for $\mathrm{CsSnI}_{3}$ with all possible intermediate values achievable by tailoring the type and relative content of halide ions (Figure 6a) [126].

By varying the bromide content in $\mathrm{CsSnI}_{3-x} \mathrm{Br}_{x}$ perovskite the $\mathrm{HP}$ bandgap can be smoothly increased from $1.27 \mathrm{eV}\left(\mathrm{CsSnI}_{3}\right)$ to $1.37 \mathrm{eV}\left(\mathrm{CsSnI}_{2} \mathrm{Br}\right)$ to $1.65 \mathrm{eV}\left(\mathrm{CsSnIBr}_{2}\right)$ and up to $1.75 \mathrm{eV}$ for $\mathrm{CsSnBr}_{3}$ (Figure 6b) [127]. The open-circuit voltage of the corresponding solar cells increases from $\approx 200 \mathrm{meV}$ to $410 \mathrm{meV}$. A combination of two tendencies - a bandgap increase resulting in a narrowing of the spectral sensitivity range and a $V_{\mathrm{oc}}$ increase contributing to a higher PCE - results in an optimal $\mathrm{HP}$ composition of $\mathrm{CsSnI}_{2} \mathrm{Br}$ yielding the highest light harvesting efficiency [127].

Similar attempts of introducing chloride ions into $\mathrm{Cs}_{2} \mathrm{SnI}_{6} \mathrm{HP}$ showed that single-phase compounds can exist only at compositions close to the individual I- and Cl-based compounds (Figure 6c), while at intermediate compositions a mixture of phases is typically produced [128]. In the case of $\mathrm{I} / \mathrm{Br}$-mixed $\mathrm{Sn}^{4+}$-based HP a series of single-phase $\mathrm{Cs}_{2} \mathrm{SnI}_{6-x} \mathrm{Br}_{x}$ compounds were prepared with a bandgap tuned from $1.3 \mathrm{eV}$ to $2.9 \mathrm{eV}$ [129]. The highest PCE of $2.1 \%$ was reported for an intermediate composition corresponding to $x=2$ [129].

Similar to the Cs-containing HPs, the optoelectronic properties of MASnX $\mathrm{X}_{3}$ HPs can also be engineered by a partial substitution of halide anions. A gradual shift from $\mathrm{MASnI}_{3}$ to $\mathrm{MASnBr}_{3}$ via a series of intermediate solid-solution compounds (some illustrated by Figure 6d) results in an $E_{\mathrm{g}}$ expansion from $1.30 \mathrm{eV}$ to $2.15 \mathrm{eV}$. Here the bandgap increment contributes mostly to a shift of the CB level to lower energies, while the VB level remains relatively unaffected [74]. For all 


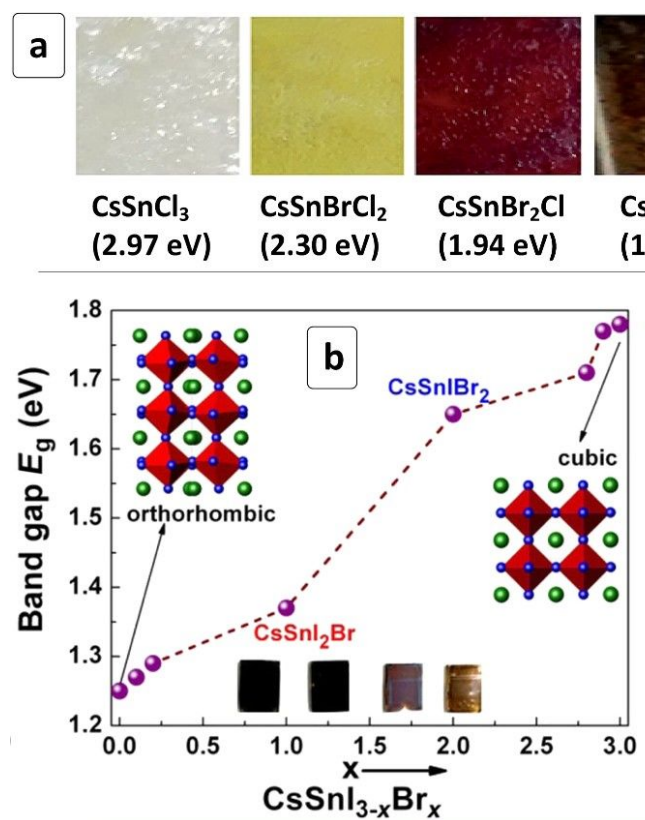

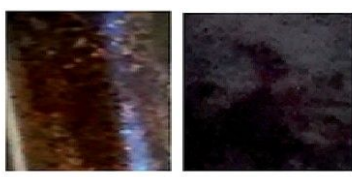

$\mathrm{CsSnBr}_{3}$ $(1.70 \mathrm{eV})$
CsSnIBr

$(1.60 \mathrm{eV})$

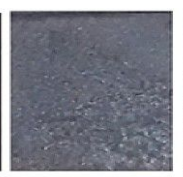

$\mathrm{CsSnl}_{2} \mathrm{Br}$

$(1.44 \mathrm{eV})$

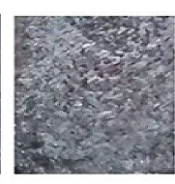

$\mathrm{CsSnl}_{3}$

$(1.31 \mathrm{eV})$
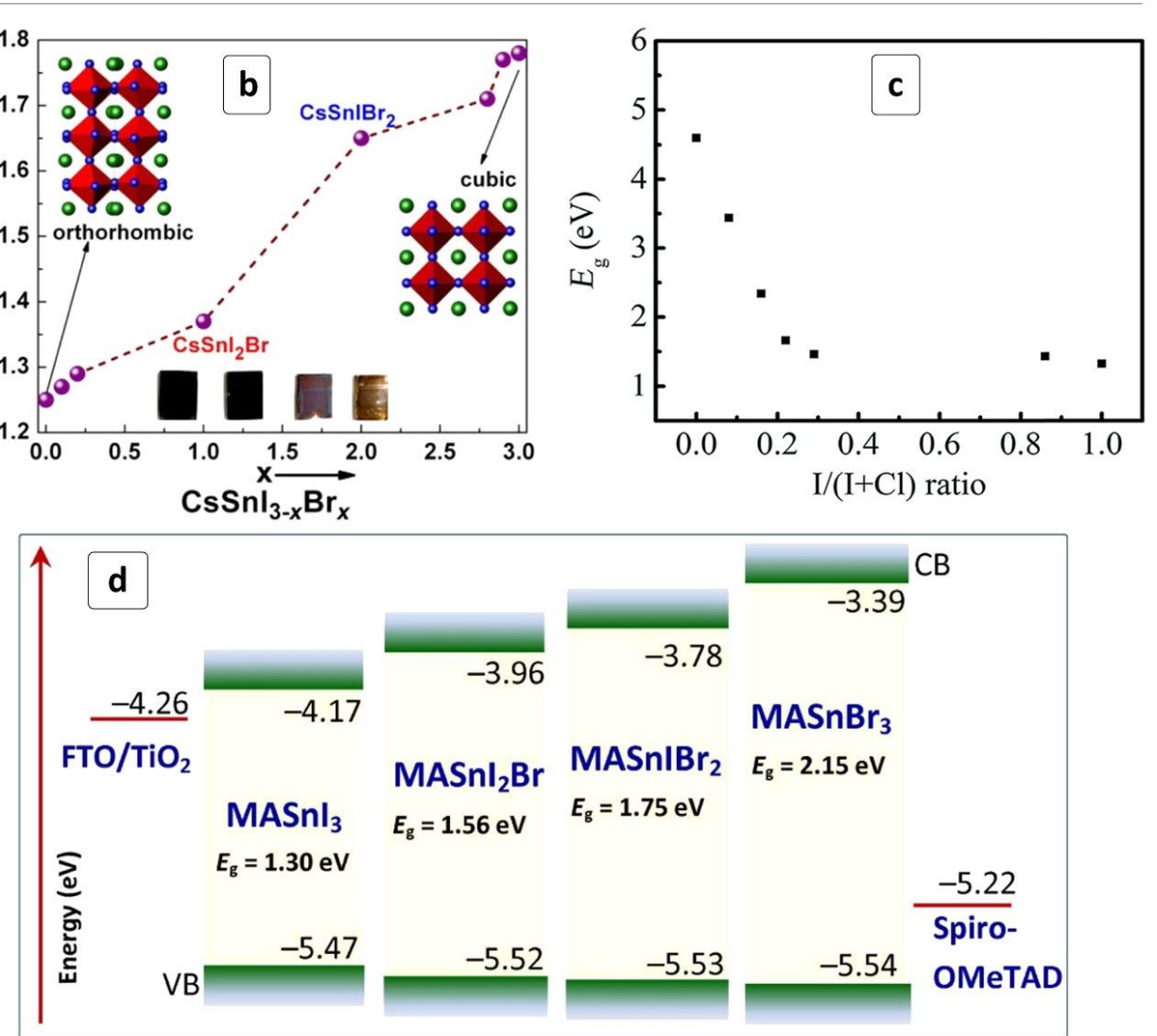

Figure 6: (a) Photographs of HP films produced from different $\mathrm{CsSnl}_{3-x} \mathrm{Br}_{x}$ and $\mathrm{CsSnBr}_{3-x} \mathrm{Cl}_{3}$ compounds (bandgaps are provided in parenthesis); (b,c) Bandgap as a function of the composition of $\mathrm{CsSnl}_{3-x} \mathrm{Br}_{x} \mathrm{HPs}$ (b) and $\mathrm{Cs}_{2} \mathrm{Snl}_{x} \mathrm{Cl}_{6-x} \mathrm{HPs}$ (c); (d) energy diagrams of solar cells based on $\mathrm{MASnl}_{3-x} \mathrm{Br}_{x} \mathrm{HPs}, \mathrm{FTO} / \mathrm{TiO}_{2}$ ETL and Spiro-OMeTAD HTL. The diagram is plotted using numerical data reported in [74]. (a) Reprinted and adapted from [126], copyright 2016 The Royal Society of Chemistry; (b) Reprinted and adapted from [127], copyright 2015 American Chemical Society; (c) Reprinted and adapted from [128], copyright 2018 The Royal Society of Chemistry.

compositions, the $\mathrm{CB} / \mathrm{VB}$ positions are suitable for the construction of solar cells with a $\mathrm{TiO}_{2}$ ETL and Spiro-OMeTAD HTL. The CB shift results in an increase in the efficiency of electron transfer to the titania scaffold. This tendency is, however, counter-balanced by a reduction of the spectral sensitivity range due to an increased $E_{\mathrm{g}}$. Summarily, both trends result in the highest PCE observed for the intermediate $\mathrm{MASnIBr}_{2} \mathrm{HP}$ (Table 1).

A combination of all three halides within a single tin-HP is a promising route to efficient and stable solar cell absorbers as shown on the example of MASnIBr ${ }_{1.8} \mathrm{Cl}_{0.2} \mathrm{HP}$ displaying PCEs higher than $3 \%$ in a HTL-free cell as well as a long-term operational stability [73].
The light-harvesting $\mathrm{MASnBr}_{3} \mathrm{HP}$ films were produced by evaporation of $\mathrm{SnBr}_{2}$ and $\mathrm{MABr}$ [78]. The co-evaporation technique was found to be preferable over a sequential deposition in terms of the photovoltaic efficiency due to the surface oxidation of the evaporated $\mathrm{SnBr}_{2}$ layer before the deposition of methylammonuim bromide [78].

The electron diffusion length in $\mathrm{MASnI}_{3}$ perovskite was estimated to be around $20 \mathrm{~nm}$ in contrast to over a micrometer in the corresponding lead HPs [111]. In view of this finding, the task of the preparation of large-as-possible HP grains with a minimized grain boundary area and surface defects seems to be of much lower significance for the Sn-based HPs, than for their lead-based counterparts. We can, therefore, expect a similar 
photovoltaic efficiency from micro- and nanometer Sn-HP crystals and try to affect the charge carrier transport through the HP/ETL and HP/HTL interfaces by tailoring the HP morphology on the nanometer scale. It was also found that the sizeselected $\mathrm{Cs}_{2} \mathrm{SnI}_{6} \mathrm{NCs}(12-49 \mathrm{~nm})$ are characterized by a much smaller effective electron mass $\left(0.12 m_{0}\right)$ as compared to the bulk HP $\left(0.56 m_{0}\right)$ [130]. Therefore, one might expect a strong influence of the NC size on the $\mathrm{CB}$ level position favorable for the "band design" of the light absorber to fit the energy levels of various ETL materials.

The Sn-based HPs can be synthesized in a variety of nanoscale morphologies, including 0D NCs, nanorods, nanoplatelets, etc., allowing possible size/shape effects to be investigated with respect to the optical, luminescent and photovoltaic properties of such materials. For example, reasonably monodisperse $\approx 10 \mathrm{~nm}$ NCs of a variety of $\mathrm{CsSnX}_{3} \mathrm{HPs}(\mathrm{X}=\mathrm{Cl}, \mathrm{Br}, \mathrm{I}, \mathrm{Cl} / \mathrm{Br}$, $\mathrm{Br} / \mathrm{I}$ ) can be produced (Figure $7 \mathrm{a}$ ) by a general hot injection method using mildly reducing and coordinating tri-octylphosphine as a solvent for $\mathrm{SnX}_{2}$ [131]. A similar approach was recently applied for the synthesis of $\mathrm{CsSnI}_{3}$ nanoplates with a thickness of less than $4 \mathrm{~nm}$ [132]. The formation of $\mathrm{CsSnX}_{3}$ nanoscale phases requires the presence of toxic tri-octylphosphine, whereby the $\mathrm{Sn}$ (II)-based NCs are unstable and prone to oxidation in other high-boiling-point solvents $[131,132]$.

$\mathrm{Sn}(\mathrm{IV})$-based $\mathrm{Cs}_{2} \mathrm{SnI}_{6} \mathrm{HP}$ was proposed as an alternative light absorber material that forms a variety of morphologies and can be synthesized in the more environmentally friendly oleic acid/ oleylamine in octadecene $[130,133,134]$. The shape of nanoscale $\mathrm{Cs}_{2} \mathrm{SnI}_{6}$ can be tuned quite easily by varying the duration of crystal growth. The reaction between Sn(IV) oleate and CsI yields $\approx 2.5 \mathrm{~nm}$ NCs in a minute after cesium iodide injection (Figure 7b), where the NCs transform into HP nanorods after a 5 min ripening at $220{ }^{\circ} \mathrm{C}$ (Figure 7c) [133]. The $\mathrm{Cs}_{2} \mathrm{SnI}_{6}$ nanorods gradually transform into nanowires (Figure $7 \mathrm{~d}$ ) with the aspect ratio increasing from 3 to 28 after a 10 min reaction. At longer reaction times $(30 \mathrm{~min}$ ) nanowires transform into nanobelts (Figure 7e) that assemble into nanoplatelets with a thickness of $\approx 8 \mathrm{~nm}$ (Figure $7 \mathrm{f}$ ) after a 60 min ripening at $220{ }^{\circ} \mathrm{C}$.
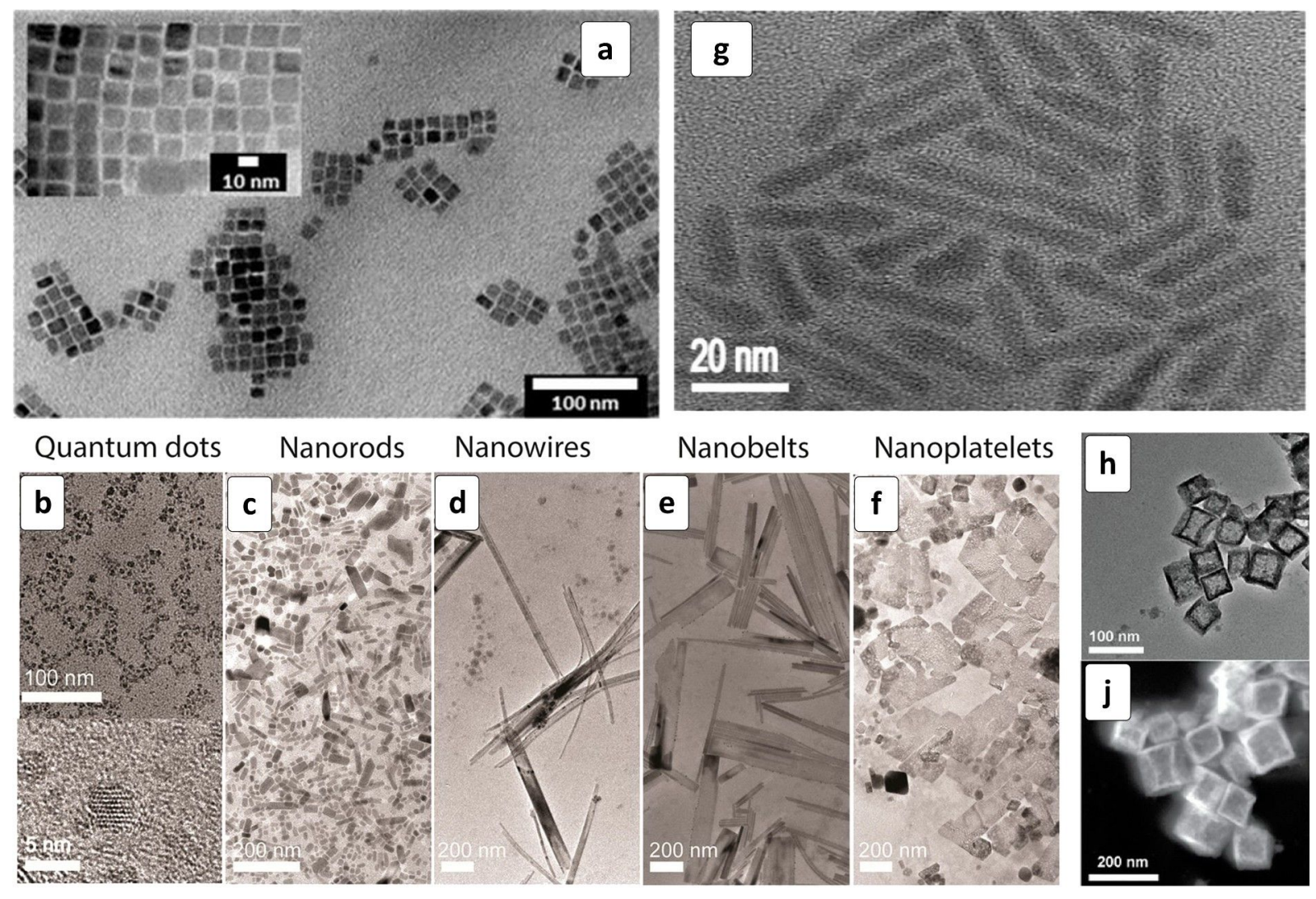

Figure 7: TEM (a-h) and STEM (j) images of CsSnl 3 nanocrystals (NCs): (a) $\mathrm{Cs}_{2} \mathrm{Snl}_{6}$ in the form of NCs (b), nanorods (c,g), nanowires (d), nanobelts (e), and nanoplatelets (f); $\mathrm{CsSnBr}_{3}$ nanocages (h,j). (a) Reproduced with permission from [131], copyright 2016 American Chemical Society; (b-f) Reprinted and adapted with permission from [133], copyright 2016 American Chemical Society; (g) Reprinted and adapted with permission from [72], copyright 2016 American Chemical Society and (h,j) Reprinted and adapted with permission from [135], copyright 2017 American Chemical Society. 
When using Cs oleate as a precursor, the average size of the resulting $\mathrm{Cs}_{2} \mathrm{SnI}_{6} \mathrm{NCs}$ can be smoothly varied from $\approx 12$ to $\approx 40 \mathrm{~nm}$ by increasing the hot-injection synthesis temperature from 80 to $220^{\circ} \mathrm{C}$ [130]. Such $\mathrm{Cs}_{2} \mathrm{SnI}_{6} \mathrm{NCs}$ showed a size-dependent bandgap, decreasing from $1.47 \mathrm{~nm}$ for the smallest NCs to $1.36 \mathrm{eV}$ to the largest ones. The NCs are free from any surface ligands and stable long enough for the preparation of solar cell electrodes [130].

The $\mathrm{Cs}_{2} \mathrm{SnI}_{6}$ HPs can be formed by in situ oxidizing unstable $\mathrm{CsSnI}_{3}$ with air oxygen [112] or directly deposited from a chemical bath [64]. The $\mathrm{Cs}_{2} \mathrm{SnI}_{6}$ perovskite is characterized by a bandgap of $1.48 \mathrm{eV}$ and absorption coefficients over $10^{5} \mathrm{~cm}^{-1}$ above $1.7 \mathrm{eV}$ [112].

$\mathrm{MASnI}_{3}$ and $\mathrm{Cs}_{2} \mathrm{SnI}_{6}$ HPs can be conveniently synthesized by the electro-assisted oxidation of $\mathrm{Pb}^{0}$ or $\mathrm{Sn}^{0}$ films (produced by evaporation) in alcohol solutions of alkali metal or alkyl ammonium halides [136]. The method is perfect for the direct formation of Sn-based HPs with tailored morphology and composition avoiding the use of unstable $\mathrm{Sn}^{2+} / \mathrm{Sn}^{4+}$ precursors and toxic solvents. Moreover, it was argued in [136] that the method allows for the thermodynamics-driven formation of HPs, resulting in a higher material quality and reproducibility as compared to the conventional kinetically quenched syntheses (solvent evaporation, spin or spray coating).

The shape control over $\mathrm{CsSnX}_{3}$ nanoscale phases grown in the presence of tri-octylphosphine oxide can be exerted by introducing complexants preferentially directing the NC growth along certain lattice planes. For example, $\mathrm{CsSnX}_{3}$ nanorods $(\mathrm{X}=\mathrm{Cl}, \mathrm{Br}, \mathrm{I})$ with a relatively homogeneous rod diameter distribution were synthesized in the presence of diethylenetriamine (Figure 7g) [72]. The $\mathrm{CsSnX}_{3}$ nanorods applied as light harvesters with $\mathrm{TiO}_{2} /$ SpiroMeOTAD ETL/HTL combination revealed relatively high PCEs increasing from $9.66 \%$ for $\mathrm{X}=\mathrm{Cl}$ to $10.46 \%$ for $\mathrm{X}=\mathrm{Br}$ to $12.96 \%$ for $\mathrm{X}=\mathrm{I}$ (Table 1 ), all three devices demonstrating a high $V_{\text {oc }}$ of $0.85-0.87 \mathrm{~V}$ [72].

A controlled self-assembly phenomenon reported in [135] resulted in the formation of hollow "nanocages" composed of $\mathrm{CsSnBr}_{3}$ NCs (Figure 7h,j). The nanocages can be stabilized against decomposition caused by oxidation, hydrolysis or photochemical processes by a post-synthesis treatment with perfluorooctanoic acid.

A series of $2 \mathrm{D}\left(\mathrm{CH}_{3}\left(\mathrm{CH}_{2}\right)_{3} \mathrm{NH}_{3}\right)_{2}\left(\mathrm{CH}_{3} \mathrm{NH}_{3}\right)_{n-1} \mathrm{Sn}_{n} \mathrm{I}_{3 n+1}$ perovskites was recently introduced as stable and promising alternatives of 3D $\mathrm{ASnX}_{3}$ HPs for photovoltaic applications [75]. The 2D HPs revealed semiconductor properties with a bandgap decreasing from $1.83 \mathrm{eV}$ for $n=1$ to $1.2 \mathrm{eV}$ at $n \rightarrow \infty$ (Figure 8a). The 2D HP layers can be selectively oriented parallel to the substrate when the HP is spin-coated from DMSO and perpendicular - if the deposition occurs from $N, N$ dimethylformamide (DMF). The CB energy position was found to strongly depend on the HP composition (Figure 8b).

This allows for the search of an optimum between the efficiency of the electron transfer to the $\mathrm{TiO}_{2}$ scaffold and the spectral sensitivity range defined by $E_{\mathrm{g}}$. The $\mathrm{Sn}_{4} \mathrm{I}_{13}$ "isomer" with a "close-to-ideal" $E_{\mathrm{g}}$ of $1.42 \mathrm{eV}$ was suggested as an optimal light harvester, displaying a promising PCE of 2.5\% (Table 1) [75].

Along with the photovoltaic cells with an HP layer sandwiched between ETL and HTL, the photo-electrochemical HP-based systems are explored as well, where an electron-shutting redoxcouple is used for the charge exchange between the lightabsorbing electrode and a counter electrode. For example, a
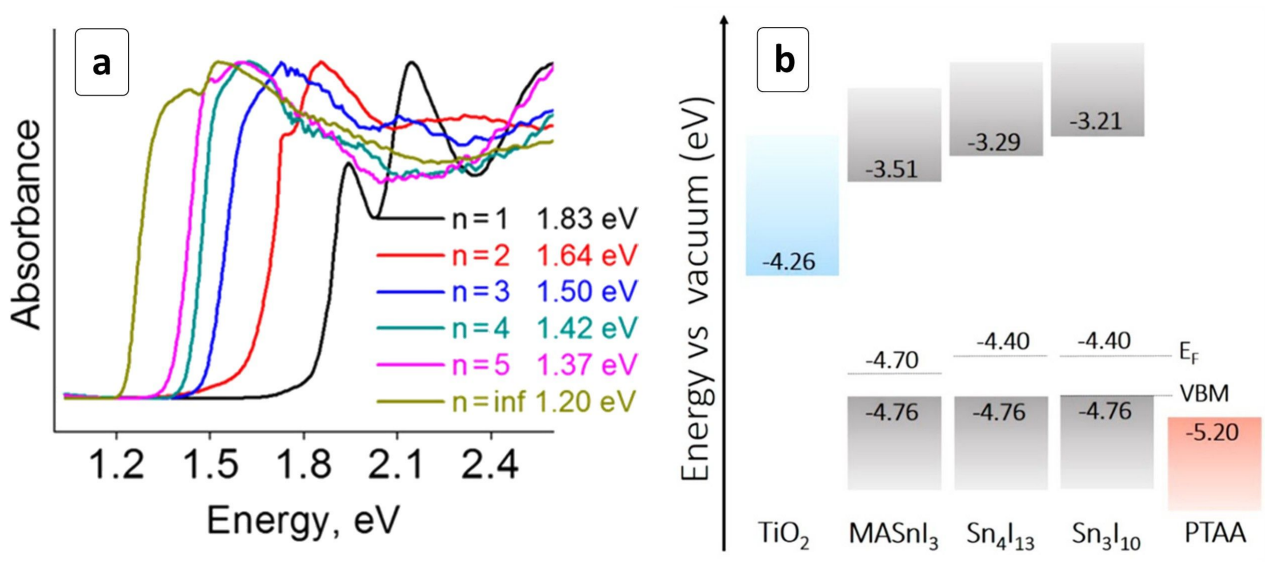

Figure 8: (a) Absorption spectra of $\left(\mathrm{CH}_{3}\left(\mathrm{CH}_{2}\right)_{3} \mathrm{NH}_{3}\right)_{2}\left(\mathrm{CH}_{3} \mathrm{NH}_{3}\right)_{n-1} \mathrm{Sn}_{n} \mathrm{I}_{3 n+1}$ homological HPs; (b) energy level alignment in solar cells with selected HPs. VBM is the valence band (VB) minimum, $E_{F}$ is Fermi energy. Reprinted with permission from [75], copyright 2017 American Chemical Society. 
solar cell based on a $\mathrm{MASnI}_{3-x} \mathrm{Br}_{x}$ film coupled to a carbon counter electron by a dissolved benzoquinone redox-couple $\mathrm{BQ}^{0} / \mathrm{BQ}^{-}$showed a PCE of $1.51 \%$ [137].

An $\mathrm{FTO} / \mathrm{TiO}_{2} / \mathrm{MASnCl}_{3}$ photoanode $\left(E_{\mathrm{g}}=2.1 \mathrm{eV}\right)$ was combined with an FTO/Pt counter electrode and a solid/liquid electrolyte consisting of polyethylene oxide soaked with an acetonitrile solution of $\mathrm{KI} / \mathrm{I}_{2}$ into a solar cell displaying PCEs of up to $0.55 \%$ [109].

The mixed $\mathrm{CsSnI}_{2.95} \mathrm{~F}_{0.05}$ was successfully tested as an efficient HTL for dye-sensitized solar cells operating with PCEs of up to $\approx 10 \%$ [138].

\section{Other $\mathrm{M}^{2+}$-based hybrid perovskites}

Germanium(II) forms a series of perovskites isostructural to MAPI with a bandgap decreasing from $3.76 \mathrm{eV}$ for $\mathrm{MAGeCl}_{3}$ to $2.81 \mathrm{eV}$ for $\mathrm{MAGeBr}_{3}$ to $1.61 \mathrm{eV}$ for $\mathrm{MAGeI}_{3}$, the latter value close to $E_{\mathrm{g}}$ of MAPI (1.55 eV) [139]. Ge-based $\mathrm{AGeI}_{3}$ HPs with $\mathrm{A}=\mathrm{Cs}^{+}\left(E_{\mathrm{g}}=1.63 \mathrm{eV}\right), \mathrm{MA}^{+}(2.0 \mathrm{eV})$, and $\mathrm{FA}^{+}$ $(2.35 \mathrm{eV})$ were reported to be stable up to $150{ }^{\circ} \mathrm{C}$ but prone to the air oxidation [140]. The VB top and CB bottom of Ge-HPs are formed predominantly by Ge s- and p-orbitals, respectively, resulting in direct "intra-atomic"-like electron transitions. As the cation A size grows, the lattice constant increases, resulting in a further splitting between the Ge-related bonding and antibonding levels and, therefore, in an increase of the observed bandgap (Figure 9a) [140]. This behavior indicates favorable conditions for bandgap tuning by cationic substitutions. All three compounds have suitable $\mathrm{CB} / \mathrm{VB}$ positions to be incorporated into the solar cells with typical ETL/HTL (Figure 9b) showing a PCE of $0.2 \%$ for $\mathrm{MAGeI}_{3}$-based cells (Table 1 ).

A DFT study of $\mathrm{CsGeI}_{3} \mathrm{HP}$ showed that the iodide vacancy in this material can serve as a deep hole trap, in contrast to the corresponding $\mathrm{Pb}$ - and $\mathrm{Sn}$-based HPs resulting in a reduction of the
$V_{\text {oc }}$ [141]. These results indicate that efforts should be applied for the synthesis of stoichiometric $\mathrm{CsGeI}_{3}$ materials as well as on the development of post-synthesis HI treatment of iodidedeficient $\mathrm{CsGeI}_{3}$ absorber layers.

Theoretical studies also showed a high susceptibility of the electron properties of $\mathrm{MAGeI}_{3}$ perovskite to the strain. Application of a compressive or dilating stress is expected to switch the HP conductivity from $\mathrm{p}$ - to n-type and vary the bandgap within a range of $1.35-2.50 \mathrm{eV}$ [142].

Typically, Ge HPs are prone to hydrolytic decomposition when coming in contact with a humid environment [144]. Possible mechanisms and pathways of the hydrolytic degradation of $\mathrm{MAGeI}_{3} \mathrm{HP}$ as a function of the crystal face were examined in detail in [145]. The stability of Ge-based HPs can be enhanced in mixed-halide HPs as well as by hydrophobic cations. In particular, by introducing cations that are more bulky than $\mathrm{MA}^{+}$, such as phenylethylamine (PEA) cation $\mathrm{C}_{6} \mathrm{H}_{5}\left(\mathrm{CH}_{2}\right)_{2} \mathrm{NH}_{3}{ }^{+}$, a layered structure can be formed with inorganic germanium iodide layers separated by organic PEA layers (Figure 9c) [143]. The (PEA) ${ }_{2} \mathrm{GeI}_{4}$ HP revealed a direct bandgap of $2.12 \mathrm{eV}$ making it suitable for tandem solar cells. This layered perovskite was also found to be much more stable in humid air than $\mathrm{MAGeI}_{3}$ because of its high hydrophobicity of the organic component [143].

The stability of $\mathrm{MAGeI}_{3} \mathrm{HP}$ and its performance as a light harvester of solar cells can also be enhanced by introducing bromide additives. By substituting $10 \% \mathrm{I}^{-}$with $\mathrm{Br}^{-}$a PCE of $0.57 \%$ was achieved (Table 1 ) in an inverted cell with a fullerene ETL [144].

The combination of $\mathrm{Sn}^{2+}$ and $\mathrm{Ge}^{2+}$ in single HPs results in solid-solution $\mathrm{CH}_{3} \mathrm{NH}_{3} \mathrm{Sn}_{(1-x)} \mathrm{Ge}_{x} \mathrm{I}_{3}$ compounds with a bandgap tunable from $1.3 \mathrm{eV}(x=0)$ to $2.0 \mathrm{eV}(x=1)$ [146].
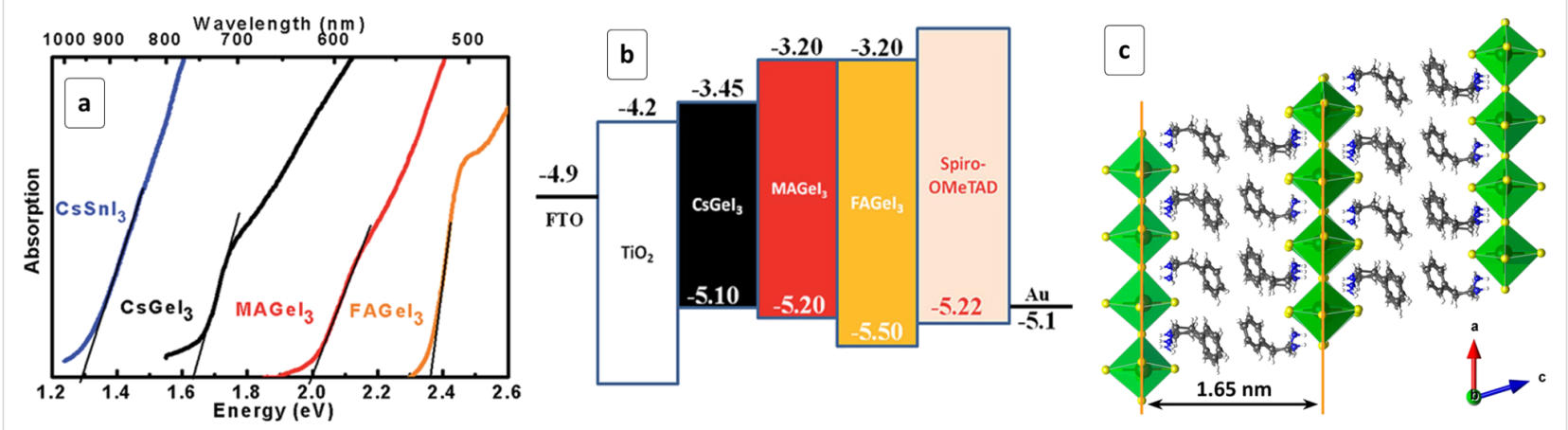

Figure 9: (a) Absorption spectra of $\mathrm{AGel}_{3} \mathrm{HPs}$ with different cations; (b) energy level alignment in solar cells with $\mathrm{AGel} \mathrm{HPs}_{3}$; (c) structure of layered $(\mathrm{PEA})_{2} \mathrm{Gel}_{4}$ HP. (a,b) Reprinted with permission from [140], copyright 2015 The Royal Society of Chemistry; (c) Reprinted with permission from [143], copyright 2017 American Chemical Society. 
A $\mathrm{Mn}^{2+}$-based analog of MAPI was produced by the spincoating of a mixture of $\mathrm{MnI}_{2}$ and MAI on mesoporous titania scaffolds [147]. After covering with a Spiro-MeOTAD HTL, the $\mathrm{MAMnI}_{3}$-based device showed a response to the visible light illumination that was stable for at least $2000 \mathrm{~s}$ in an on/off cycling test [147]. A similar response to the UV light was observed for $\mathrm{MA}_{2} \mathrm{MnCl}_{4}$ perovskite incorporated into an $\mathrm{FTO} /$ $\mathrm{TiO}_{2} / \mathrm{HP} /$ carbon device [148].

One of the first $\mathrm{Cu}^{2+}$-based HPs $\left(\mathrm{C}_{4} \mathrm{H}_{9} \mathrm{NH}_{3}\right)_{2} \mathrm{CuCl}_{4}$ was synthesized as early as in 2005 by reacting buthylamine hydrochloride with $\mathrm{CuCl}_{2}$ [149]. However, the potential of the hybrid perovskites was not yet realized at that time and this material was not tested as a potential light harvester.

A highly stable $\mathrm{C}_{6} \mathrm{H}_{4} \mathrm{NH}_{2} \mathrm{CuBr}_{2} \mathrm{I}$ compound was synthesized by reacting 2-iodaniline with $\mathrm{CuBr}_{2}$ [150]. It displayed extraordinary hydrophobicity and retained stability even after a $4 \mathrm{~h}$ immersion in water. This stability is coupled with a high sensitivity to visible light and a bandgap of $1.64 \mathrm{eV}$. A solar cell trial of this material showed a PCE of $\approx 0.5 \%$ [150] indicating plenty of room for further studies. A two-dimensional layered $\left(\mathrm{C}_{6} \mathrm{H}_{5} \mathrm{CH}_{2} \mathrm{NH}_{3}\right)_{2} \mathrm{CuBr}_{4}$ perovskite $\left(E_{\mathrm{g}}=1.81 \mathrm{eV}\right)$ demonstrated a high stability and the feasibility for future photovoltaic applications [151].

Recently, the first example of layered 2D copper-based $\left(\mathrm{CH}_{3} \mathrm{NH}_{3}\right)_{2} \mathrm{CuCl}_{x} \mathrm{Br}_{4-x}$ HPs has been reported [152] thereby demonstrating the appealing potential of such compounds for photovoltaic applications. The perovskite with $x=4$ was studied in detail and found to be formed by single layers of $\mathrm{CuCl}_{4} \mathrm{Br}_{2}$ octahedra separated by cation-filled galleries with a size of $\approx 1 \mathrm{~nm}$ (Figure 10a). The materials are characterized by strong absorbance below $650 \mathrm{~nm}$ with absorption coefficients of $\approx 10^{5} \mathrm{~cm}^{-1}$ and a composition-dependent bandgap ranging from $2.48 \mathrm{eV}$ for $\mathrm{MA}_{2} \mathrm{CuCl}_{4}$ to $1.80 \mathrm{eV}$ for $\mathrm{MA}_{2} \mathrm{CuCl}_{0.5} \mathrm{Br}_{3.5}$ [152] (Figure 10b) and resulting in a gamut of HP colors from yellow to dark brown (Figure 10c).

\section{$\mathrm{Sb}$ - and Bi-based hybrid perovskites}

In contrast to $\mathrm{Sn}^{2+}$-based HPs that are prone to oxidation and hydrolysis, $\mathrm{Bi}$ - and $\mathrm{Sb}$-based perovskites reveal a reasonable chemical/photochemical stability, retaining composition and structure in prolonged tests even without additional encapsulation. In the case of antimony, stable compounds of $\mathrm{MA}_{3} \mathrm{Sb}_{2} \mathrm{I}_{9}$ $[90,153], \mathrm{MASbSI}_{2}$ [87], and $\mathrm{Cs}_{3} \mathrm{Sb}_{2} \mathrm{I}_{9}$ [88-90,154] were reported, while for bismuth, a larger array of compositions was studied, including $\mathrm{MA}_{3} \mathrm{Bi}_{2} \mathrm{I}_{9}$ (MABI) [84,85,155-163], $\mathrm{Cs}_{3} \mathrm{Bi}_{2} \mathrm{X}_{9}[164,165]$, and $\mathrm{MA}_{2} \mathrm{KBiCl}_{6}$ [166]. The reported bandgaps of selected $\mathrm{Bi}$ - and $\mathrm{Sb}$-based HPs are collected in Table 3 .

\section{Bi-based HPs}

The MABI perovskite is composed of $\mathrm{Bi}_{2} \mathrm{I}_{9}$ bi-octahedral units with two bismuth ions in the center of an octahedra connected via three iodine atoms. MABI shows two distinct electron transitions near the absorption band edge - an indirect transition with $E_{\mathrm{g}}{ }^{\mathrm{i}}=1.99 \mathrm{eV}$ and a direct one with $E_{\mathrm{g}}{ }^{\mathrm{d}}=2.15 \mathrm{eV}$ [155]. Both transitions contribute to the light-harvesting by the Bi-based HPs as indicated by detailed PL studies on lumines-
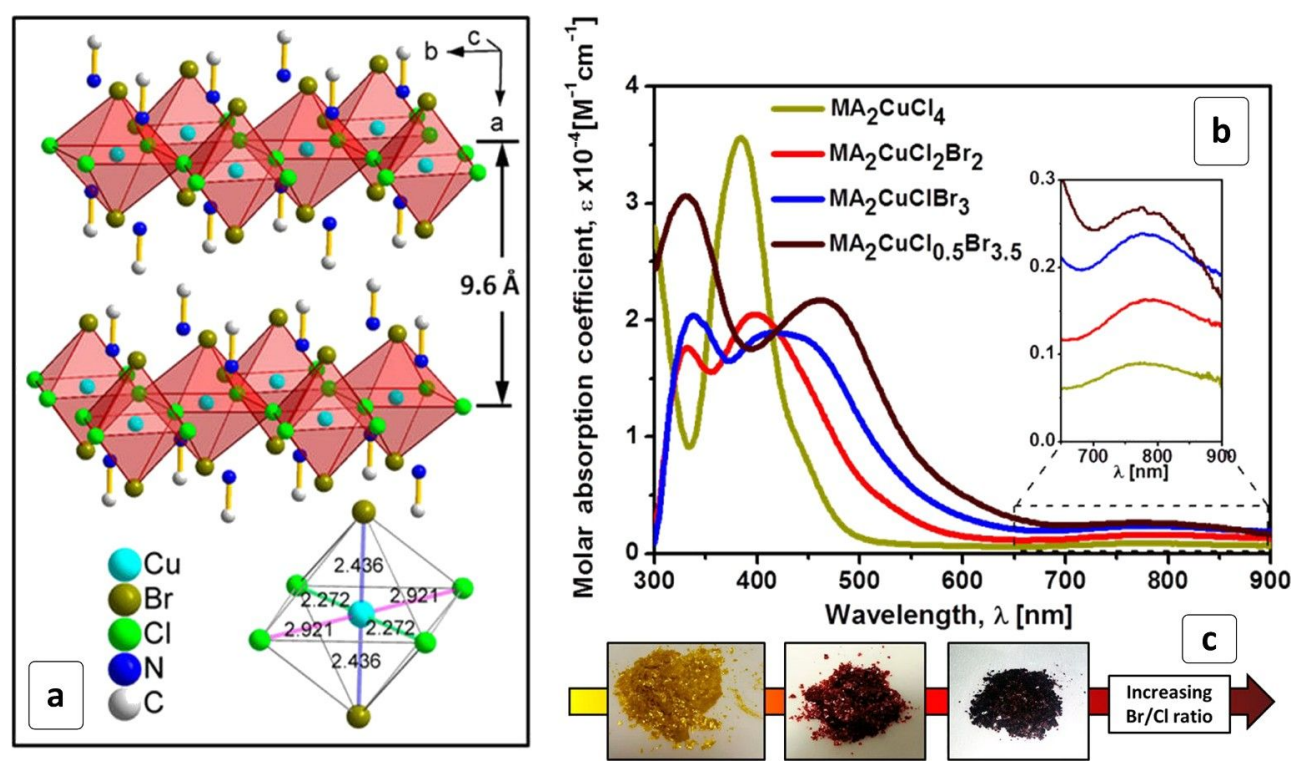

Figure 10: Structure (a), absorption spectra (b) and photographs (c) of $\left(\mathrm{CH}_{3} \mathrm{NH}_{3}\right)_{2} \mathrm{CuCl}_{x} \mathrm{Br}_{4-x} \mathrm{HPs}$ of different composition. Reprinted and adapted with permission from [152], copyright 2016 American Chemical Society. 
Table 3: Bandgap and approximate absorption band edge position $\left(\lambda_{\mathrm{e}}\right)$ of selected $\mathrm{Bi}$ - and $\mathrm{Sb}$-based hybrid perovskites.

\begin{tabular}{llll} 
Perovskite & $E_{\mathrm{g}}, \mathrm{eV}$ & $\lambda_{\mathrm{e}}, \mathrm{nm}$ & Ref. \\
\hline $\mathrm{MA}_{3} \mathrm{Bi}_{2} \mathrm{l}_{9}$ & 1.99 & 630 & {$[155]$} \\
& 2.11 & 590 & {$[85]$} \\
& 2.17 & 570 & {$[86]$} \\
& 2.40 & 520 & {$[161]$} \\
$\left(\mathrm{MA}_{2}\right) \mathrm{KBiCl}_{6}$ & 3.04 & 410 & {$[166]$} \\
$\mathrm{MA}_{3} \mathrm{Sb}_{2} \mathrm{l}_{9}$ & 1.80 & 690 & {$[154]$} \\
& 1.95 & 640 & {$[90]$} \\
$\mathrm{MA}_{3} \mathrm{Sb}_{2} \mathrm{l}_{8} \mathrm{Cl}$ & 2.14 & 580 & {$[153]$} \\
$\mathrm{MA}_{3} \mathrm{Sb}_{2} \mathrm{I}_{7} \mathrm{Cl}{ }_{2}$ & 1.90 & 650 & {$[154]$} \\
$\mathrm{MASbS}_{2}$ & 2.00 & 620 & {$[154]$} \\
$\mathrm{Cs}_{3} \mathrm{Sb}_{2} \mathrm{l}_{9}$ & 2.03 & 610 & {$[87]$} \\
$\mathrm{Rb}_{3} \mathrm{Sb}_{2} \mathrm{l}_{9}$ & 2.00 & 620 & {$[90]$} \\
& 2.05 & 600 & {$[88]$} \\
& 1.98 & 630 & {$[91]$}
\end{tabular}

cent $\mathrm{Cs}_{3} \mathrm{Bi}_{2} \mathrm{X}_{9} \mathrm{NCs}$ [159]. A study of single-crystal and polycrystalline MABI showed that both materials have a long exciton lifetime and a high carrier mobility $[161,163]$.

A transient absorption study of MABI crystals showed only a minor change of the exciton dynamics when the crystal size was reduced from micrometers to a few hundred nanometers [167]. A combination of MABI with a $\mathrm{TiO}_{2}$ scaffold resulted in a depopulation of bound excitons and electron transfer to the titania. These observations indicate that, in contrast to $\mathrm{Pb}$-based HPs, for MABI, a bulk-heterojunction solar cell architecture is preferable to sub-micrometer HP domains.

Typically, the MABI-based solar cells demonstrate a high resistivity to air oxidation and ambient humidity [85,155$157,160,168]$. Similar high stability to the degradation under ambient atmosphere was reported for highly luminescent $\mathrm{Cs}_{3} \mathrm{Bi}_{2} \mathrm{X}_{9}(\mathrm{X}=\mathrm{Cl}, \mathrm{Br}, \mathrm{I})$ crystals emitting in a broad range from $\approx 390$ to $\approx 550 \mathrm{~nm}$ depending on the composition of the halide component [164]. It is assumed that the moisture stability of the perovskites can originate from inherent self-passivation with a surface $\mathrm{BiOX}$ layer [164]. The water vapors were found to passivate the surface of $\mathrm{Cs}_{3} \mathrm{Bi}_{2} \mathrm{X}_{9} \mathrm{NCs}$ resulting in a drastic $\mathrm{PL}$ enhancement [165]. The water was found to act similar to the addition of the surfactant oleic acid, confirming the assumption of the moisture-induced passivation of the surface trap states and providing the nanocrystalline $\mathrm{Cs}_{3} \mathrm{Bi}_{2} \mathrm{X}_{9}$ luminophores with prolonged stability [165]. Along with the chemical and photochemical stability, MABI retains perfect integrity during charging/discharging events. In particular, a MABI-based electrochemical capacitor retains around $85 \%$ of its initial maximal capacitance after more than thousand charge/discharge cycles [158].

A cell comprised on a MABI layer sandwiched between an FTO/TiO 2 scaffold and a Spiro-MeOTAD/Au layer showed a PCE of $0.164 \%$ and very good stability of photovoltaic parameters even when stored in the open humid air [157]. The cell also showed almost no hysteresis over a broad range of scan rates (150-1500 mV/s). A hysteresis-free cell was also constructed by combining the single-crystalline MABI with a P3HT HTL [85].

A layer of $\mathrm{CsBi}_{3} \mathrm{I}_{10}$ perovskite deposited by a conventional spin-coating/drying method on top of gold electrodes demonstrated a high photoresponse in the range of $\lambda<700 \mathrm{~nm}$ [169]. The photodetector is characterized by an on/off ratio as high as $\approx 10^{5}$ and a prolonged stability retaining the unvaried response after a shelf-storage for at least three months (Figure 11a).
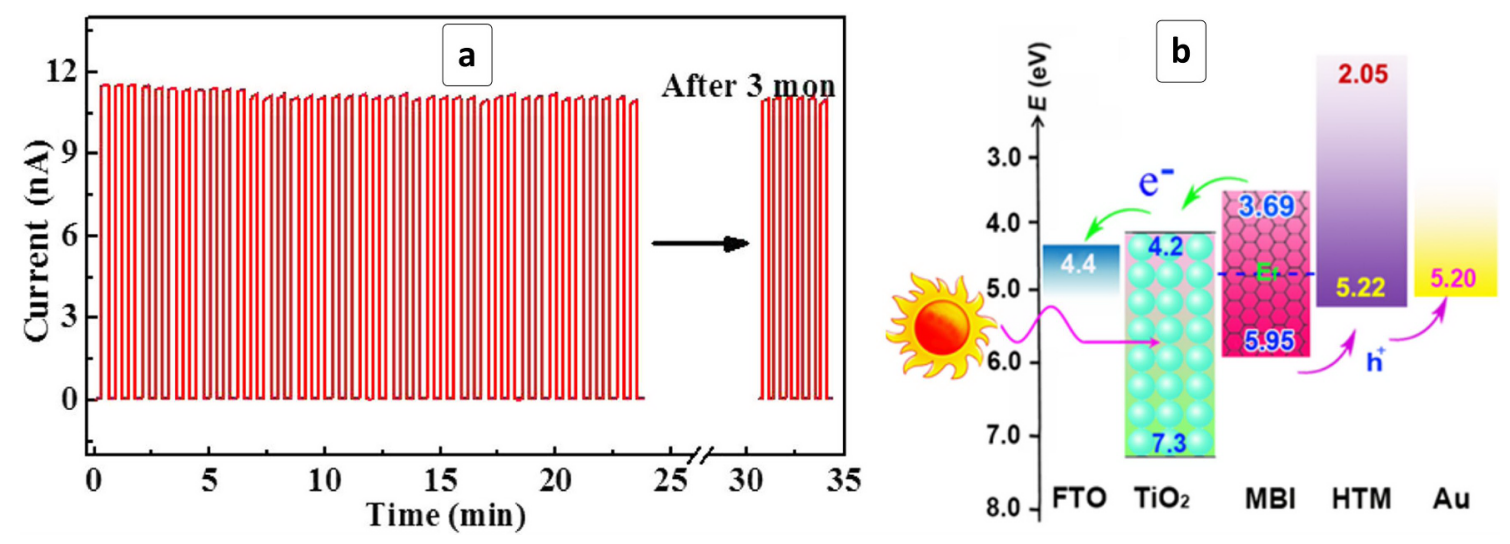

Figure 11: (a) Cyclic photoresponse of a red light photodetector based on $\mathrm{CsBi}_{3} \mathrm{l}_{10} \mathrm{HP}$ with a freshly prepared photosensitive layer and after the three months of storage (last five cycles). Reprinted with permission from [169], copyright 2017 American Chemical Society. (b) Energy diagram of a solar cell based on MABI (MBI) HP, mesoporous $\mathrm{TiO}_{2}$ ETL and Spiro-OMeTAD HTL. Reprinted with permission from [84], copyright 2017 American Chemical Society. 
The efficiency of solar cells based on $\mathrm{Cs}_{3} \mathrm{Bi}_{2} \mathrm{I}_{9}$ HP nanosheets was found to depend on the composition of the HTL layer. The best PCE of 3.2\% was observed for copper(I) iodide HTLs, a value claimed to be the highest achieved to date for the Bi-based HP family [170].

The morphology of MABI layers produced on titania scaffolds by a simple spin-coating of a $\mathrm{BiI}_{3}+\mathrm{MAI}$ mixture followed by a heat treatment was found to depend on the morphology of the scaffold, varying from island-like for the compact $\mathrm{TiO}_{2}$ layers to a more homogeneous MABI deposit on the mesoporous $\mathrm{TiO}_{2}$ [157].

The $\mathrm{TiO}_{2} / \mathrm{MABI}$ composites can be produced by a double-step interdiffusion method including sequential deposition of $\mathrm{BiI}_{3}$ and $\mathrm{CH}_{3} \mathrm{NH}_{3} \mathrm{I}$ layers followed by annealing at $100{ }^{\circ} \mathrm{C}$ [162] The last step yields a much more uniform and homogeneous MABI layer than conventional single-step spin-coating/ annealing resulting in almost doubled PCE.

Highly compact and pin-hole-free MABI films can be produced by a two-step process including the high-vacuum deposition of $\mathrm{BiI}_{3}$ followed by the conversion of bismuth triiodide into MABI [84]. The high quality of the HP layer resulted in a record PCE of $1.54 \%$ in a cell with a titania ETL and a SpiroMeOTAD HTL (Table 1). The cell configuration allows for an efficient electron transfer from MABI to the $\mathrm{TiO}_{2}$ scaffold while the holes are withdrawn to the Spiro-MeOTAD HTL and then - into the gold back contact (Figure 11b). The charge separation efficiency is evidenced by a relatively high FF of almost $80 \%$, while a high $V_{\text {oc }}$ of $0.83 \mathrm{~V}$ observed for such cells attests to the structural perfection of the light-absorbing HP layer [84].

A similar $V_{\text {oc }}(0.895 \mathrm{~V})$ was reported for a MABI-based cell produced without HTLs with a single carbon back contact [86]. In this case, a top light conversion efficiency was only $0.054 \%$ (Table 1), indicating the crucial role of the hole transfer dynamics for the total cell performance.

The efficiency of MABI-based cells with the solution-processed HP layers is also limited by a rough interface between MABI and typical ETL/HTL materials. The interface quality can be increased by controlling the rate of MABI crystallization, in particular, by introducing additions of $N$-methylpyrrolidone (NMP) to DMF which is typically used as a solvent for the spin-coating deposition of MABI layers [160]. NMP slows the HP crystallization favoring the formation of a more uniform MABI layer and providing a $\approx 50 \%$ enhancement of the photocurrent generation efficiency. Simultaneously, the optimized morphology shows an enhanced stability, the cells retaining their character- istics after 30 days of exposure to ambient conditions (relative humidity of 50-60\%) [160].

The structure and characteristics of $(\mathrm{MA})_{2} \mathrm{KBiCl}_{6}$ perovskite [166] are very similar to $\mathrm{MAPbCl}_{3}$, however, the high bandgap of this material $(3.04 \mathrm{eV})$ is more suitable for UV photodetectors than for the photovoltaic applications.

The organo-inorganic iodobismuthates $\mathrm{C}_{5} \mathrm{H}_{6} \mathrm{NBiI}_{4}, \mathrm{C}_{6} \mathrm{H}_{8} \mathrm{NBiI}_{4}$ and $\left(\mathrm{C}_{6} \mathrm{H}_{13} \mathrm{~N}\right)_{2} \mathrm{BiI}_{5}$ displayed bandgaps of around $2 \mathrm{eV}$ and stability under the ambient conditions [171,172]. Aromatic cations were found to contribute to the conduction band of these compounds, facilitating the transport of charge carriers. As a result, mesoscopic solar cells based on such iodobismuthates showed a PCE of $\approx 1 \%$ even without additional HTLs [171].

\section{Sb-based hybrid perovskites}

Antimony-based $\mathrm{MA}_{3} \mathrm{Sb}_{2} \mathrm{I}_{9}$ and $\mathrm{Cs}_{3} \mathrm{Sb}_{2} \mathrm{I}_{9}$ perovskites displayed bandgaps of $1.95 \mathrm{eV}$ and $2 \mathrm{eV}$, respectively, and $\mathrm{CB} / \mathrm{VB}$ positions suitable for most of ETL/HTL combinations (Figure 2d) [90]. Amorphous $\mathrm{MA}_{3} \mathrm{Sb}_{2} \mathrm{I}_{9}$ films were reported to have a bandgap of $2.14 \mathrm{eV}$ and relatively high absorption coefficients of an order of $10^{5} \mathrm{~cm}^{-1}$ [153]. The films also demonstrated considerable sub-bandgap absorption with a characteristic Urbach energy of $\approx 60 \mathrm{meV}$, indicating a substantial level of structural and energetic disorder. Due to the disorder, planar inverted solar cells based on amorphous $\mathrm{MA}_{3} \mathrm{Sb}_{2} \mathrm{I}_{9}$ showed low photocurrent densities, however, with a relatively high opencircuit voltage $(\approx 890 \mathrm{meV})$ and a decent fill factor (55\%) [153], indicating the good potential of this light absorber for further studies and improvements. In particular, a careful control of the $\mathrm{MA}_{3} \mathrm{Sb}_{2} \mathrm{I}_{9}$ stoichiometry and introduction of $\mathrm{HI}$ additives during the film formation as well as an additional fullerene ETL into the solar cell configuration allowed for a PCE beyond $2 \%$ [90].

$\mathrm{Cs}_{3} \mathrm{Sb}_{2} \mathrm{I}_{9}$ HP has a bandgap of $\approx 2 \mathrm{eV}$ and an intrinsic weak p-type conductivity $[88,90]$. The energies of lowest direct $\left(E_{\mathrm{g}}{ }^{\mathrm{d}}\right)$ and indirect $\left(E_{\mathrm{g}}{ }^{\mathrm{i}}\right)$ electron transitions differ only by $\approx 0.02 \mathrm{eV}$ and both transitions are characterized by absorption coefficients similar to those of MAPI [88].

$\mathrm{Cs}_{3} \mathrm{Sb}_{2} \mathrm{I}_{9}$ can exist as two polymorphs - a layered (2D) modification built by two-dimensional layers of polyanions and a "dimer" (0D) form built of isolated dioctahedral $\mathrm{Sb}_{2} \mathrm{I}_{9}{ }^{3-}$ anions [89]. The HP formation can be directed to one of these forms by tailoring the temperature of annealing, the $0 \mathrm{D}$ and $2 \mathrm{D}$ modifications forming at 150 and $250{ }^{\circ} \mathrm{C}$, respectively. The layered 2D form demonstrated higher electron and hole mobilities and a better tolerance to defects as compared to the dimer-built $0 \mathrm{D}$ 
polymorph. The $2 \mathrm{D}-\mathrm{Cs}_{3} \mathrm{Sb}_{2} \mathrm{I}_{9} \mathrm{HP}$ can be formed by annealing the original metal iodide mixture at $250{ }^{\circ} \mathrm{C}$ provided that a portion of $\mathrm{SbI}_{3}$ lost during the heating due to a high $\mathrm{SbI}_{3}$ vapor pressure at the annealing temperature is compensated [89]. A comparative study of inverted solar cells composed of 2D- and 0D- $\mathrm{Cs}_{3} \mathrm{Sb}_{2} \mathrm{I}_{9}$ (produced at $150{ }^{\circ} \mathrm{C}$ ), a PEDOT:PSS HTL and a $\mathrm{PC}_{70} \mathrm{BM}$ ETL resulted in PCEs of $1.5 \%$ and $0.89 \%$ for $2 \mathrm{D}$ - and 0D-form, respectively [89]. This finding, along with a higher stability of 2D-HP-based devices, suggests that the layered form of $\mathrm{Cs}_{3} \mathrm{Sb}_{2} \mathrm{I}_{9}$ is preferable for photovoltaic applications.

The incorporation of other halide ions allows the crystal structure and optoelectronic properties of $\mathrm{MA}_{3} \mathrm{Sb}_{2} \mathrm{I}_{9} \mathrm{HP}$ to be altered. In particular, the introduction of chloride results in a transformation of dimer-like $\mathrm{MA}_{3} \mathrm{Sb}_{2} \mathrm{I}_{9}$ built of bi-octahedral $\mathrm{Sb}_{2} \mathrm{I}_{9}$ units into a layered $\mathrm{MA}_{3} \mathrm{Sb}_{2} \mathrm{Cl}_{x} \mathrm{I}_{9-x}$ compound where antimony iodide octahedra are bound to infinite chains via a shared $\mathrm{I}^{-}$anion (Figure 12a) [154]. Simultaneously, the bandgap broadens from $1.8 \mathrm{eV}\left(\mathrm{MA}_{3} \mathrm{Sb}_{2} \mathrm{I}_{9}\right)$ to $2.0 \mathrm{eV}$ for $\mathrm{MA}_{3} \mathrm{Sb}_{2} \mathrm{Cl}_{2} \mathrm{I}_{7}$. Solar cells comprising such $2 \mathrm{D} \mathrm{MA}{ }_{3} \mathrm{Sb}_{2} \mathrm{Cl}_{x} \mathrm{I}_{9-x}$ HPs displayed PCEs surpassing 2\% (Table 1), while the highest PCE reported for "conventional" Sb-based halide HPs is lower than $1 \%$ [154]. Similar to the Bi-based HPs, such cells demonstrated good stability in the humid air environment and no hysteresis between $C-V$ curves obtained at a direct and reverse potential scans (Figure 12b).

The $\mathrm{Sb}_{2} \mathrm{I}_{9}$ dimer-based modification of Sb-HPs is typical for the compounds with both bulky organic cations and $\mathrm{Cs}^{+}$and forms as a result of steric factors (Figure 13a). As this modification has a relatively low charge transport efficiency, various approaches are developed to forward the HP formation to other
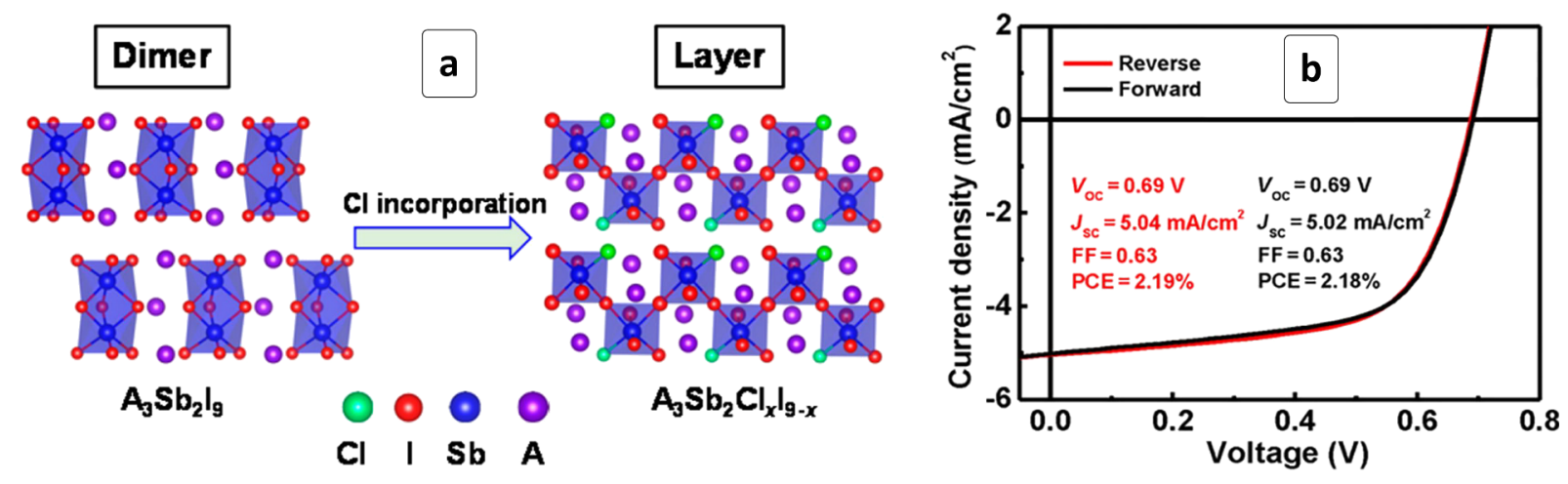

Figure 12: Schematic structure of $\mathrm{MASb}_{2} \mathrm{Cl}_{x} \mathrm{I}_{9-x} \mathrm{HP}(\mathrm{a})$ and current-voltage characteristics of a solar cell based on $\mathrm{MA}_{3} \mathrm{Sb}_{2} \mathrm{Cl}_{x} \mathrm{I}_{9-x} \mathrm{HP}$ registered at a forward and reverse bias (b). Reprinted and adapted with permission from [154], copyright 2018 American Chemical Society.

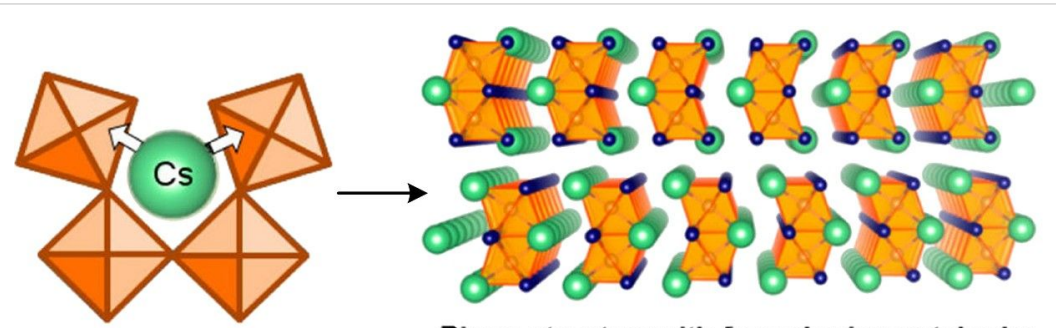

Dimer structure with face sharing octahedra

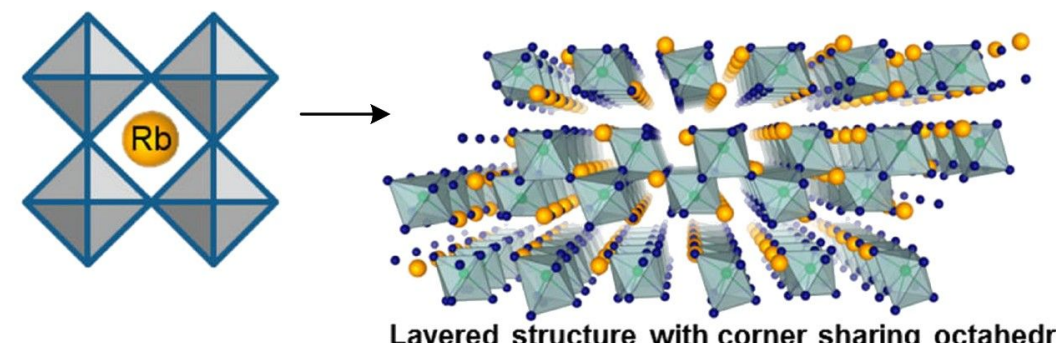

Figure 13: Schematic of the influence of the cation size on the structure of $A_{3} S_{2} l_{9}(A=C s, R b)$. Reprinted and adapted with permission from [91], copyright 2016 American Chemical Society. 
modifications, including the above-discussed introduction of $\mathrm{Cl}^{-}$ions as well as the replacement of bulky cations with smaller ones, for example, with $\mathrm{Rb}^{+}$[91]. The rubidium cations can be accommodated by the layered modification (Figure 13b) and the latter forms irrespective of the HP synthesis method [91]. The $\mathrm{Rb}_{3} \mathrm{Sb}_{2} \mathrm{I}_{9} \mathrm{HP}$ is characterized by a bandgap of $1.98 \mathrm{eV}$ and a higher (less negative) $\mathrm{CB}$ position as compared to the $\mathrm{MA}^{+}$and $\mathrm{Cs}^{+}$-based counterparts, which is favorable for the electron transfer to typical ETL materials (Figure 2d).

Using a combination of halide and chalcogenide anions for building an organo-inorganic pHP structure potentially allows for the introduction of central metal ions in the oxidation states of +3 and +4 . This idea was realized in the case of $\mathrm{MASbSI}_{2}$ HP produced by a sequential stepwise method by reacting $\mathrm{Sb}_{2} \mathrm{~S}_{3}$ with $\mathrm{SbI}_{3}$ and then with MAI on the surface of a mesoporous $\mathrm{TiO}_{2}$ scaffold [87]. The MASbSI 2 HP displayed a bandgap of $1.62 \mathrm{eV}$ and $\mathrm{CB} / \mathrm{VB}$ positions suitable for the electron/hole transport to $\mathrm{TiO}_{2}$ and a variety of HTL materials, respectively (Figure 14a). A MASbSI 2 -based solar cell demonstrated a PCE of more than 3\% (Table 1), in addition to a reasonable stability in a 30-day trial (Figure 14b) and no discernible hysteresis between the forward and reverse $C-V$ scans (Figure 14c) [87].

Recently it was found that organo-inorganic bromoantimonate ( $N$-ethylpyridinium $)_{3} \mathrm{SbBr}_{6}$ forms perovskite-like $3 \mathrm{D}$ crystalline framework compounds that have great potential as solar cell absorbers [173]. A solar cell based on the particular ( $N$-ethylpyridinium $)_{3} \mathrm{SbBr}_{6}$ displayed an external quantum efficiency of $\approx 80 \%$ and a PCE of $\approx 4 \%$ thus coming into the same league as lead-halide HPs [173].
A series of ( $N$-methylpyrrolidinium) ${ }_{3} \mathrm{Sb}_{2} \mathrm{Cl}_{9-9 x} \mathrm{Br}_{9 x}(x=0-1)$ HPs was reported to have bandgaps tunable from $2.76 \mathrm{eV}$ $(x=1)$ to $3.31 \mathrm{eV}(x=0)$ and to exhibit photosensitivity levels high enough for the application of such compounds in UV-vis photodetectors [174].

The search for new lead-free HPs based on $\mathrm{M}^{3+}$ cations continues on. It often starts from the theoretical estimation of the stability, structure and optoelectronic properties of various HPs and selection of the most promising ones, stimulating further experimental work. For example, a broad theoretical screening of various mono- and bi-metallic lead-free perovskites among more than 480 materials focused on the 10 most promising in terms of the bandgap. Among these, the smallest $E_{\mathrm{g}}$ was found for $\mathrm{Cs}_{3} \mathrm{Ga}_{2} \mathrm{I}_{9}\left(E_{\mathrm{g}}=1.72 \mathrm{eV}\right)$ [175], which is still to be synthesized and tested in photovoltaic applications.

A series of HPs based on lanthanide cations was modeled and Eu-, Dy-, Tm-, and Yb-based HPs selected as the materials with the most promising bandgaps in the range of 2.0-3.2 eV [176]. It was found that localized f-electrons of lanthanide ions have a strong contribution to the VB top, where a strong influence of the lanthanide ion on the properties of HPs is expected. A combination of a theoretical screening with a following experimental verification recently led to a series of $\mathrm{Cs}_{2} \mathrm{TiI}_{x} \mathrm{Br}_{6-x}$ HPs with bandgaps varying from $1.38 \mathrm{eV}$ to $1.78 \mathrm{eV}$ depending on the $\mathrm{I} / \mathrm{Br}$ ratio [177].

\section{Lead-free hybrid perovskites based on $\mathrm{A}^{+} / \mathrm{A}^{3+}$ metal compositions}

Ag-Bi, Ag-Sb: A series of stable lead-free bimetallic HPs with a cation pair aliovalent to a pair of $\mathrm{Pb}^{2+}\left(\mathrm{Sn}^{2+}\right)$ ions such as
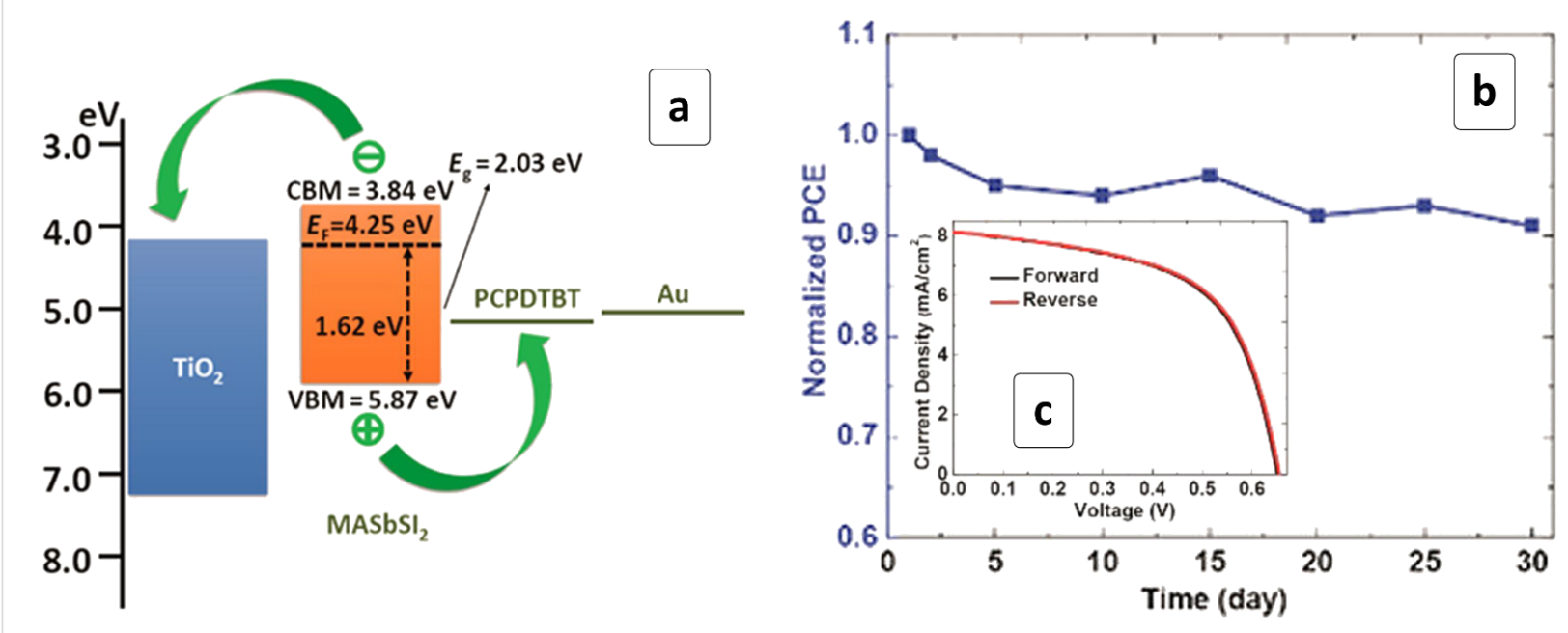

Figure 14: Energy diagram (a), normalized IPCE tested for a period of 30 days (b) as well as current-voltage characteristics registered at forward and reverse bias (c) of a solar cell based on $\mathrm{MASbSI}_{2} \mathrm{HP}$. The PCPSTBT abbreviation is explained in the notes of Table 1. Reprinted and adapted with permission from [87], copyright 2018 American Chemical Society. 
$\mathrm{A}_{2} \mathrm{AgBiX}_{6}, \mathrm{~A}_{2} \mathrm{AgSbX}_{6}$, and $\mathrm{A}_{2} \mathrm{AgInX}_{6}(\mathrm{~A}=\mathrm{MA}$ or $\mathrm{Cs}$, $\mathrm{X}=\mathrm{Cl}, \mathrm{Br}$ ) was reported. The bandgaps of selected $\mathrm{A}^{+} / \mathrm{A}^{3+}{ }_{-}$ HPs are presented in Table 4.

Table 4: Bandgap and approximate absorption band edge position $\left(\lambda_{\mathrm{e}}\right)$ of selected $A^{+} / A^{3+}$-based HPs.

\begin{tabular}{llll} 
Perovskite & $E_{\mathrm{g}}, \mathrm{eV}$ & $\lambda_{\mathrm{e}}, \mathrm{nm}$ & Ref. \\
\hline $\mathrm{MA}_{2} \mathrm{AgInl}_{6}$ & 1.93 & 640 & {$[178]$} \\
$\mathrm{Cs}_{2} \mathrm{AgInCl}_{6}$ & $3.2-3.3$ & $380-390$ & {$[179]$} \\
$\mathrm{Cs}_{2} \mathrm{AgBiCl}_{6}$ & 2.77 & 450 & {$[180]$} \\
& 2.20 & 560 & {$[181,182]$} \\
$\mathrm{Cs}_{2} \mathrm{AgBiBr}_{6}$ & $1.90-1.95$ & $640-650$ & {$[182-184]$} \\
$\mathrm{MA}_{2} \mathrm{AgBiBr}_{6}$ & 2.02 & 610 & {$[150,185,186]$} \\
$\mathrm{MA}_{2} \mathrm{AgBil}_{6}$ & 1.96 & 630 & {$[187]$} \\
$\mathrm{Cs}_{2} \mathrm{Au}_{2} \mathrm{I}_{6}$ & 1.31 & 950 & {$[188]$} \\
& & & {$[189]$}
\end{tabular}

$\mathrm{Cs}_{2} \mathrm{AgInCl}_{6} \mathrm{HP}$ was produced by a hydrothermal synthesis allowing the size of the final crystallites to be tailored by adjusting the hydrothermal treatment duration [179]. The perovskite crystallizes in the rock-salt structure with alternating $\left[\mathrm{AgCl}_{6}\right]$ and $\left[\mathrm{InCl}_{6}\right]$ octahedra (Figure 15a) and shows a direct bandgap of $3.23 \mathrm{eV}$, as well as an excellent stability to the ambient moisture, light, and heat [179].

$\mathrm{Cs}_{2} \mathrm{AgSbCl}_{6} \mathrm{HP}$ (Figure 15b) [190] and $\mathrm{Cs}_{2} \mathrm{AgBiCl}_{6} \mathrm{HP}$ (Figure 15c) $[180,181]$ are isostructural to $\mathrm{Cs}_{2} \mathrm{AgInCl}_{6}$ and display comparable photochemical, hydrolytic and thermal stability.

Despite a more complex composition as compared with the $\mathrm{Pb}$-based analog, the $\mathrm{Cs}_{2} \mathrm{AgInCl}_{6} \mathrm{HP}$ can be prepared with a trap state density of $\approx 10^{9} \mathrm{~cm}^{-3}$, which is much lower than that reported for the best lead halide HPs [191]. Such close-to-ideal materials can be used as light-absorbing bodies of very sensi- tive, stable and fast UV photodetectors. The doping of $\mathrm{Cs}_{2} \mathrm{AgInCl}_{6}$ HPs with $\mathrm{Mn}^{2+}$ imparts this HP with the property of visible-range luminescence [192].

Theoretical studies predicted $\mathrm{Cs}_{2} \mathrm{AgInBr}_{6} \mathrm{HP}$ to be thermodynamically stable $[193,194]$, showing a distinct n-type conductivity and shallow trap levels for Ag-rich and Br-poor compositions [194].

$\mathrm{MA}_{2} \mathrm{AgSbI}_{9} \mathrm{HP}$ was found to be a stable compound both by DFT calculations and experimental evidence, showing excellent resistivity to the ambient air/humidity [178]. The material revealed a band gap of $1.93 \mathrm{eV}$ and $\mathrm{CB} / \mathrm{VB}$ positions $(-6.28 \mathrm{eV} /-4.35 \mathrm{eV})$ suitable for most ETL/HTL materials used in the HP solar cells.

The substitution of chloride ions with $\mathrm{Br}^{-}$in Ag-Bi-based HP results in a shrinking of the bandgap from $2.77 \mathrm{eV}$ to $2.19 \mathrm{eV}$ [180], both values being smaller than $E_{\mathrm{g}}$ of corresponding $\mathrm{Pb}$-based HPs. The electron transitions contributing to the absorption band edge were found to be of an indirect character in accordance with DFT predictions $[182,195,196]$ with the calculated bandgaps of $2.2 \mathrm{eV}[181,182]$ and $1.9 \mathrm{eV}$ [182] for the Cl-based and Br-based HPs, respectively. The calculations also showed that a partial substitution of silver(I) with copper(I) should result in a narrowing of the bandgap to 1.6-1.9 eV, which would not compromise the HP stability [197], but these conclusions are still to be verified experimentally.

A DFT modeling of $\mathrm{TiO}_{2} / \mathrm{Cs}_{2} \mathrm{AgBiX}_{6}(\mathrm{X}=\mathrm{Cl}, \mathrm{Br})$ interfaces showed them to be very favorable for the photoinduced charge separation due to an appropriate band alignment and a state density gradient along the interface [198]. The calculations also showed that the bandgap of $\mathrm{Cs}_{2} \mathrm{AgBiBr}_{6} \mathrm{HP}$ can be continuously tuned from $1.93 \mathrm{eV}$ down to $0.44 \mathrm{eV}$ by introducing a control lattice disorder the latter value characteristic of completely
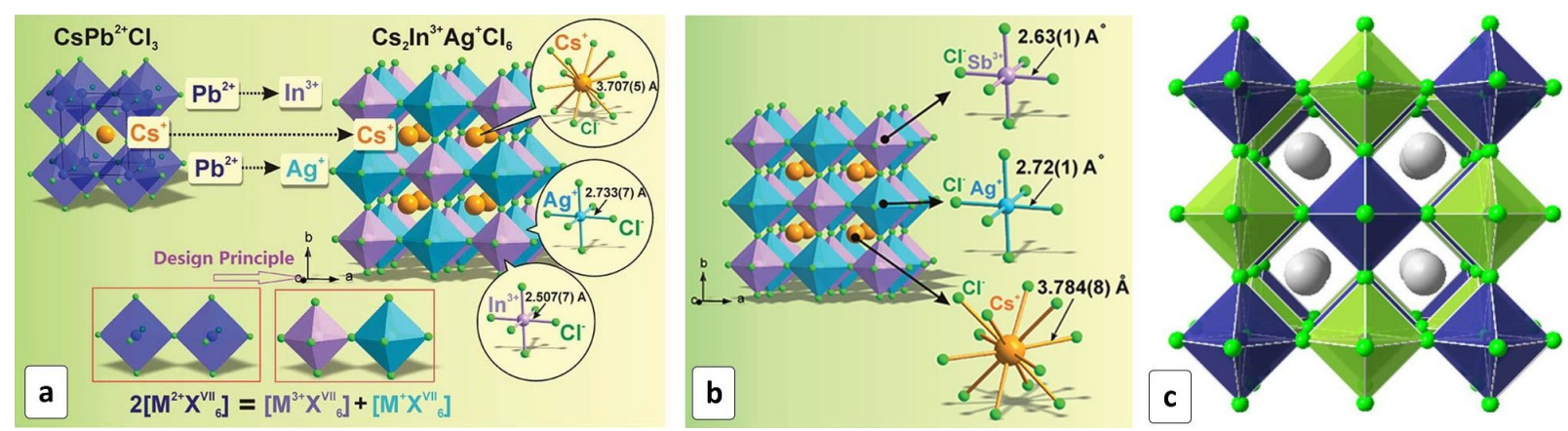

Figure 15: (a) Evolution of the crystal structure from $\mathrm{CsPbCl}_{3}$ to $\mathrm{Cs}_{2} \mathrm{AgInCl}_{6} \mathrm{HP}$; (b) Crystal structure of $\mathrm{Cs}_{2} \mathrm{AgSbCl}_{6} \mathrm{HP}$; (c) $\mathrm{Crystal}$ structure of $\mathrm{Cs}_{2} \mathrm{AgBiCl}_{6} \mathrm{HP} ; \mathrm{Cs}^{+}$ions are presented as gray spheres and $\mathrm{Cl}^{-}$as green spheres, the $\mathrm{Ag}$ and $\mathrm{Bi}$ centered octahedra are shown as blue and green ones, respectively. (a) Reproduced with permission from [179], copyright 2017 The Royal Society of Chemistry; (b) Reproduced with permission from [190], copyright 2018 The Royal Society of Chemistry; (c) Reprinted with permissions from [180], copyright 2016 American Chemical Society. 
disordered alloy [183]. As a practical means to exert such a disordering, the controlled doping of the perovskite was proposed [183]. However, such disordering will inevitably limit the charge transport efficiency and boost the electron-hole recombination and, therefore, a certain equilibrium between the light harvesting capability and the photovoltaic efficiency can be expected in such approach.

The bandgap of $\mathrm{Cs}_{2} \mathrm{AgBiBr}_{6} \mathrm{HP}$ was also found to decrease upon application of a high-pressure treatment [185]. Under $15 \mathrm{GPa}$ pressure, the AgBi-based perovskite displays a bandgap of $\approx 1.7 \mathrm{eV}(\approx 22 \%$ lower than at the ambient pressure) close to the $E_{\mathrm{g}}$ of the "classical" MAPI, retaining about $8 \%$ residual $E_{\mathrm{g}}$ shrinkage after the pressure is released [185].

The results of the DFT simulations of the electron structure of more than 11,000 various compositions of lead-free HPs were assembled as a material database available for the screening of possible light harvesters of the photovoltaic solar cells [199]. A comprehensive theoretical screening of more than $480 \mathrm{~A}_{2} \mathrm{MM}^{\prime} \mathrm{X}_{6}, \mathrm{AMX}_{4}$, and $\mathrm{A}_{3} \mathrm{M}_{2} \mathrm{X}_{9}$ compounds put the focus on the ten most promising materials with bandgaps between $1.5-2.5 \mathrm{eV}$ [175].

Time-resolved microwave conductance studies of $\mathrm{Cs}_{2} \mathrm{AgBiBr}_{6}$ HP in the form of thin films and crystals revealed the presence of mobile charges with lifetimes on the order of microseconds as well as a low level of trap-state-mediated recombination, which is promising for the photovoltaic applications of this material [200].

Similar to $\mathrm{MABI}, \mathrm{Cs}_{2} \mathrm{AgBiBr}_{6}$ perovskite showed a remarkable tolerance to a variation of the grain size and the defect density, maintaining an unchanged PL yield both for the bulk crystal and finely powdered samples [183]. These findings show the feasibility of the design of bulk heterojunction solar cell architectures with nanometer- and micrometer-sized HP domains.

The performance of $\mathrm{Cs}_{2} \mathrm{AgBiBr}_{6} \mathrm{HP}$-based solar cells is typically limited by the low quality of the HP layer, resulting from the poor solubility of the Ag and Bi halide precursors. To address this problem, a variety of solvents and deposition modes were tested and an approach to produce very uniform $\mathrm{Cs}_{2} \mathrm{AgBiBr}_{6}$ films was proposed by exploiting DMSO as a "universal" solvent and a special series of thermal treatments of both the precursor solutions and spin-coated films [186]. The solar cells with the optimized films sandwiched between a $\mathrm{TiO}_{2}$ ETL and a Spiro-MeOTAD HTL showed a PCE of $2.43 \%$ and an open-circuit voltage of almost one volt, which is the highest value currently reported for Bi-based HPs. The devices also displayed a remarkable stability in working conditions even without additional encapsulation [186].

The superior stability of $\mathrm{Cs}_{2} \mathrm{AgBiBr}_{6} \mathrm{HP}$ as compared to MAPI was rationalized by a detailed theoretical structural analysis [201] that showed the framework of the AgBi-HP to be much more rigid with considerably lower thermal expansion coefficients as a result of the presence of relatively stronger $\mathrm{Ag}-\mathrm{Br}$ and $\mathrm{Bi}-\mathrm{Br}$ bonds.

The $\mathrm{Cs}_{2} \mathrm{AgBiCl}_{6}$ and $\mathrm{Cs}_{2} \mathrm{AgBiBr}_{6} \mathrm{NCs}$ synthesized by a hotinjection approach (Figure 16a) can be converted to the $\mathrm{Cs}_{2} \mathrm{AgBiI}_{6}$ phase either by exchanging $\mathrm{Cl}(\mathrm{Br})$ with iodide anions (Figure 16b) or by exchanging $\mathrm{Cs}^{+}$cations in $\mathrm{Cs}_{3} \mathrm{BiBr}_{6}$ $\mathrm{NCs}$ with $\mathrm{Ag}^{+}$(Figure 16c) [202]. The NCs preserve the average size $(\approx 8 \mathrm{~nm}$ ) and size distribution (Figure $16 \mathrm{~d}-\mathrm{e}$ ) during the ion-exchange conversions, showing a good morphology control provided by this method. The indirect band gap of $\mathrm{Cs}_{2} \mathrm{AgBiX}_{6}$ NCs decreases from $\approx 2.8 \mathrm{eV}$ for $\mathrm{X}=\mathrm{Cl}$ to $\approx 2.2 \mathrm{eV}$ for $\mathrm{X}=\mathrm{Br}$ to $\approx 1.75 \mathrm{eV}$ for $\mathrm{X}=\mathrm{I}$ [202].

Stable $\mathrm{MA}_{2} \mathrm{AgBiBr}_{6} \mathrm{HP}$ was produced by a hydrothermal treatment of a mixture of $\mathrm{MABr}, \mathrm{BiBr}_{3}, \mathrm{AgBr}$, and $\mathrm{HBr}$ in water [187]. The formation of the bimetallic HP proceeds, most probably, via a step of the $\mathrm{MA}_{3} \mathrm{Bi}_{2} \mathrm{Br}_{9}$ phase formation, which is present as a residual in the final $\mathrm{MA}_{2} \mathrm{AgBiBr}_{6} \mathrm{HP}$, making this approach similar to the above-discussed ion exchange method. Additionally, the authors note the unsuccessful attempts to apply the hydrothermal method for the synthesis of (MA) ${ }_{2} \mathrm{AgBiI}_{6}$ and $(\mathrm{FA})_{2} \mathrm{AgBiBr}_{6}$, the reaction yielding only the monometallic Bi-based phases [187]. The $\mathrm{MA}_{2} \mathrm{AgBiBr}_{6} \mathrm{HP}$ revealed an indirect bandgap of $\approx 2 \mathrm{eV}$ close to the range reported for the Cs-based analog (1.95-2.19 eV) [187].

The lead-free $\mathrm{MA}_{2} \mathrm{AgBiI}_{6} \mathrm{HP}$ was synthesized by a solid-state reaction and revealed an indirect bandgap of $1.96 \mathrm{eV}$ and a high stability to air exposure [188].

A broad theoretical modeling of the structures and properties of $\mathrm{A}_{2} \mathrm{M}^{+} \mathrm{M}^{3+} \mathrm{X}_{6} \mathrm{HP}$ materials focused on two prospective materials with a direct bandgap of around $1 \mathrm{eV}-\mathrm{Cs}_{2} \mathrm{InSbX}_{6}$ and $\mathrm{Cs}_{2} \mathrm{InBiX}_{6}$ [203]. However, experimental attempts to exchange $\mathrm{Ag}^{+}$to $\mathrm{In}^{+}$in $\mathrm{Cs}_{2} \mathrm{AgBiBr}_{6} \mathrm{HP}$ were unsuccessful due to the ready oxidation of $\mathrm{In}^{+}$to $\mathrm{In}^{3+}$ [204]. At the same time, theoretical calculations [204] predicted that introduction of bulky MA or FA cations will stabilize $\mathrm{In}^{+}$, providing the compound with the optoelectronic properties close to those of MAPI and, therefore, a further pursuit in this direction may be fruitful. DFT calculations also indicated that $\mathrm{MATl}_{0.5} \mathrm{Bi}_{0.5} \mathrm{I}_{3}$ may be a potential candidate for a solar cell absorber with properties similar to those of MAPI [205]. 


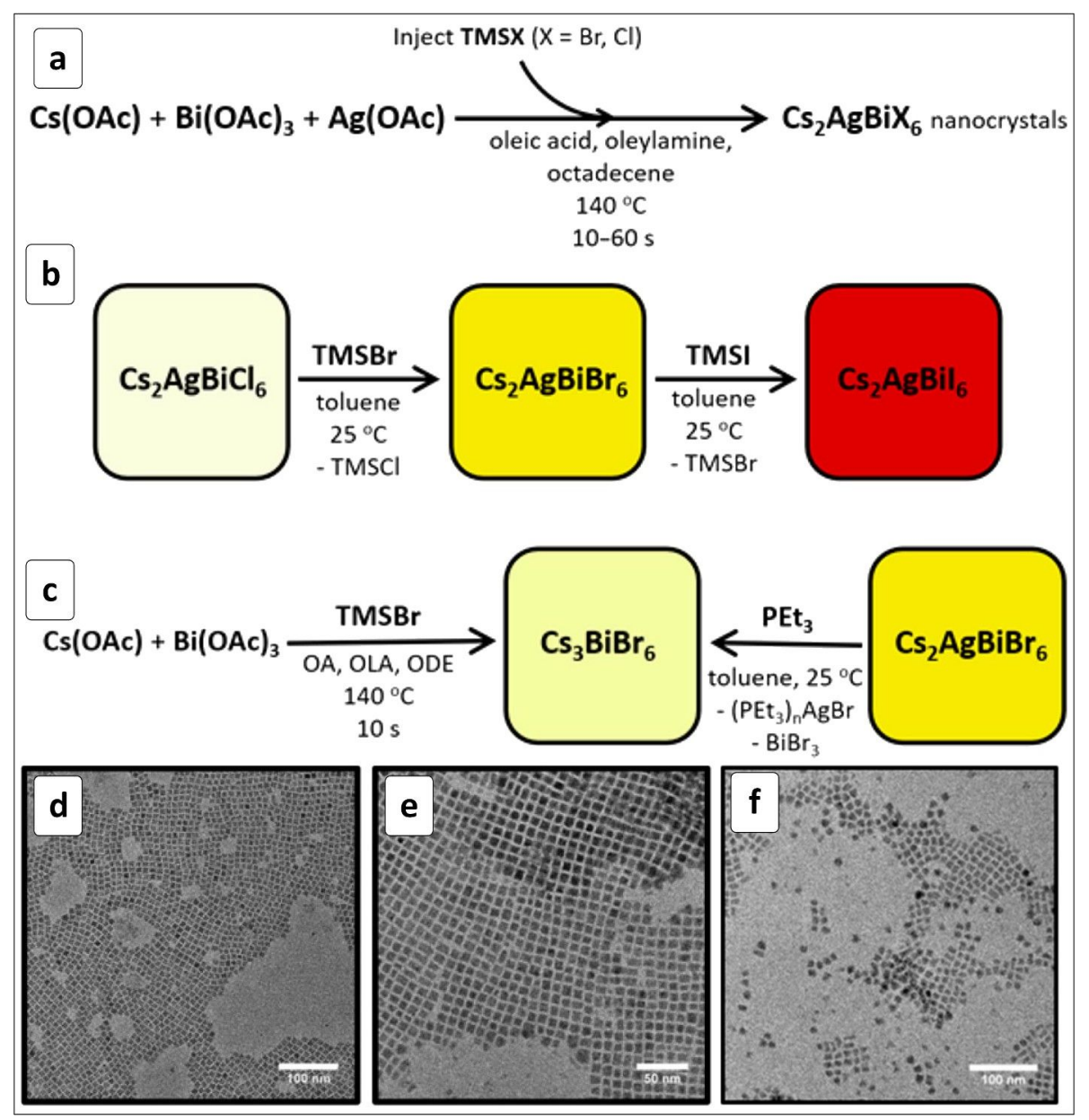

Figure 16: Scheme of the synthesis of $\mathrm{Cs}_{2} \mathrm{AgBiX}_{6} \mathrm{NCs}(\mathrm{a}-\mathrm{c})$ and TEM images of $\mathrm{Cs}_{2} \mathrm{AgBiCl}_{6}(\mathrm{~d}), \mathrm{Cs}_{2} \mathrm{AgBiBr}_{6}(\mathrm{e})$, and $\mathrm{Cs}_{2} \mathrm{AgBil}{ }_{6} \mathrm{NCs}$ (f). OAc is acetate anion, Et - ethyl, OA - oleic acid, OLA - oleylamine, ODE - octadecene, TMS - trimethylsilyl. Reprinted and adapted with permission from [202], copyright 2018 American Chemical Society.

Recently, a new $\mathrm{Cs}_{2} \mathrm{Au}_{2} \mathrm{I}_{6} \mathrm{HP}$ was reported to have crystallized in a distorted tetragonal mix-valence $\mathrm{Au}^{+} / \mathrm{Au}^{3+}$ perovskite structure with a "close-to-ideal" bandgap of $1.31 \mathrm{eV}$ [189]. Preliminary tests showed high promise of this material for thin-film photovoltaics.

\section{Conclusion and outlook}

The present review shows that lead-free hybrid perovskites combine the many possibilities in composition with environmentally benign constituents, in addition to being relatively robust against the influence of light, air and moisture, and can be synthesized in a variety of possible morphologies $(0 \mathrm{D}, 1 \mathrm{D}$, $2 \mathrm{D}$, etc.). The progress in this area is evident with the highest PCEs achieved to date already comparable and competitive with the efficiency of "conventional" lead-based perovskites. This progress is even more pronounced on the background of a saturation of the studies of $\mathrm{Pb}$ HPs and the light conversion efficiency achieved. The lead-free HP-based solar cells could soon become competitive to their $\mathrm{Pb}$-based analogs in the near future because even with an inferior PCE, lead-free HPs are not acutely toxic and do not pose the severe concerns of possible environmental damage and the post-utilization recycling problems that Pb-based HPs do.

To increase the competitiveness of lead-free HP-based solar cells, several vital issues should be addressed. Among them an inferior efficiency of charge transport, high recombination losses, and a limited spectral sensitivity range that is typical for such materials. The most promising avenues for addressing the charge separation/transport issues seem to be in an adapted morphological design of lead-free HPs, in particular, by implementing nanodimensional and layered architectures. The limitations in spectral sensitivity can be solved by designing composite light-harvesting systems with other semiconductors, such as narrow-bandgap $\mathrm{Cd}$ - and $\mathrm{Pb}$-free binary and multinary metal chalcogenides. 
In contrast to $\mathrm{Pb}$-based HPs, the lead-free analogs typically display a relatively short-range free charge migration distance on the order of several tens of nanometers. In this view, a decrease of the HP crystal size to $10-100 \mathrm{~nm}$ should not fundamentally affect the charge transport properties but might open broad possibilities of increasing the efficiency of interfacial electron transfer and allow the construction of "ideal" bulk heterojunctions with ETL and HTL materials by intermixing nanometer-sized particles of components. In this view, the leadfree HPs can potentially be utilized in the nano-dispersed form, differing drastically from $\mathrm{Pb}$-HPs where a larger HP grain size and a smaller grain boundary typically mean a higher light conversion efficiency.

The utilization of nanometer building blocks for the design of lead-free HP-based solar cells requires reliable synthetic methods allowing for a precise control over the HP morphology. In this area, conventional synthetic strategies are typically used, and the HP NCs are grown in high-boiling-point solvents in the presence of surface-passivating ligands. These approaches seem to be quite appropriate for the synthesis of highly luminescent perovskites. However, for photovoltaic applications, new methods are needed to produce NCs with a free surface or containing only small passivating ligands as well as to form various composites; in particular, HP NCs supported on mesoporous metal oxide scaffolds. In this view, of particular significance are methods based on the formation of metal NCs as precursors for development of perovskite NCs. The metal NCs can be deposited by a variety of methods, but only the evaporative deposition of $\mathrm{Pb}$ and $\mathrm{Sn} \mathrm{NCs}$ followed by their transformation into corresponding HPs has been probed (recently by Hodes et al. [136]). The transformation of metal NCs into perovskites was found to yield light absorbers of a higher quality and allowed for better morphology control as compared to the conventional spin/cast dropping deposition. At the same time, this method excludes toxic $(\mathrm{Pb})$ or unstable $(\mathrm{Sn})$ precursors. This strategy may be considered as very promising because metal NCs can be deposited by a variety of methods (electrochemical/electrocatalytic deposition, photochemical/ photocatalytic deposition, thermal evaporation, "seed" growth on pre-deposited nuclei, etc.). This could allow for a precise method of control over the metal NC size that is suitable both for single metals ( $\mathrm{Sn}, \mathrm{Sb}, \mathrm{Bi}$, etc.) and for bimetallic alloys (Ag-Bi, Ag-Sb, Ag-In, etc.) that can then be converted into a plethora of hybrid perovskites. The feasibility of the exact translation of the morphology of primary metal NCs into the morphology of the final HPs still remains to be explored.

Layered 1D and 2D HP materials show great promise due to a strong anisotropy of electron properties, facilitating the charge separation and transport, as well as the unique morphological variability $[57,58,64]$. The latter can be achieved both by introducing various interlayer additives and by varying the thickness and composition of the layers themselves. For example, a strong effect on the light absorption, electron mobility, and internal electric field was predicted for ultra-thin $\mathrm{CsSnI}_{3} \mathrm{HP}$ with the layer number as small as 1-3 [206]. The thickness dependence seems to resemble that of layered metal dichalcogenides, $\mathrm{MoS}_{2}$ and $\mathrm{WS}_{2}$, where single and few-layer materials differ drastically from corresponding bulk semiconductors. We may expect similar effects arising for layered lead-free HPs, potentially contributing to new designs of solar cells and enhanced light conversion efficiencies [14,207].

Simultaneously, the formation of interlayer voids or intermediate layers of other semiconductors/dielectrics may result in a regular quantum-well structure that is strongly beneficial for the photoinduced charge separation between the separated HP sheets [207,208]. Finally, a combination of single layers of two and more different lead-free HPs into a composite material may offer unprecedented variability of optical properties and band design. The feasibility of such an approach was probed by DFT calculations for $\mathrm{Cs}_{3+n} \mathrm{M}_{n} \mathrm{Sb}_{2} \mathrm{X}_{9+3 n}(\mathrm{M}=\mathrm{Sn}, \mathrm{Ge})$ compounds formed by inserting variable $\left[\mathrm{SnI}_{6}\right]$ or $\left[\mathrm{GeI}_{6}\right]$ octahedral layers into the $\left[\mathrm{Sb}_{2} \mathrm{I}_{9}\right]$ bilayers. It was found, in particular, that adjusting the thickness of the inserted octahedral layers is an effective approach to tune the bandgap and effective mass of the charge carriers over a broad range [209].

Except for Sn-based HPs, the lead-free perovskites typically have larger bandgaps than "conventional" $\mathrm{Pb}$-based compounds and, therefore, a limited spectral sensitivity range. This limitation can be avoided by designing tandem solar cells, for example with silicon or kesterite $\mathrm{Cu}_{2} \mathrm{ZnSn}(\mathrm{S}, \mathrm{Se})_{4}$ absorbers. The feasibility of such an approach was demonstrated in 2014 by Todorov et al. who reported a relatively simple tandem solar cell based on a planar heterojunction between microcrystalline layers of kesterite and MAPI that displayed an unprecedented high $V_{\text {oc }}$ of $1350 \mathrm{mV}$ and a PCE exceeding 20\% [210].

Alternatively, the lead-free HPs can be directly coupled with broadband-absorbing inorganic NCs to give a double benefit of extended spectral sensitivity range and a possibility of the photoinduced electron/hole separation between HP and inorganic NCs. Such systems have recently emerged as a new research hotspot, the attention focused mainly on combinations of $\mathrm{PbS}$ or $\mathrm{PbSe} \mathrm{NCs}$ with $\mathrm{Pb}$-based perovskites. In particular, $\mathrm{PbS} \mathrm{NCs}$ introduced into MAPI-based solar cells were found to act simultaneously as a co-absorber and an HTL, rendering the use of additional organic hole transporting materials superfluous [211,212]. A shell of MAPI on the surface of PbS NCs was found to act as an efficient electron acceptor and a passivating 
agent, minimizing the recombinational losses in lead sulfide NCs [213,214].

To date, no reports can be found on analogous systems comprising lead-free HPs and cadmium- and lead-free semiconductors, such as $\mathrm{CuInS}(\mathrm{Se})_{2}$ or $\mathrm{Cu}_{2} \mathrm{ZnSnS}(\mathrm{Se})_{4}$, where both an "ideal" spectral sensitivity range and an efficient charge carrier separation between $n$-conducting HPs and $p$-conducting metal chalcogenides can be simultaneously achieved. This venue seems to be especially promising in view of recent developments in the synthetic approaches to both multinary metal chalcogenide NCs and lead-free HP NCs with highly controlled composition and morphology. We may expect that the combination of nanometer building blocks of inorganic semiconductors and hybrid perovskites will allow for the construction of "green" and efficient bulk-heterojunction configurations with a panchromatic spectral response and competitive light conversion efficiencies.

\section{Acknowledgements}

This work was supported by the European Union's Horizon 2020 research and innovation program under the Marie Skłodowska-Curie grant agreement No 701254.

\section{ORCID ${ }^{\circledR}$ iDs}

Oleksandr Stroyuk - https://orcid.org/0000-0001-5054-2746

\section{References}

1. Green, M. A.; Hishikawa, Y.; Warta, W.; Dunlop, E. D.; Levi, D. H.; Hohl-Ebinger, J.; Ho-Baillie, A. W. H. Prog. Photovoltaics 2017, 25, 668-676. doi:10.1002/pip.2909

2. Hagfeldt, A.; Boschloo, G.; Sun, L.; Kloo, L.; Pettersson, H. Chem. Rev. 2010, 110, 6595-6663. doi:10.1021/cr900356p

3. Sandroni, M.; Wegner, K. D.; Aldakov, D.; Reiss, P. ACS Energy Lett. 2017, 2, 1076-1088. doi:10.1021/acsenergylett.7b00003

4. Reiss, P.; Carrière, M.; Lincheneau, C.; Vaure, L.; Tamang, S. Chem. Rev. 2016, 116, 10731-10819. doi:10.1021/acs.chemrev.6b00116

5. Wang, W.; Feng, W.; Du, J.; Xue, W.; Zhang, L.; Zhao, L.; Li, Y.; Zhong, X. Adv. Mater. 2018, 30, 1705746. doi:10.1002/adma.201705746

6. Kazim, S.; Nazeeruddin, M. K.; Grätzel, M.; Ahmad, S. Angew. Chem., Int. Ed. 2014, 53, 2812-2824. doi:10.1002/anie.201308719

7. Wang, B.; Xiao, X.; Chen, T. Nanoscale 2014, 6, 12287-12297. doi:10.1039/c4nr04144e

8. Gamliel, S.; Etgar, L. RSC Adv. 2014, 4, 29012-29021. doi:10.1039/c4ra03981e

9. Giorgi, G.; Yamashita, K. J. Mater. Chem. A 2015, 3, 8981-8991. doi:10.1039/c4ta05046k

10. Jung, H. S.; Park, N.-G. Small 2015, 11, 10-25. doi:10.1002/smll.201402767

11. Liu, X.; Zhao, W.; Cui, H.; Xie, Y.; Wang, Y.; Xu, T.; Huang, F. Inorg. Chem. Front. 2015, 2, 315-335. doi:10.1039/c4qi00163j
12. Luo, S.; Daoud, W. A. J. Mater. Chem. A 2015, 3, 8992-9010. doi:10.1039/c4ta04953e

13. Zuo, C.; Bolink, H. J.; Han, H.; Huang, J.; Cahen, D.; Ding, L. Adv. Sci. 2016, 3, 1500324. doi:10.1002/advs.201500324

14. Pedesseau, L.; Sapori, D.; Traore, B.; Robles, R.; Fang, H.-H.; Loi, M. A.; Tsai, H.; Nie, W.; Blancon, J.-C.; Neukirch, A.; Tretiak, S.; Mohite, A. D.; Katan, C.; Even, J.; Kepenekian, M. ACS Nano 2016, 10, 9776-9786. doi:10.1021/acsnano.6b05944

15. bin Mohd Yusoff, A. R.; Nazeeruddin, M. K. J. Phys. Chem. Lett. 2016, 7, 851-866. doi:10.1021/acs.jpclett.5b02893

16. Saparov, B.; Mitzi, D. B. Chem. Rev. 2016, 116, 4558-4596. doi:10.1021/acs.chemrev.5b00715

17. Polman, A.; Knight, M.; Garnett, E. C.; Ehrler, B.; Sinke, W. C. Science 2016, 352, aad4424. doi:10.1126/science.aad4424

18. Correa-Baena, J.-P.; Abate, A.; Saliba, M.; Tress, W.; Jesper Jacobsson, T.; Grätzel, M.; Hagfeldt, A. Energy Environ. Sci. 2017, 10, 710-727. doi:10.1039/c6ee03397k

19. Bhatt, M. D.; Lee, J. S. New J. Chem. 2017, 41, 10508-10527. doi:10.1039/c7nj02691a

20. Niu, G.; Guo, X.; Wang, L. J. Mater. Chem. A 2015, 3, 8970-8980. doi:10.1039/C4TA04994B

21. Ono, L. K.; Juarez-Perez, E. J.; Qi, Y. ACS Appl. Mater. Interfaces 2017, 9, 30197-30246. doi:10.1021/acsami.7b06001

22. Calvo, M. E. J. Mater. Chem. A 2017, 5, 20561-20578. doi:10.1039/c7ta05666d

23. Yang, S.; Fu, W.; Zhang, Z.; Chen, H.; Li, C.-Z. J. Mater. Chem. A 2017, 5, 11462-11482. doi:10.1039/c7ta00366h

24. Dou, L. J. Mater. Chem. C 2017, 5, 11165-11173. doi:10.1039/c7tc02863f

25. Matthews, P. D.; Lewis, D. J.; O'Brien, P. J. Mater. Chem. A 2017, 5, 17135-17150. doi:10.1039/c7ta04544a

26. Assadi, M. K.; Bakhoda, S.; Saidur, R.; Hanaei, H. Renewable Sustainable Energy Rev. 2018, 81, 2812-2822. doi:10.1016/j.rser.2017.06.088

27. Dubey, A.; Adhikari, N.; Mabrouk, S.; Wu, F.; Chen, K.; Yang, S.; Qiao, Q. J. Mater. Chem. A 2018, 6, 2406-2431. doi:10.1039/c7ta08277k

28. Kostopoulou, A.; Kymakis, E.; Stratakis, E. J. Mater. Chem. A 2018, 6, 9765-9798. doi:10.1039/c8ta01964a

29. Ansari, M. I. H.; Qurashi, A.; Nazeeruddin, M. K. J. Photochem. Photobiol., C 2018, 35, 1-24. doi:10.1016/j.jphotochemrev.2017.11.002

30. Nakazaki, J.; Segawa, H. J. Photochem. Photobiol., C 2018, 35, 74-107. doi:10.1016/j.jphotochemrev.2018.02.002

31. Kim, B. J.; Lee, S.; Jung, H. S. J. Mater. Chem. A 2018, 6, 12215-12236. doi:10.1039/C8TA02159G

32. Sum, T. C.; Mathews, N. Energy Environ. Sci. 2014, 7, 2518-2534. doi:10.1039/c4ee00673a

33. Hsiao, Y.-C.; Wu, T.; Li, M.; Liu, Q.; Qin, W.; Hu, B. J. Mater. Chem. A 2015, 3, 15372-15385. doi:10.1039/c5ta01376c

34. Shi, J.; Xu, X.; Li, D.; Meng, Q. Small 2015, 11, 2472-2486. doi:10.1002/smll.201403534

35. Zhao, Y.; Zhu, K. Chem. Soc. Rev. 2016, 45, 655-689. doi:10.1039/c4cs00458b

36. Berhe, T. A.; Su, W.-N.; Chen, C.-H.; Pan, C.-J.; Cheng, J.-H.; Chen, H.-M.; Tsai, M.-C.; Chen, L.-Y.; Dubale, A. A.; Hwang, B.-J. Energy Environ. Sci. 2016, 9, 323-356. doi:10.1039/c5ee02733k

37. Saba, M.; Quochi, F.; Mura, A.; Bongiovanni, G. Acc. Chem. Res. 2016, 49, 166-173. doi:10.1021/acs.accounts.5b00445 
38. Johnston, M. B.; Herz, L. M. Acc. Chem. Res. 2016, 49, 146-154. doi:10.1021/acs.accounts.5b00411

39. Mehmood, U.; Al-Ahmed, A.; Afzaal, M.; Al-Sulaiman, F. A.; Daud, M. Renewable Sustainable Energy Rev. 2017, 78, 1-14. doi:10.1016/j.rser.2017.04.105

40. Kadro, J. M.; Hagfeldt, A. Joule 2017, 1, $29-46$. doi:10.1016/j.joule.2017.07.013

41. Peng, J.; Chen, Y.; Zheng, K.; Pullerits, T.; Liang, Z. Chem. Soc. Rev. 2017, 46, 5714-5729. doi:10.1039/c6cs00942e

42. Abate, A. Joule 2017, 1, 659-664. doi:10.1016/j.joule.2017.09.007

43. Ahmadi, M.; Wu, T.; Hu, B. Adv. Mater. 2017, 29, 1605242. doi:10.1002/adma.201605242

44. Chakraborty, S.; Xie, W.; Mathews, N.; Sherburne, M.; Ahuja, R.; Asta, M.; Mhaisalkar, S. G. ACS Energy Lett. 2017, 2, 837-845. doi:10.1021/acsenergylett.7b00035

45. Green, M. A.; Ho-Baillie, A. ACS Energy Lett. 2017, 2, 822-830. doi:10.1021/acsenergylett.7b00137

46. Ono, L. K.; Qi, Y. J. Phys. D: Appl. Phys. 2018, 51, 093001. doi:10.1088/1361-6463/aaa727

47. Chen, P.; Bai, Y.; Lyu, M.; Yun, J.-H.; Hao, M.; Wang, L. Sol. RRL 2018, 2, 1700186. doi:10.1002/solr.201700186

48. Saliba, M.; Correa-Baena, J.-P.; Grätzel, M.; Hagfeldt, A.; Abate, A. Angew. Chem., Int. Ed. 2018, 57, 2554-2569. doi:10.1002/anie.201703226

49. Chen, H.; Xiang, S.; Li, W.; Liu, H.; Zhu, L.; Yang, S. Sol. RRL 2018, 2, 1700188. doi:10.1002/solr.201700188

50. Zhang, Q.; Yin, Y. ACS Cent. Sci. 2018, 4, 668-679. doi:10.1021/acscentsci.8b00201

51. Konstantakou, M.; Stergiopoulos, T. J. Mater. Chem. A 2017, 5, 11518-11549. doi:10.1039/c7ta00929a

52. Dong, Y.; Zou, Y.; Song, J.; Song, X.; Zeng, H. J. Mater. Chem. C 2017, 5, 11369-11394. doi:10.1039/c7tc03612d

53. Swarnkar, A.; Ravi, V. K.; Nag, A. ACS Energy Lett. 2017, 2, 1089-1098. doi:10.1021/acsenergylett.7b00191

54. Sun, J.; Yang, J.; Lee, J. I.; Cho, J. H.; Kang, M. S. J. Phys. Chem. Lett. 2018, 9, 1573-1583. doi:10.1021/acs.jpclett.8b00301

55. Yang, G.-L.; Zhong, H.-Z. Chin. Chem. Lett. 2016, 27, 1124-1130. doi:10.1016/j.cclet.2016.06.047

56. Bai, S.; Yuan, Z.; Gao, F. J. Mater. Chem. C 2016, 4, 3898-3904. doi:10.1039/c5tc04116c

57. Chatterjee, S.; Pal, A. J. J. Mater. Chem. A 2018, 6, 3793-3823. doi:10.1039/c7ta09943f

58. Yan, J.; Qu, W.; Wu, G.; Heremans, P.; Chen, H. J. Mater. Chem. A 2018, 6, 11063-11077. doi:10.1039/c8ta02288g

59. Hu, H.; Dong, B.; Zhang, W. J. Mater. Chem. A 2017, 5 , 11436-11449. doi:10.1039/c7ta00269f

60. Giustino, F.; Snaith, H. J. ACS Energy Lett. 2016, 1, 1233-1240. doi:10.1021/acsenergylett.6b00499

61. Zhang, M.; Lyu, M.; Chen, P.; Hao, M.; Yun, J.-H.; Wang, L. Asia-Pac. J. Chem. Eng. 2016, 11, 392-398. doi:10.1002/apj.1998

62. Ganose, A. M.; Savory, C. N.; Scanlon, D. O. Chem. Commun. 2017, 53, 20-44. doi:10.1039/c6cc06475b

63. Liu, C.; Li, W.; Fan, J.; Mai, Y. J. Energy Chem. 2018, 27, 1054-1066. doi:10.1016/j.jechem.2017.10.028

64. Liang, L.; Gao, P. Adv. Sci. 2018, 5, 1700331. doi:10.1002/advs.201700331

65. Pazoki, M.; Edvinsson, T. Sustainable Energy Fuels 2018, 2, 1430-1445. doi:10.1039/C8SE00143J
66. Boix, P. P.; Agarwala, S.; Koh, T. M.; Mathews, N.; Mhaisalkar, S. G. J. Phys. Chem. Lett. 2015, 6, 898-907. doi:10.1021/jz502547f

67. Kojima, A.; Teshima, K.; Shirai, Y.; Miyasaka, T. J. Am. Chem. Soc. 2009, 131, 6050-6051. doi:10.1021/ja809598r

68. Ogomi, Y.; Morita, A.; Tsukamoto, S.; Saitho, T.; Fujikawa, N.; Shen, Q.; Toyoda, T.; Yoshino, K.; Pandey, S. S.; Ma, T.; Hayase, S. J. Phys. Chem. Lett. 2014, 5, 1004-1011. doi:10.1021/jz5002117

69. Liang, J.; Zhao, P.; Wang, C.; Wang, Y.; Hu, Y.; Zhu, G.; Ma, L.; Liu, J.; Jin, Z. J. Am. Chem. Soc. 2017, 139, 14009-14012. doi:10.1021/jacs.7b07949

70. Yang, Z.; Rajagopal, A.; Jen, A. K.-Y. Adv. Mater. 2017, 29, 1704418. doi:10.1002/adma.201704418

71. Ke, W.; Stoumpos, C. C.; Spanopoulos, I.; Mao, L.; Chen, M.; Wasielewski, M. R.; Kanatzidis, M. G. J. Am. Chem. Soc. 2017, 139, 14800-14806. doi:10.1021/jacs.7b09018

72. Chen, L.-J.; Lee, C.-R.; Chuang, Y.-J.; Wu, Z.-H.; Chen, C. J. Phys. Chem. Lett. 2016, 7, 5028-5035. doi:10.1021/acs.jpclett.6b02344

73. Tsai, C.-M.; Mohanta, N.; Wang, C.-Y.; Lin, Y.-P.; Yang, Y.-W.; Wang, C.-L.; Hung, C.-H.; Diau, E. W.-G. Angew. Chem., Int. Ed. 2017, 56, 13819-13823. doi:10.1002/anie.201707037

74. Hao, F.; Stoumpos, C. C.; Cao, D. H.; Chang, R. P. H.; Kanatzidis, M. G. Nat. Photonics 2014, 8, 489-494. doi:10.1038/NPHOTON.2014.82

75. Cao, D. H.; Stoumpos, C. C.; Yokoyama, T.; Logsdon, J. L.; Song, T.-B.; Farha, O. K.; Wasielewski, M. R.; Hupp, J. T.; Kanatzidis, M. G. ACS Energy Lett. 2017, 2, 982-990. doi:10.1021/acsenergylett.7b00202

76. Shao, S.; Liu, J.; Portale, G.; Fang, H.-H.; Blake, G. R.; ten Brink, G. H.; Koster, L. J. A.; Loi, M. A. Adv. Energy Mater. 2018, 8, 1702019. doi:10.1002/aenm.201702019

77. Zhu, Z.; Chueh, C.-C.; Li, N.; Mao, C.; Jen, A. K.-Y. Adv. Mater. 2018, 30, 1703800. doi:10.1002/adma.201703800

78. Jung, M.-C.; Raga, S. R.; Qi, Y. RSC Adv. 2016, 6, 2819-2825. doi:10.1039/c5ra21291j

79. Bernal, C.; Yang, K. J. Phys. Chem. C 2014, 118, 24383-24388. doi:10.1021/jp509358f

80. Song, T.-B.; Yokoyama, T.; Aramaki, S.; Kanatzidis, M. G. ACS Energy Lett. 2017, 2, 897-903. doi:10.1021/acsenergylett.7b00171

81. Yu, Y.; Zhao, D.; Grice, C. R.; Meng, W.; Wang, C.; Liao, W.; Cimaroli, A. J.; Zhang, H.; Zhu, K.; Yan, Y. RSC Adv. 2016, 6, 90248-90254. doi:10.1039/c6ra19476a

82. Koh, T. M.; Krishnamoorthy, T.; Yantara, N.; Shi, C.; Leong, W. L.; Boix, P. P.; Grimsdale, A. C.; Mhaisalkar, S. G.; Mathews, N. J. Mater. Chem. A 2015, 3, 14996-15000. doi:10.1039/c5ta00190k

83. Jiang, Y.; Zhang, H.; Qiu, X.; Cao, B. Mater. Lett. 2017, 199, 50-52. doi:10.1016/j.matlet.2017.04.046

84. Zhang, Z.; Li, X.; Xia, X.; Wang, Z.; Huang, Z.; Lei, B.; Gao, Y. J. Phys. Chem. Lett. 2017, 8, 4300-4307. doi:10.1021/acs.jpclett.7b01952

85. Lyu, M.; Yun, J.-H.; Cai, M.; Jiao, Y.; Bernhardt, P. V.; Zhang, M.; Wang, Q.; Du, A.; Wang, H.; Liu, G.; Wang, L. Nano Res. 2016, 9 , 692-702. doi:10.1007/s12274-015-0948-y

86. Kong, M.; Hu, H.; Wan, L.; Chen, M.; Gan, Y.; Wang, J.; Chen, F.; Dong, B.; Eder, D.; Wang, S. RSC Adv. 2017, 7, 35549-35557. doi:10.1039/c7ra04924b

87. Nie, R.; Mehta, A.; Park, B.-w.; Kwon, H.-W.; Im, J.; Seok, S. I. J. Am. Chem. Soc. 2018, 140, 872-875. doi:10.1021/jacs.7b11332 
88. Saparov, B.; Hong, F.; Sun, J.-P.; Duan, H.-S.; Meng, W.; Cameron, S.; Hill, I. G.; Yan, Y.; Mitzi, D. B. Chem. Mater. 2015, 27, 5622-5632. doi:10.1021/acs.chemmater.5b01989

89. Singh, A.; Boopathi, K. M.; Mohapatra, A.; Chen, Y. F.; Li, G.; Chu, C. W. ACS Appl. Mater. Interfaces 2018, 10, 2566-2573. doi:10.1021/acsami.7b16349

90. Boopathi, K. M.; Karuppuswamy, P.; Singh, A.; Hanmandlu, C.; Lin, L.; Abbas, S. A.; Chang, C. C.; Wang, P. C.; Li, G.; Chu, C. W. J. Mater. Chem. A 2017, 5, 20843-20850. doi:10.1039/c7ta06679a

91. Harikesh, P. C.; Mulmudi, H. K.; Ghosh, B.; Goh, T. W.; Teng, Y. T.; Thirumal, K.; Lockrey, M.; Weber, K.; Koh, T. M.; Li, S.; Mhaisalkar, S.; Mathews, N. Chem. Mater. 2016, 28, 7496-7504. doi:10.1021/acs.chemmater.6b03310

92. Stoumpos, C. C.; Malliakas, C. D.; Kanatzidis, M. G. Inorg. Chem. 2013, 52, 9019-9038. doi:10.1021/ic401215x

93. Zong, Y.; Wang, N.; Zhang, L.; Ju, M.-G.; Zeng, X. C.; Sun, X. W.; Zhou, Y.; Padture, N. P. Angew. Chem., Int. Ed. 2017, 56, 12658-12662. doi:10.1002/anie.201705965

94. Tsai, C.-M.; Wu, H.-P.; Chang, S.-T.; Huang, C.-F.; Wang, C.-H.; Narra, S.; Yang, Y.-W.; Wang, C.-L.; Hung, C.-H.; Diau, E. W.-G. ACS Energy Lett. 2016, 1, 1086-1093. doi:10.1021/acsenergylett.6b00514

95. Liu, F.; Ding, C.; Zhang, Y.; Ripolles, T. S.; Kamisaka, T.; Toyoda, T.; Hayase, S.; Minemoto, T.; Yoshino, K.; Dai, S.; Yanagida, M.; Noguchi, H.; Shen, Q. J. Am. Chem. Soc. 2017, 139, 16708-16719. doi:10.1021/jacs.7b08628

96. Leijtens, T.; Prasanna, R.; Gold-Parker, A.; Toney, M. F.; McGehee, M. D. ACS Energy Lett. 2017, 2, 2159-2165. doi:10.1021/acsenergylett.7b00636

97. Eperon, G. E.; Ginger, D. S. ACS Energy Lett. 2017, 2, 1190-1196. doi:10.1021/acsenergylett.7b00290

98. Liu, C.; Li, W.; Li, H.; Zhang, C.; Fan, J.; Mai, Y. Nanoscale 2017, 9, 13967-13975. doi:10.1039/c7nr03507a

99. Arunkumar, P.; Gil, K. H.; Won, S.; Unithrattil, S.; Kim, Y. H.; Kim, H. J.; Im, W. B. J. Phys. Chem. Lett. 2017, 8, 4161-4166. doi:10.1021/acs.jpclett.7b01440

100.Liu, H.; Wu, Z.; Shao, J.; Yao, D.; Gao, H.; Liu, Y.; Yu, W.; Zhang, H.; Yang, B. ACS Nano 2017, 11, 2239-2247. doi:10.1021/acsnano.6b08747

101.Singh, P.; Rana, P. J. S.; Dhingra, P.; Kar, P. J. Mater. Chem. C 2016 , 4, 3101-3105. doi:10.1039/c6tc00650g

102.Lau, C. F. J.; Zhang, M.; Deng, X.; Zheng, J.; Bing, J.; Ma, Q.; Kim, J.; Hu, L.; Green, M. A.; Huang, S.; Ho-Baillie, A. ACS Energy Lett. 2017, 2, 2319-2325. doi:10.1021/acsenergylett.7b00751

103.Lau, C. F. J.; Deng, X.; Zheng, J.; Kim, J.; Zhang, Z.; Zhang, M.; Bing, J.; Wilkinson, B.; Hu, L.; Patterson, R.; Huang, S.; Ho-Baillie, A. J. Mater. Chem. A 2018, 6, 5580-5586. doi:10.1039/c7ta11154a

104.Wang, Z.-K.; Li, M.; Yang, Y.-G.; Hu, Y.; Ma, H.; Gao, X.-Y.; Liao, L.-S. Adv. Mater. 2016, 28, 6695-6703. doi:10.1002/adma.201600626

105.Zhu, F.; Gentry, N. E.; Men, L.; White, M. A.; Vela, J. J. Phys. Chem. C 2018, 122, 14082-14090. doi:10.1021/acs.jpcc.8b01191

106.Wang, L.-Z.; Zhao, Y.-Q.; Liu, B.; Wu, L.-J.; Cai, M.-Q. Phys. Chem. Chem. Phys. 2016, 18, 22188-22195. doi:10.1039/c6cp03605h

107.Yao, Z.; Yang, Z.; Liu, Y.; Zhao, W.; Zhang, X.; Liu, B.; Wu, H.; Liu, S. (Frank). RSC Adv. 2017, 7, 38155-38159. doi:10.1039/c7ra07101a
108.Zhang, M.; Lyu, M.; Yun, J.-H.; Noori, M.; Zhou, X.; Cooling, N. A.; Wang, Q.; Yu, H.; Dastoor, P. C.; Wang, L. Nano Res. 2016, 9 , 1570-1577. doi:10.1007/s12274-016-1051-8

109. Rahul; Singh, P. K.; Singh, R.; Singh, V.; Bhattacharya, B.; Khan, Z. H. Mater. Res. Bull. 2018, 97, 572-577. doi:10.1016/j.materresbull.2017.09.054

110.Moghe, D.; Wang, L.; Traverse, C. J.; Redoute, A.; Sponseller, M.; Brown, P. R.; Bulović, V.; Lunt, R. R. Nano Energy 2016, 28 , 469-474. doi:10.1016/j.nanoen.2016.09.009

111. Noel, N. K.; Stranks, S. D.; Abate, A.; Wehrenfennig, C.; Guarnera, S.; Haghighirad, A.-A.; Sadhanala, A.; Eperon, G. E.; Pathak, S. K.; Johnston, M. B.; Petrozza, A.; Herz, L. M.; Snaith, H. J. Energy Environ. Sci. 2014, 7, 3061-3068. doi:10.1039/c4ee01076k

112. Qu, X.; Cao, B.; Yuan, S.; Chen, X.; Qiu, Z.; Jiang, Y.; Ye, Q.; Wang, H.; Zeng, H.; Liu, J.; Kanatzidis, M. G. Sol. Energy Mater. Sol. Cells 2017, 159, 227-234. doi:10.1016/j.solmat.2016.09.022

113.Fujihara, T.; Terakawa, S.; Matsushima, T.; Qin, C.; Yahiro, M.; Adachi, C. J. Mater. Chem. C 2017, 5, 1121-1127. doi:10.1039/c6tc05069g

114.Hao, F.; Stoumpos, C. C.; Guo, P.; Zhou, N.; Marks, T. J.; Chang, R. P. H.; Kanatzidis, M. G. J. Am. Chem. Soc. 2015, 137, 11445-11452. doi:10.1021/jacs.5b06658

115.Yokoyama, T.; Cao, D. H.; Stoumpos, C. C.; Song, T.-B.; Sato, Y.; Aramaki, S.; Kanatzidis, M. G. J. Phys. Chem. Lett. 2016, 7, 776-782. doi:10.1021/acs.jpclett.6b00118

116.Lee, Y. M.; Park, J.; Yu, B. D.; Hong, S.; Jung, M.-C.; Nakamura, M. J. Phys. Chem. Lett. 2018, 9, 2293-2297. doi:10.1021/acs.jpclett.8b00494

117.Jung, Y.-K.; Lee, J.-H.; Walsh, A.; Soon, A. Chem. Mater. 2017, 29, 3181-3188. doi:10.1021/acs.chemmater.7b00260

118. Handa, T.; Yamada, T.; Kubota, H.; Ise, S.; Miyamoto, Y.; Kanemitsu, Y. J. Phys. Chem. C 2017, 121, 16158-16165. doi:10.1021/acs.jpcc.7b06199

119.Song, T.-B.; Yokoyama, T.; Stoumpos, C. C.; Logsdon, J.; Cao, D. H.; Wasielewski, M. R.; Aramaki, S.; Kanatzidis, M. G. J. Am. Chem. Soc. 2017, 139, 836-842. doi:10.1021/jacs.6b10734

120.Lee, S. J.; Shin, S. S.; Im, J.; Ahn, T. K.; Noh, J. H.; Jeon, N. J.; Seok, S. I.; Seo, J. ACS Energy Lett. 2018, 3, 46-53. doi:10.1021/acsenergylett.7b00976

121.Li, W.; Li, J.; Li, J.; Fan, J.; Mai, Y.; Wang, L. J. Mater. Chem. A 2016, 4, 17104-17110. doi:10.1039/c6ta08332c

122. Waleed, A.; Tavakoli, M. M.; Gu, L.; Wang, Z.; Zhang, D.; Manikandan, A.; Zhang, Q.; Zhang, R.; Chueh, Y.-L.; Fan, Z. Nano Lett. 2017, 17, 523-530. doi:10.1021/acs.nanolett.6b04587

123. Nishikubo, R.; Ishida, N.; Katsuki, Y.; Wakamiya, A.; Saeki, A. J. Phys. Chem. C 2017, 121, 19650-19656. doi:10.1021/acs.jpcc.7b06294

124. Gupta, S.; Cahen, D.; Hodes, G. J. Phys. Chem. C 2018, 122, 13926-13936. doi:10.1021/acs.jpcc.8b01045

125.Ma, L.; Hao, F.; Stoumpos, C. C.; Phelan, B. T.; Wasielewski, M. R.; Kanatzidis, M. G. J. Am. Chem. Soc. 2016, 138, 14750-14755. doi:10.1021/jacs.6b09257

126. Peedikakkandy, L.; Bhargava, P. RSC Adv. 2016, 6, 19857-19860. doi:10.1039/c5ra22317b

127.Sabba, D.; Mulmudi, H. K.; Prabhakar, R. R.; Krishnamoorthy, T.; Baikie, T.; Boix, P. P.; Mhaisalkar, S.; Mathews, N. J. Phys. Chem. C 2015, 119, 1763-1767. doi:10.1021/jp5126624 
128.Zhu, W.; Xin, G.; Wang, Y.; Min, X.; Yao, T.; Xu, W.; Fang, M.; Shi, S.; Shi, J.; Lian, J. J. Mater. Chem. A 2018, 6, 2577-2584. doi:10.1039/c7ta10040j

129.Lee, B.; Krenselewski, A.; Baik, S. I.; Seidman, D. N.; Chang, R. P. H. Sustainable Energy Fuels 2017, 1, 710-724. doi:10.1039/c7se00100b

130.Dolzhnikov, D. S.; Wang, C.; Xu, Y.; Kanatzidis, M. G.; Weiss, E. A. Chem. Mater. 2017, 29, 7901-7907. doi:10.1021/acs.chemmater.7b02803

131.Jellicoe, T. C.; Richter, J. M.; Glass, H. F. J.; Tabachnyk, M.; Brady, R.; Dutton, S. E.; Rao, A.; Friend, R. H.; Credgington, D.; Greenham, N. C.; Böhm, M. L. J. Am. Chem. Soc. 2016, 138, 2941-2944. doi:10.1021/jacs.5b13470

132.Wong, A. B.; Bekenstein, Y.; Kang, J.; Kley, C. S.; Kim, D.; Gibson, N. A.; Zhang, D.; Yu, Y.; Leone, S. R.; Wang, L.-W.; Alivisatos, A. P.; Yang, P. Nano Lett. 2018, 18, 2060-2066. doi:10.1021/acs.nanolett.8b00077

133.Wang, A.; Yan, X.; Zhang, M.; Sun, S.; Yang, M.; Shen, W.; Pan, X.; Wang, P.; Deng, Z. Chem. Mater. 2016, 28, 8132-8140. doi:10.1021/acs.chemmater.6b01329

134.Rajendra Kumar, G.; Kim, H.-J.; Karupannan, S.; Prabakar, K. J. Phys. Chem. C 2017, 121, 16447-16453. doi:10.1021/acs.jpcc.7b06278

135.Wang, A.; Guo, Y.; Muhammad, F.; Deng, Z. Chem. Mater. 2017, 29 , 6493-6501. doi:10.1021/acs.chemmater.7b02089

136. Rakita, Y.; Gupta, S.; Cahen, D.; Hodes, G. Chem. Mater. 2017, 29 , 8620-8629. doi:10.1021/acs.chemmater.7b02314

137.Hsu, H.-Y.; Ji, L.; Du, M.; Zhao, J.; Yu, E. T.; Bard, A. J. Electrochim. Acta 2016, 220, 205-210. doi:10.1016/j.electacta.2016.10.049

138. Ma, S.; Shang, M.; Yu, L.; Dong, L. J. Mater. Chem. A 2015, 3, 1222-1229. doi:10.1039/c4ta04593a

139.Sun, P.-P.; Li, Q.-S.; Yang, L.-N.; Li, Z.-S. Nanoscale 2016, 8, 1503-1512. doi:10.1039/c5nr05337d

140.Krishnamoorthy, T.; Ding, H.; Yan, C.; Leong, W. L.; Baikie, T.; Zhang, Z.; Sherburne, M.; Li, S.; Asta, M.; Mathews, N.; Mhaisalkar, S. G. J. Mater. Chem. A 2015, 3, 23829-23832. doi:10.1039/c5ta05741h

141.Ming, W.; Shi, H.; Du, M.-H. J. Mater. Chem. A 2016, 4, 13852-13858. doi:10.1039/c6ta04685a

142.Zhao, Y.-Q.; Liu, B.; Yu, Z.-L.; Cao, D.; Cai, M.-Q. Electrochim. Acta 2017, 247, 891-898. doi:10.1016/j.electacta.2017.06.154

143.Cheng, P.; Wu, T.; Zhang, J.; Li, Y.; Liu, J.; Jiang, L.; Mao, X.; Lu, R.-F.; Deng, W.-Q.; Han, K. J. Phys. Chem. Lett. 2017, 8, 4402-4406. doi:10.1021/acs.jpclett.7b01985

144.Kopacic, I.; Friesenbichler, B.; Hoefler, S. F.; Kunert, B.; Plank, H.; Rath, T.; Trimmel, G. ACS Appl. Energy Mater. 2018, 1, 343-347. doi:10.1021/acsaem.8b00007

145.Sun, P.-P.; Chi, W.-J.; Li, Z.-S. Phys. Chem. Chem. Phys. 2016, 18, 24526-24536. doi:10.1039/c6cp04344e

146.Nagane, S.; Ghosh, D.; Hoye, R. L. Z.; Zhao, B.; Ahmad, S.; Walker, A. B.; Islam, M. S.; Ogale, S.; Sadhanala, A. J. Phys. Chem. C 2018, 122, 5940-5947. doi:10.1021/acs.jpcc.8b00480

147.Zhang, X.; Yin, J.; Nie, Z.; Zhang, Q.; Sui, N.; Chen, B.; Zhang, Y.; Qu, K.; Zhao, J.; Zhou, H. RSC Adv. 2017, 7, 37419-37425. doi:10.1039/c7ra04235c

148.Nie, Z.; Yin, J.; Zhou, H.; Chai, N.; Chen, B.; Zhang, Y.; Qu, K.; Shen, G.; Ma, H.; Li, Y.; Zhao, J.; Zhang, X. ACS Appl. Mater. Interfaces 2016, 8, 28187-28193. doi:10.1021/acsami.6b08962
149.Xiao, Z.-L.; Chen, H.-Z.; Shi, M.-M.; Wu, G.; Zhou, R.-J.; Yang, Z.-S.; Wang, M.; Tang, B.-Z. Mater. Sci. Eng., B 2005, 117, 313-316. doi:10.1016/j.mseb.2004.12.052

150.Li, X.; Zhong, X.; Hu, Y.; Li, B.; Sheng, Y.; Zhang, Y.; Weng, C.; Feng, M.; Han, H.; Wang, J. J. Phys. Chem. Lett. 2017, 8, 1804-1809. doi:10.1021/acs.jpclett.7b00086

151.Li, X.; Li, B.; Chang, J.; Ding, B.; Zheng, S.; Wu, Y.; Yang, J.; Yang, G.; Zhong, X.; Wang, J. ACS Appl. Energy Mater. 2018, 1, 2709-2716. doi:10.1021/acsaem.8b00372

152. Cortecchia, D.; Dewi, H. A.; Yin, J.; Bruno, A.; Chen, S.; Baikie, T.; Boix, P. P.; Grätzel, M.; Mhaisalkar, S.; Soci, C.; Mathews, N. Inorg. Chem. 2016, 55, 1044-1052. doi:10.1021/acs.inorgchem.5b01896

153. Hebig, J.-C.; Kühn, I.; Flohre, J.; Kirchartz, T. ACS Energy Lett. 2016, 1, 309-314. doi:10.1021/acsenergylett.6b00170

154.Jiang, F.; Yang, D.; Jiang, Y.; Liu, T.; Zhao, X.; Ming, Y.; Luo, B.; Qin, F.; Fan, J.; Han, H.; Zhang, L.; Zhou, Y. J. Am. Chem. Soc. 2018, 140, 1019-1027. doi:10.1021/jacs.7b10739

155.McDonald, C.; Ni, C.; Švrček, V.; Lozac'h, M.; Connor, P. A.; Maguire, P.; Irvine, J. T. S.; Mariotti, D. Nanoscale 2017, 9, 18759-18771. doi:10.1039/c7nr05764d

156. Eckhardt, K.; Bon, V.; Getzschmann, J.; Grothe, J.; Wisser, F. M.; Kaskel, S. Chem. Commun. 2016, 52, 3058-3060. doi:10.1039/c5cc10455f

157.Singh, T.; Kulkarni, A.; Ikegami, M.; Miyasaka, T. ACS Appl. Mater. Interfaces 2016, 8, 14542-14547. doi:10.1021/acsami.6b02843

158.Pious, J. K.; Lekshmi, M. L.; Muthu, C.; Rakhi, R. B.; Nair, V. C. ACS Omega 2017, 2, 5798-5802. doi:10.1021/acsomega.7b00973

159.Zhang, Y.; Yin, J.; Parida, M. R.; Ahmed, G. H.; Pan, J.; Bakr, O. M.; Brédas, J.-L.; Mohammed, O. F. J. Phys. Chem. Lett. 2017, 8, 3173-3177. doi:10.1021/acs.jpclett.7b01381

160. Kulkarni, A.; Singh, T.; Ikegami, M.; Miyasaka, T. RSC Adv. 2017, 7, 9456-9460. doi:10.1039/c6ra28190g

161.Abulikemu, M.; Ould-Chikh, S.; Miao, X.; Alarousu, E.; Murali, B.; Ngongang Ndjawa, G. O.; Barbé, J.; El Labban, A.; Amassian, A.; Del Gobbo, S. J. Mater. Chem. A 2016, 4, 12504-12515. doi:10.1039/c6ta04657f

162.Wang, H.; Tian, J.; Jiang, K.; Zhang, Y.; Fan, H.; Huang, J.; Yang, L.-m.; Guan, B.; Song, Y. RSC Adv. 2017, 7, 43826-43830. doi:10.1039/c7ra07123j

163.Ni, C.; Hedley, G.; Payne, J.; Svrcek, V.; McDonald, C.; Jagadamma, L. K.; Edwards, P.; Martin, R.; Jain, G.; Carolan, D.; Mariotti, D.; Maguire, P.; Samuel, I.; Irvine, J. Nat. Commun. 2017, 8, 170. doi:10.1038/s41467-017-00261-9

164.Leng, M.; Yang, Y.; Zeng, K.; Chen, Z.; Tan, Z.; Li, S.; Li, J.; Xu, B.; Li, D.; Hautzinger, M. P.; Fu, Y.; Zhai, T.; Xu, L.; Niu, G.; Jin, S.; Tang, J. Adv. Funct. Mater. 2018, 28, 1704446. doi:10.1002/adfm.201704446

165. Yang, B.; Chen, J.; Hong, F.; Mao, X.; Zheng, K.; Yang, S.; Li, Y.; Pullerits, T.; Deng, W.; Han, K. Angew. Chem., Int. Ed. 2017, 56, 12471-12475. doi:10.1002/anie.201704739

166.Wei, F.; Deng, Z.; Sun, S.; Xie, F.; Kieslich, G.; Evans, D. M.; Carpenter, M. A.; Bristowe, P. D.; Cheetham, A. K. Mater. Horiz. 2016, 3, 328-332. doi:10.1039/c6mh00053c

167.Scholz, M.; Flender, O.; Oum, K.; Lenzer, T. J. Phys. Chem. C 2017, 121, 12110-12116. doi:10.1021/acs.jpcc.7b04543

168. Khoram, P.; Brittman, S.; Dzik, W. I.; Reek, J. N. H.; Garnett, E. C. J. Phys. Chem. C 2016, 120, 6475-6481. doi:10.1021/acs.jpcc.6b02011 
169.Tong, X.-W.; Kong, W.-Y.; Wang, Y.-Y.; Zhu, J.-M.; Luo, L.-B.; Wang, Z.-H. ACS Appl. Mater. Interfaces 2017, 9, 18977-18985. doi:10.1021/acsami.7b04616

170.Bai, F.; Hu, Y.; Hu, Y.; Qiu, T.; Miao, X.; Zhang, S. Sol. Energy Mater. Sol. Cells 2018, 184, 15-21. doi:10.1016/j.solmat.2018.04.032

171.Li, T.; Hu, Y.; Morrison, C. A.; Wu, W.; Han, H.; Robertson, N. Sustainable Energy Fuels 2017, 1, 308-316. doi:10.1039/c6se00061d

172.Zhang, W.; Tao, K.; Ji, C.; Sun, Z.; Han, S.; Zhang, J.; Wu, Z.; Luo, J. Inorg. Chem. 2018, 57, 4239-4243. doi:10.1021/acs.inorgchem.8b00152

173.Adonin, S. A.; Frolova, L. A.; Sokolov, M. N.; Shilov, G. V.; Korchagin, D. V.; Fedin, V. P.; Aldoshin, S. M.; Stevenson, K. J.; Troshin, P. A. Adv. Energy Mater. 2018, 8, 1701140. doi:10.1002/aenm.201701140

174.Ji, C.; Sun, Z.; Zeb, A.; Liu, S.; Zhang, J.; Hong, M.; Luo, J. J. Phys. Chem. Lett. 2017, 8, 2012-2018. doi:10.1021/acs.jpclett.7b00673

175. Jain, A.; Voznyy, O.; Sargent, E. H. J. Phys. Chem. C 2017, 121, 7183-7187. doi:10.1021/acs.jpcc.7b02221

176.Pazoki, M.; Röckert, A.; Wolf, M. J.; Imani, R.; Edvinsson, T.; Kullgren, J. J. Mater. Chem. A 2017, 5, 23131-23138. doi:10.1039/c7ta07716e

177.Ju, M.-G.; Chen, M.; Zhou, Y.; Garces, H. F.; Dai, J.; Ma, L.; Padture, N. P.; Zeng, X. C. ACS Energy Lett. 2018, 3, 297-304. doi:10.1021/acsenergylett.7b01167

178.Li, Y.-J.; Wu, T.; Sun, L.; Yang, R.-X.; Jiang, L.; Cheng, P.-F.; Hao, Q.-Q.; Wang, T.-J.; Lu, R.-F.; Deng, W.-Q. RSC Adv. 2017, 7, 35175-35180. doi:10.1039/c7ra06130g

179.Zhou, J.; Xia, Z.; Molokeev, M. S.; Zhang, X.; Peng, D.; Liu, Q. J. Mater. Chem. A 2017, 5, 15031-15037. doi:10.1039/c7ta04690a

180.McClure, E. T.; Ball, M. R.; Windl, W.; Woodward, P. M. Chem. Mater. 2016, 28, 1348-1354. doi:10.1021/acs.chemmater.5b04231

181.Volonakis, G.; Filip, M. R.; Haghighirad, A. A.; Sakai, N.; Wenger, B.; Snaith, H. J.; Giustino, F. J. Phys. Chem. Lett. 2016, 7, 1254-1259. doi:10.1021/acs.jpclett.6b00376

182. Filip, M. R.; Hillman, S.; Haghighirad, A. A.; Snaith, H. J.; Giustino, F. J. Phys. Chem. Lett. 2016, 7, 2579-2585. doi:10.1021/acs.jpclett.6b01041

183. Yang, J.; Zhang, P.; Wei, S.-H. J. Phys. Chem. Lett. 2018, 9, 31-35. doi:10.1021/acs.jpclett.7b02992

184.Slavney, A. H.; Hu, T.; Lindenberg, A. M.; Karunadasa, H. I. J. Am. Chem. Soc. 2016, 138, 2138-2141. doi:10.1021/jacs.5b13294

185.Li, Q.; Wang, Y.; Pan, W.; Yang, W.; Zou, B.; Tang, J.; Quan, Z. Angew. Chem., Int. Ed. 2017, 56, 15969-15973. doi:10.1002/anie.201708684

186.Greul, E.; Petrus, M. L.; Binek, A.; Docampo, P.; Bein, T. J. Mater. Chem. A 2017, 5, 19972-19981. doi:10.1039/c7ta06816f

187.Wei, F.; Deng, Z.; Sun, S.; Zhang, F.; Evans, D. M.; Kieslich, G.; Tominaka, S.; Carpenter, M. A.; Zhang, J.; Bristowe, P. D.; Cheetham, A. K. Chem. Mater. 2017, 29, 1089-1094. doi:10.1021/acs.chemmater.6b03944

188.Cheng, P.; Wu, T.; Li, Y.; Jiang, L.; Deng, W.; Han, K. New J. Chem. 2017, 41, 9598-9601. doi:10.1039/c7nj02365k

189.Debbichi, L.; Lee, S.; Cho, H.; Rappe, A. M.; Hong, K.-H.; Jang, M. S.; Kim, H. Adv. Mater. 2018, 30, 1707001. doi:10.1002/adma.201707001

190.Zhou, J.; Rong, X.; Molokeev, M. S.; Zhang, X.; Xia, Z. J. Mater. Chem. A 2018, 6, 2346-2352. doi:10.1039/c7ta10062k
191.Luo, J.; Li, S.; Wu, H.; Zhou, Y.; Li, Y.; Liu, J.; Li, J.; Li, K.; Yi, F.; Niu, G.; Tang, J. ACS Photonics 2018, 5, 398-405. doi:10.1021/acsphotonics.7b00837

192. Nila Nandha, K.; Nag, A. Chem. Commun. 2018, 54, 5205-5208. doi:10.1039/c8cc01982g

193.Dai, J.; Ma, L.; Ju, M.; Huang, J.; Zeng, X. C. Phys. Chem. Chem. Phys. 2017, 19, 21691-21695. doi:10.1039/c7cp03448b

194.Xu, J.; Liu, J.-B.; Liu, B.-X.; Huang, B. J. Phys. Chem. Lett. 2017, 8, 4391-4396. doi:10.1021/acs.jpclett.7b02008

195.Lozhkina, O. A.; Murashkina, A. A.; Elizarov, M. S.; Shilovskikh, V. V.; Zolotarev, A. A.; Kapitonov, Y. V.; Kevorkyants, R.; Emeline, A. V.; Miyasaka, T. Chem. Phys. Lett. 2018, 694, 18-22. doi:10.1016/j.cplett.2018.01.031

196.Savory, C. N.; Walsh, A.; Scanlon, D. O. ACS Energy Lett. 2016, 1 , 949-955. doi:10.1021/acsenergylett.6b00471

197.Filip, M. R.; Liu, X.; Miglio, A.; Hautier, G.; Giustino, F. J. Phys. Chem. C 2018, 122, 158-170. doi:10.1021/acs.jpcc.7b10370

198. Feng, H.-J.; Deng, W.; Yang, K.; Huang, J.; Zeng, X. C. J. Phys. Chem. C 2017, 121, 4471-4480. doi:10.1021/acs.jpcc.7b00138

199. Nakajima, T.; Sawada, K. J. Phys. Chem. Lett. 2017, 8, 4826-4831. doi:10.1021/acs.jpclett.7b02203

200.Bartesaghi, D.; Slavney, A. H.; Gélvez-Rueda, M. C.; Connor, B. A.; Grozema, F. C.; Karunadasa, H. I.; Savenije, T. J. J. Phys. Chem. C 2018, 122, 4809-4816. doi:10.1021/acs.jpcc.8b00572

201.Dong, L.; Sun, S.; Deng, Z.; Li, W.; Wei, F.; Qi, Y.; Li, Y.; Li, X.; Lu, P.; Ramamurty, U. Comput. Mater. Sci. 2018, 141, 49-58. doi:10.1016/j.commatsci.2017.09.014

202.Creutz, S. E.; Crites, E. N.; De Siena, M. C.; Gamelin, D. R. Nano Lett. 2018, 18, 1118-1123. doi:10.1021/acs.nanolett.7b04659

203.Zhao, X.-G.; Yang, J.-H.; Fu, Y.; Yang, D.; Xu, Q.; Yu, L.; Wei, S.-H.; Zhang, L. J. Am. Chem. Soc. 2017, 139, 2630-2638. doi:10.1021/jacs.6b09645

204. Volonakis, G.; Haghighirad, A. A.; Snaith, H. J.; Giustino, F. J. Phys. Chem. Lett. 2017, 8, 3917-3924. doi:10.1021/acs.jpclett.7b01584

205. Giorgi, G.; Yamashita, K. Chem. Lett. 2015, 44, 826-828. doi:10.1246/cl.150143

206. Liu, B.; Long, M.; Cai, M.-Q.; Yang, J. J. Phys. D: Appl. Phys. 2018, 51, 105101. doi:10.1088/1361-6463/aaa7ca

207. Etgar, L. Energy Environ. Sci. 2018, 11, 234-242. doi:10.1039/c7ee03397d

208. Straus, D. B.; Kagan, C. R. J. Phys. Chem. Lett. 2018, 9, 1434-1447. doi:10.1021/acs.jpclett.8b00201

209.Tang, G.; Xiao, Z.; Hosono, H.; Kamiya, T.; Fang, D.; Hong, J. J. Phys. Chem. Lett. 2018, 9, 43-48. doi:10.1021/acs.jpclett.7b02829

210.Todorov, T.; Gershon, T.; Gunawan, O.; Sturdevant, C.; Guha, S. Appl. Phys. Lett. 2014, 105, 173902. doi:10.1063/1.4899275

211.Etgar, L.; Gao, P.; Qin, P.; Graetzel, M.; Nazeeruddin, M. K. J. Mater. Chem. A 2014, 2, 11586-11590. doi:10.1039/c4ta02711f

212.Li, Y.; Zhu, J.; Huang, Y.; Wei, J.; Liu, F.; Shao, Z.; Hu, L.; Chen, S.; Yang, S.; Tang, J.; Yao, J.; Dai, S. Nanoscale 2015, 7, 9902-9907. doi:10.1039/c5nr00420a

213. Hu, L.; Yang, Z.; Mandelis, A.; Melnikov, A.; Lan, X.; Walters, G.; Hoogland, S.; Sargent, E. H. J. Phys. Chem. C 2016, 120, 14416-14427. doi:10.1021/acs.jpcc.6b04468 
214.Yang, Z.; Janmohamed, A.; Lan, X.; García de Arquer, F. P.;

Voznyy, O.; Yassitepe, E.; Kim, G.-H.; Ning, Z.; Gong, X.; Comin, R.;

Sargent, E. H. Nano Lett. 2015, 15, 7539-7543.

doi:10.1021/acs.nanolett.5b03271

\section{License and Terms}

This is an Open Access article under the terms of the Creative Commons Attribution License

(http://creativecommons.org/licenses/by/4.0). Please note that the reuse, redistribution and reproduction in particular requires that the authors and source are credited.

The license is subject to the Beilstein Journal of

Nanotechnology terms and conditions:

(https://www.beilstein-journals.org/bjnano)

The definitive version of this article is the electronic one which can be found at:

doi:10.3762/bjnano.9.207 